University of Louisville

ThinkIR: The University of Louisville's Institutional Repository

Electronic Theses and Dissertations

$12-2020$

\title{
Undergraduate students use moral reasoning and belief in genetic determinism in response to a CRISPR/Cas9 socioscientific Issue.
}

Katie M. Seiter

University of Louisville

Follow this and additional works at: https://ir.library.louisville.edu/etd

Part of the Biology Commons, and the Higher Education Commons

\section{Recommended Citation}

Seiter, Katie M., "Undergraduate students use moral reasoning and belief in genetic determinism in response to a CRISPR/Cas9 socioscientific Issue." (2020). Electronic Theses and Dissertations. Paper 3556.

https://doi.org/10.18297/etd/3556

This Doctoral Dissertation is brought to you for free and open access by ThinkIR: The University of Louisville's Institutional Repository. It has been accepted for inclusion in Electronic Theses and Dissertations by an authorized administrator of ThinkIR: The University of Louisville's Institutional Repository. This title appears here courtesy of the author, who has retained all other copyrights. For more information, please contact thinkir@louisville.edu. 
UNDERGRADUATE STUDENTS USE MORAL REASONING AND BELIEF IN GENETIC DETERMINISM IN RESPONSE TO A CRISPR/CAS9 SOCIOSCIENTIFIC

ISSUE

\title{
By
}

Katie M. Seiter

\author{
A Dissertation \\ Submitted to the Faculty of the \\ College of Arts and Sciences of the University of Louisville \\ in Partial Fulfillment of the Requirements \\ for the Degree of
}

Doctor of Philosophy in Biology

\author{
Biology Department \\ University of Louisville \\ Louisville, Kentucky
}

December 2020 



\title{
UNDERGRADUATE STUDENTS USE MORAL REASONING AND BELIEF IN GENETIC DETERMINISM IN RESPONSE TO A CRISPR/CAS9 SOCIOSCIENTIFIC ISSUE
}

By

\author{
Katie M. Seiter \\ A Dissertation Approved on
}

November $20^{\text {th }}, 2020$

By the following Dissertation Committee:

Linda Fuselier

Deborah Yoder-Himes

\begin{tabular}{l}
\hline Michael Perlin \\
\hline Justin McFadden
\end{tabular}

Justin McFadden

Meena Balgopal 


\section{DEDICATION}

This dissertation is dedicated to my husband,

Mr. Kevin Donald Seiter, and my parents,

Mr. Richard Nicholas Humrick

and

Mrs. Toni Marie Humrick,

whose support has provided me with this

opportunity to advance my education. 


\section{ACKNOWLEDGEMENTS}

I would like to thank my advisor, Dr. Linda Fuselier, who has guided me and whose wise feedback and support has been invaluable to me during this chapter in my life. I would also like to thank my other committee members, Dr. Deborah Yoder-Himes, Dr. Michael Perlin, Dr. Justin McFadden, and Dr. Meena Balgopal, for their assistance and feedback on my research projects and dissertation. I would also like to thank Dr. Perri Eason, for her encouragement and wise words that inspired me to continue in the doctoral program during the hardest moments, and my husband and children, Henry and Lillian, who motivated me to persevere in the program. Lastly, I would like to thank my parents for providing childcare that allowed me to persist through two pregnancies, one of which occurred during a worldwide pandemic. 


\section{ABSTRACT \\ UNDERGRADUATE STUDENTS USE MORAL REASONING AND BELIEF IN GENETIC DETERMINISM IN RESPONSE TO A CRISPR/CAS9 SOCIOSCIENTIFIC ISSUE}

Katie M. Seiter

November $20^{\text {th }}, 2020$

This dissertation explores how students reason about genetic engineering socioscientific issues (SSIs) related to a recently developed, powerful genome editing technology called CRISPR/Cas9. It is divided into three chapters.

Chapter One describes an exploratory study that characterized students' moral reasoning using a sociocultural theoretical framework. I used content analysis and logistic regression to investigate how academic and social factors influenced moral reasoning. Students generally opposed the use of CRISPR/Cas9 technology for non-medical enhancements, and the moral considerations used were influenced by genetics knowledge level and demographic variables such as gender and socio-economic status. Further investigation of moral perspectives for students from traditionally marginalized groups should be considered so they can be integrated into curricula to foster diverse classroom environments.

Chapter Two describes how I investigated belief in genetic determinism, a dimension of genetic essentialism that is inconsistent with the current multifactorial 
model of genetics because it overestimates the impact genes have on character expression, while underestimating environmental impacts. Quantitative measures of belief in genetic determinism from questionnaires indicated students held an accurate understanding of genetics and low-to-medium BGD, but BGD was widespread in students' writing. Although biology students were more likely to express BGD, nonmajor students were more likely to display one-gene-one-trait misconceptions. These results underscore the need to alter genetics instruction so that it reflects the ongoing paradigm shift of genetics understanding.

Chapter Three describes a practitioner study that used a jigsaw activity to engage students in a recent, real-life CRISPR/Cas9 research study as an SSI. The purpose was to teach students about bioethics without promoting the use of BGD. After the lesson, students demonstrated an appreciation for bioethics related to the case study they evaluated and acknowledged environmental influences on complex characteristics. The developed lesson is an ideal method for integrating SSIs and bioethics into undergraduate biology curricula. 
TABLE OF CONTENTS

PAGE

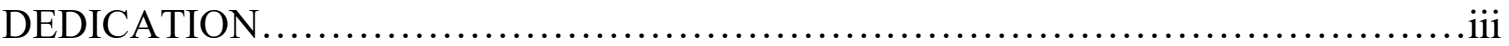

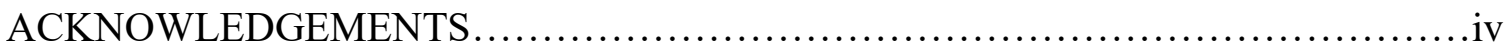

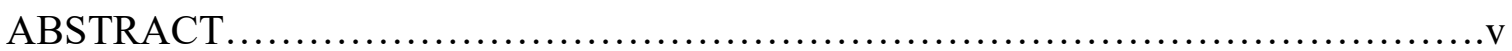

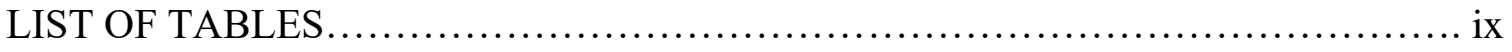

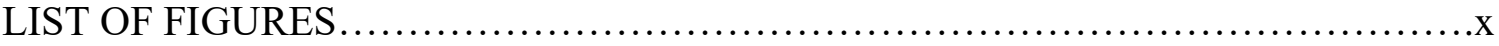

CHAPTER ONE: CONTENT LEVEL AND SOCIAL FACTORS INFLUENCE

STUDENT MORAL REASONING ABOUT CRISPR/CAS9 IN HUMANS .............

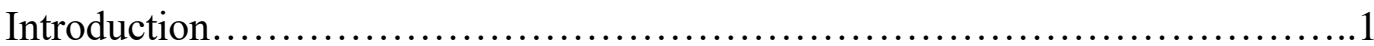

Methods........................................................... 10

Results.............................................................. 19

Discussion..................................................... 40

Limitations............................................................ 47

Implications for Science Education.................................. 48

CHAPTER TWO: GENETICS KNOWLEDGE INFLUENCES UNDERGRADUATE STUDENTS BELIEF IN GENETIC DETERMINISM $\ldots \ldots \ldots \ldots \ldots \ldots \ldots \ldots \ldots \ldots \ldots . \ldots \ldots$

Introduction............................................................ 51

Methods.............................................................. 59

Results......................................................... 75

Discussion........................................................... 87

Limitations ....................................................... 95

Recommendations for Science Education Research.......................96 
CHAPTER THREE: USING A CRISPR/CAS9 SOCIOSCIENTIFIC ISSUE TO TEACH

UNDERGRADUATE STUDENTS ABOUT BIOETHICS............................99

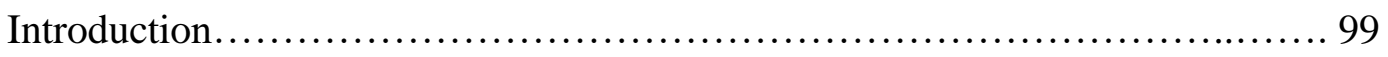

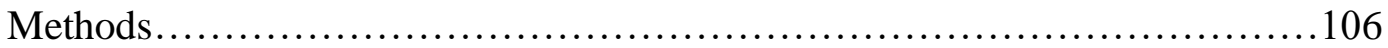

Results................................................................. 115

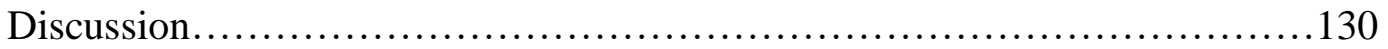

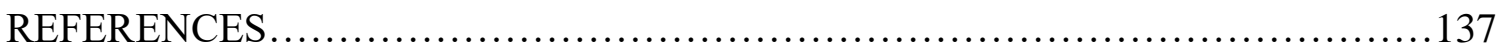

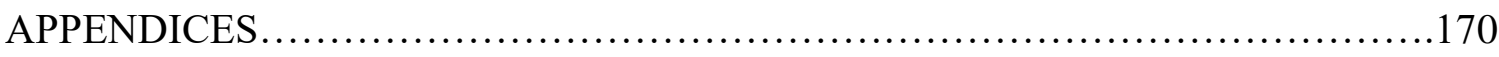

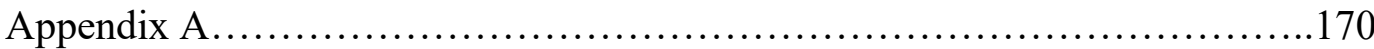

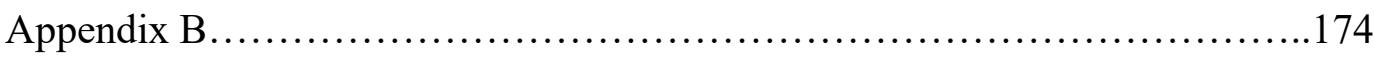

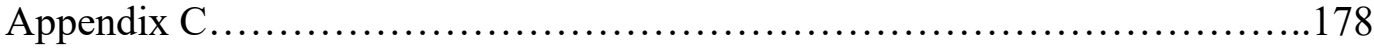

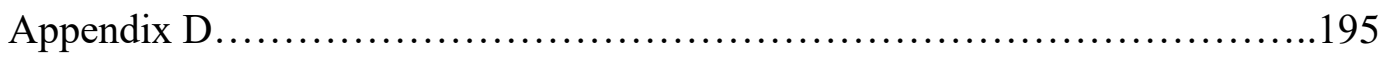

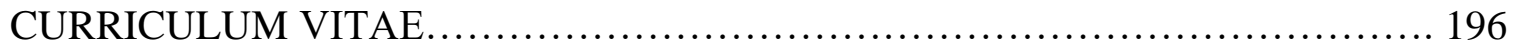




\section{LIST OF TABLES}

TABLE

PAGE

1. Demographic data for the sample population................................ 13

2. Demographic information for students by academic level.................... 16

3. Consequences and principles identified in student responses................... 20

4. Logistic regression model evaluation for each of the six most common consequences and principles......................................... 38

5. Demographic information for the PUGGS, essay, and students who completed both....................................................6 60

6. Themes and contexts that BGD appeared in................................67

7. Statements used for characterizing terminology used in student's trait BGD instances...................................................... 72

8. Average BGD scores................................................ 76

9. The average score and standard deviation (SD) for each of the

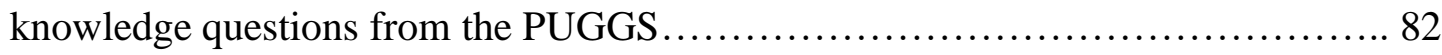

10. Logistic regression model statistics for each of the three BGD categories...........86

11. Student learning outcomes and associated assessments...................... 105

12. Descriptive statistics for each of the reading guides......................... 116

13. Ethical considerations that students used in responses to assessment questions......120 


\section{LIST OF FIGURES}

FIGURE

PAGE

1. Proportion of students from each content knowledge level that

discussed eugenics.................................................. 30

2. Proportion of students from each content knowledge level that discussed

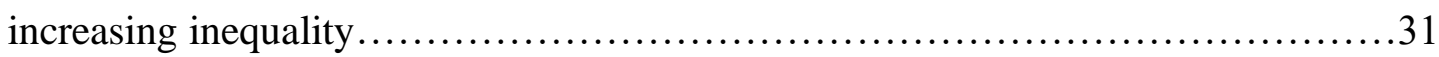

3. Proportion of students from each content knowledge level that discussed

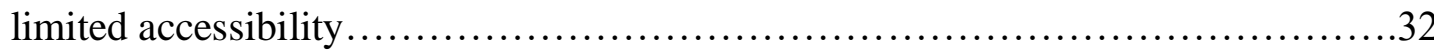

4. Proportion of students from each content knowledge level and gender that discussed the loss of diversity......................................... 33

5. Proportion of students from each gender that used the precautionary principle...... 34

6. Proportion of students from each content knowledge level and Pell group that discussed the nature principle...................................... 34

7. Proportion of students from each Pell group that discussed the uniqueness

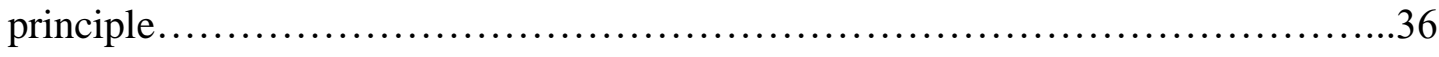

8. Proportion of students from each content knowledge level that discussed

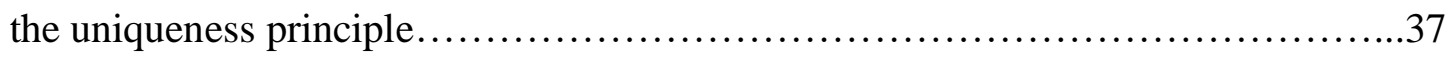

9. Severity of BGD proportions by academic level........................... 79

10. Frequency of students who scored correctly for each genetics knowledge

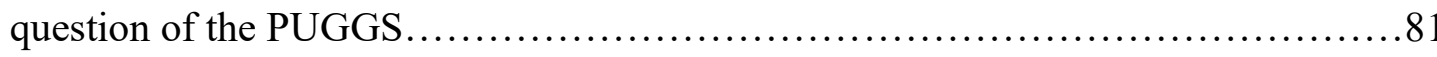


11. Average number of BGD instances for each academic level + SEM............. 84

12. Proportion of students from each academic level that used at least one instance of BGD in the context of "traits"......................................... 85

13. The proportion of students who used each type of justification for the second assessment question................................................. 125

14. The proportion of gene, genes, and environmental references that were in the context of each of the four characteristics .................................... 128

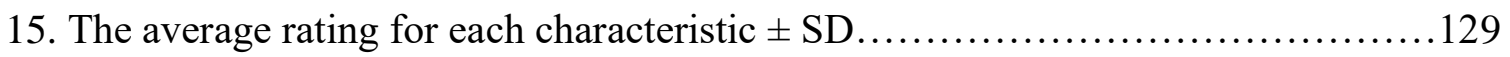


CHAPTER ONE

CONTENT LEVEL AND SOCIAL FACTORS INFLUENCE STUDENT MORAL REASONING ABOUT CRISPR/CAS9 IN HUMANS

\section{INTRODUCTION}

\section{Socioscientific Issues}

As global citizens, our students are asked to consider and reason about socioscientific issues (SSIs), relevant, open-ended, contentious, ethical and social dilemmas centered around science (Abd-El-Khalick, 2003; Balgopal, Wallace, \& Dahlberg, 2017; Lee et al., 2012; Sadler \& Zeidler, 2004; Zeidler \& Schafer, 1984). The use of SSIs encourages the development of compassion and exploration of diverse moral (American Association for the Advancement of Science, 1990; Lee et al., 2012; National Research Council, 1996; Sadler \& Zeidler, 2004; Zeidler \& Keefer, 2003; Zeidler et al., 2005) and sociocultural perspectives (Zeidler et al., 2019). The use of SSIs goes beyond a basic integration of science and societal issues, such as science-technology-society (STS), by simultaneously calling attention to ethical issues and taking into account personal beliefs or moral/ethical development of students. SSI-based instruction gives students the opportunity to reflect on ethical dilemmas and moral judgements through interaction with peers and engagement in social discourse (Zeidler \& Keefer, 2003; Zeidler et al., 2005). The SSI framework proposed by Zeidler et al. (2005) outlines four pedagogical issues 
that are limited in traditional STS instruction but that are important for teaching about SSIs: the nature of science (NOS), classroom discourse, culture, and case-based issues.

Many relevant, contemporary SSIs that are gaining increasingly more media attention are those concerning genetic engineering. These include issues such as the use of human gene therapy, genetic enhancement, germline and somatic cell modifications, and genetic screening technologies (Cribbs \& Perera, 2017; Gunderson, 2007; Hammond, 2010; Wenz, 2005). Most recently, the development of a genome editing technology, CRISPR/Cas9, brought these issues to the forefront of public discourse. CRISPR/Cas9, developed in 2012, can be used to disrupt genes and alter nucleotide sequences through the use of two main molecules: a single guide RNA that is complementary to the targeted DNA region and the Cas9 enzyme which cleaves the DNA at the targeted site (Jinek et al., 2013). CRISPR, which stands for Clustered Regularly Interspaced Palindromic Repeats, is a genetic locus present in bacteria and archaea that functions as an "adaptive immune system". Originally discovered in 1993, its function in bacteria was not fully understood until decades later when researchers discovered that the system provides immunity against viruses through the use of an endonuclease, Cas9, and RNA that is complementary to invading viral DNA (Barrangou et al., 2007; Jinek et al., 2012; Lander, 2016; Mojica et al., 2005). Scientists later discovered that they could use molecules from this bacterial system to easily modify DNA in other organisms (Jinek et al., 2013; Lander, 2016), including humans.

In addition to creating whole gene mutations, CRISPR/Cas9 technology can also provide researchers with the ability to quickly and efficiently edit one specific nucleic acid base, a previously difficult (if not nearly impossible) accomplishment, in a variety of 
cell types, including those that were unalterable by traditional genome editing techniques (Jinek et al., 2013; Kleinstiver et al., 2016; Ran et al., 2013; Reardon, 2016).

Furthermore, genetically modified forms of the Cas9 enzyme can be used to alter gene regulation and/or epigenetic expression. For example, it can be deactivated and fused with transcription regulators that recruit transcription activators or repressors to increase or decrease gene expression, respectively. This has been used to increase the expression of a protein important for reducing symptoms of muscular dystrophy (Kemaladewi et al., 2019; Russa \& Qi, 2015).

Vector molecules required for CRISPR/Cas9 genetic engineering are easily accessible and can be affordably ordered through research supply companies and inserted into cells through viral delivery systems (Xu et al., 2019) using commonly employed techniques. These characteristics of CRISPR/Cas9 -- simplicity, efficiency, affordability and versatility -- have led to the rapid and widespread use of this powerful technology and catapulted the possibility of human genetic enhancement to a new level never before imagined.

Given its rapid development and ease of use in scientific research, the potential uses of the technology raise ethical concerns that move beyond those related to past technology. Of particular interest is the potential to edit germline cells. For example, a Chinese scientist recently claimed to have modified human embryos (germline cells) to be resistant to human immunodeficiency virus (HIV; Cribbs \& Perera, 2017; Krimsky, 2019). Another concern is that the tool will be used for non-medical enhancements. I consider the modification of genes to treat or attempt to prevent a disease, such as HIV or cystic fibrosis, to be a medical use of the technology. Non-medical enhancements are 
those that are performed for purposes other than treating diseases or conditions that may limit quality of life or life expectancy. For example, these include attempts to influence eye color, hair color, skin color, height, and intelligence.

Jennifer Doudna, who was involved in the discovery and development of CRISPR/Cas9 technology and received the 2020 Nobel Prize in Chemistry with Emmanuelle Charpentier, recently wrote a book about her work. In it, she describes how the powerful technology raises novel ethical issues.

"By the time scientists had employed CRISPR in primate embryos to create the first gene-edited monkeys, I was asking myself how long it would be before some maverick scientists attempted to do the same in humans....here I was, watching a technology I had helped create being used in ways that could radically transform both our species and the world in which we live. Would it inadvertently widen social or genetic inequalities or usher in a new eugenics movement?" (Doudna, 2018, p. xvii)

She emphasizes that such issues must be considered in the scientific community going forward and has helped organize such discussions (Doudna, 2018) in global scientific committees, such as the initiative to develop international guidelines regarding the use of CRISPR/Cas9 technology ("Human Genome Editing Initiative", n.d.) by the International Commission on the Clinical Use of Human Germline Genome Editing. Although the technology is very new, and it has not yet been addressed in depth by the science education community, the ethical and moral implications of the use of CRISPR/Cas9 make this an excellent, immediately relevant, SSI for the college classroom. 


\section{Theoretical Framework}

I use a sociocultural theoretical framework (Vygotsky, 1978) to link social experience and moral reasoning and examine how students from a variety of backgrounds reason about a CRISPR/Cas9 as an SSI. A sociocultural framework emphasizes the role that social interactions and cultural context have on an individual's cognitive development and ability to make meaning out of knowledge (Vygotsky, 1978). A student's ability to reason morally is influenced not only by content knowledge (Sadler, 2004a) but also by interest (Piaget, 1972), context, values, cultural background (Schwartz, 1992), past experiences (Zeidler \& Schafer, 1984), and demographic features such as religious affiliation (Siani \& Assaraf, 2015) and gender (Gilligan, 1982). These influences (among others) constitute the sociocultural location of students thus, linking moral reasoning and sociocultural context.

Use of moral reasoning aids in the resolution of SSIs (Sadler \& Zeidler, 2003; Zeidler \& Schafer, 1984; Zeidler \& Sadler, 2007). I define moral reasoning as the application of moral considerations, or factors a person uses to justify a moral judgement, which is their position about what is right and wrong (Sadler \& Donnelly, 2006). Moral reasoning, a form of informal reasoning, uses the social domain of knowledge because it requires weighing potential risks to members of society and coming to a conclusion based on what is best for all members, not just oneself (Fleming, 1986). In science education literature, moral reasoning is studied as a component of moral development (Zeidler \& Schafer, 1984), and authors often use the terms moral reasoning interchangeably with moral development (as observed in King \& Mayhew, 2002). 
Kohlberg (1981) offers a theory of moral development in which cognitive development precedes the ability to understand the moral implications of a situation and conceptual knowledge has an impact on moral reasoning. Support for this theory is found in the many investigations that show a positive association between attainment of higher education and advancement of moral development (King \& Mayhew, 2002). Kohlberg identified six "levels" of moral development divided among three "stages", preconventional, conventional, and post-conventional. The post-conventional stage contains the two highest "levels" of moral reasoning, where stage five is defined by a concern for the well-being of others, and stage six is defined as using one's individual principles (Kohlberg, 1981). The level of moral reasoning has conventionally been measured using the Defining Issues Test (DIT), a multiple-choice test that asks individuals to assess, resolve, and rank ethical dilemmas (Rest, 1974; Rest et al., 1999).

In an investigation of how students used moral reasoning to resolve genetic dilemmas, Sadler and Zeidler (2003) found that students used reasoning based in consequences, principles, emotion and intuition. Consequence-based moral reasoning involves the use of utilitarianism to evaluate the projected outcome of a situation, while principle-based moral reasoning involves the application of principles or ethics to the situation (Sadler \& Zeidler, 2003). In general, the use of consequence-based moral reasoning is associated with Kohlberg's fifth stage of moral development since it involves the use of utilitarianism to evaluate the projected outcome of a situation as applied to the welfare of other members of society. Principle-based moral reasoning is generally associated with the sixth stage since it involves the application of an individual's universal principles to assess whether the issue being discussed should or 
should not be permitted. Recent criticisms regarding the validity of these "levels" of reasoning and the judgements of principle-based moral reasoning being associated with higher stages of moral development, highlight the limitations of applying Kohlberg's stage theory (Nucci, 2016). I used principle and consequence-based reasoning as a structure for identifying types of moral reasoning without assigning a particular stage to either and to facilitate comparisons with other studies about moral reasoning.

The influence of content knowledge on informal reasoning, in general, has been extensively studied (reviewed by Sadler, 2004a) but, Zeidler and Schafer (1984) were the first to investigate the impact of content knowledge on moral reasoning in the context of college biology education. They found that science majors who displayed higher levels of content knowledge used higher levels of moral reasoning for specific environmental issues. Furthermore, they found that individuals who used higher levels of moral reasoning were better able to defend their justifications and persuade others, compared to those students that used lower levels of moral reasoning. In contrast, a recent study (Siani \& Assaraf, 2015) found that, for most contexts, life science college students (who had a better understanding of genetics than non-science majors) did not differ significantly from non-science students in the type of moral reasoning they used (e.g., consequence versus principle-based). Thus, additional research is required to evaluate the association between content knowledge and moral reasoning, which is one objective of my study.

Moral reasoning, in particular, is influenced by interactions with ones' cultural environment and participation in sociocultural activities (Öhman \& Östman, 2007). The cultural context that influences learning includes an individual's identity, agency, and power over their production of knowledge, and important components of identity include 
someone's socio-economic status (SES), gender, and ethnicity (Destin et al., 2017; Holvino, 2008; Lewis \& Moje, 2003; Rogers \& Meltzoff, 2017). Criticisms of Kohlberg's theory of moral development stress the importance of an individual's interactions and development within social contexts (i.e., SES, gender, ethnicity), and assert that this sociocultural context cannot be disregarded in the promotion of moral development among students (Nucci, 2016). It is therefore important to adopt this sociocultural perspective to better understand how individuals with different backgrounds and experiences use moral reasoning.

There are few studies of how demographic or social factors such as gender, SES, and ethnicity influence moral reasoning in association with SSI's. Gilligan (1982) identified gender differences in moral reasoning and proposed that care-based morality was more strongly associated with women than men, but this was not in the context of science education or SSIs. In the context of higher education, Mayhew (2012) found that women showed significantly higher gains in moral reasoning compared to men after completion of their first year in college. Siani and Assaraf (2015) found that religious students used more principle-based moral reasoning compared to non-religious students and, for some scenarios, though inconsistently, men and women differed in their use of consequence-based moral reasoning compared to principle-based moral reasoning (Siani \& Assaraf, 2015). It is important to note that, although they had a large sample size, their study was limited to students of a middle or higher SES.

Investigations into the association between SES and moral reasoning largely focus on children or adolescents and have yielded conflicting results. For example, Vera-Estay et al. (2016) found that SES factors, such as family income and parental level of 
education, did not influence moral reasoning, which was consistent with some past research (Caravita et al., 2012; Dhull \& Kumar, 2012). However, these results contradicted other studies of children and adults (Colby et al., 1983; Haidt et al., 1993). Haidt et al. (1993) found that high SES individuals from both Brazil and the United States judged morally offensive acts (i.e. harmful) differently than acts that were just disrespectful (i.e. performed without poor intentions) whereas individuals from low SES judged the latter as being just as morally wrong as the former. Thus, the relationship between SES and moral reasoning in college-level students is understudied.

In general, it is understood that ethnicity influences how students use moral reasoning (Mayhew, 2012; Moreland \& Leach, 2001), but studies investigating this association are lacking (reviewed in King and Mayhew, 2002) and complicated by the multiple dimensions of what is meant by ethnicity, e.g., intersections with religious affiliations and other identities (Kim, 2011). Additional work is needed to identify how diverse groups of students are employing moral reasoning in the resolution of SSIs. Knowing more about how different groups of students engage in reasoning about genetic dilemmas will provide insight into how to foster diverse classroom environments and discourse, an imperative in science education (Cobern \& Loving, 2000; Lemke, 2001; Zeidler et al., 2005).

\section{Research Questions}

I used sociocultural perspective as a framework to investigate the range of ways that students from a variety of demographic backgrounds use moral reasoning (Zeidler et al., 2005). My study focused on gender and SES and was guided by the following research questions: 
1. How do students use moral reasoning when examining an SSI concerning the use of CRISPR/Cas9 technology for non-medical enhancement in humans? I was specifically interested in the application of moral reasoning to the use of CRISPR/Cas9 as opposed to genetic modification in general or other technologies used for genetic modification in humans.

2. How do students across a range of levels of genetics knowledge (non-majors, lower level biology majors, and upper level biology majors) differ in their use of moral reasoning about CRISPR/Cas9?

3. How does use of moral reasoning about CRISPR/Cas9 differ across students from different socio-economic backgrounds and genders?

\section{METHODS}

I taught a lesson about CRISPR/Cas9 technology that varied in length from 30 to 75-minutes in four biology courses: four sections of introductory biology for nonscience-majors (hereafter non-majors), two sections of introductory biology for biology majors, two sections of microbiology for biology majors, and one section of an advanced genetics course for biology majors. The lesson was the only lesson on CRISPR/Cas9 and its application to SSIs that the students experienced in the course. As part of the lesson, students were asked to read a news article (Pollack, 2014) about CRISPR/Cas9 and write a persuasive essay. The article that students were asked to read covered five main topics: 1) the history of CRISPR discovery and description of how CRISPR functions in bacteria, 2) how CRISPR/Cas9 can be used for targeted genetic modification and how it compares with other techniques for genetic modification, 3) examples of CRISPR/Cas9 use including genetic modification of lab animals, disease treatment, and agricultural 
applications, 4) possible off-target effects, and 5) possible ethical issues such as animal experimentation, human germline editing, and the development of "designer babies".

For the essay prompt, students were asked to argue for or against the use of CRISPR/Cas9 in non-medical (i.e., not related to the treatment of disease) genetic modification in humans, to describe the reasoning behind their position and to discuss a potential social dilemma involving CRISPR/Cas9 (for prompt, see Appendix A). Students completed the work via an online learning management system (Blackboard) coupled with software (Respondus LockDown Browser 4.0) that prevents access to other websites, browsers, and applications, therefore limiting the ability of students to use outside resources. Students were required to complete the lesson as part of their course, were awarded some points for the work and were permitted only one attempt to complete the assignment. The amount of course credit varied depending upon the course instructor. All students were expected to complete the writing assignment but only students who consented to use of their materials were included in the study.

Participants were from a research-intensive, public university in the Midwestern United States. All students that were at least 18 years of age and enrolled in the courses in which the lessons were taught were invited to participate in the study. A total of 566 students agreed to participate in the study. Cases were removed from the study (13\%, $n=72$ ) when: any part of the essay showed evidence of plagiarism, the assignment was not completed through Respondus Lockdown Browser as instructed, the student responded to the consent but did not complete the assignment and/or demographics questions, the student was under 18 years of age, or more than one attempt was submitted. 
Because I was focused on moral reasoning specifically about CRISPR/Cas9, and content knowledge is important to argumentation (Sadler, 2004a; Sadler \& Donnelly, 2006), I used the first part of the prompt to evaluate student understanding of CRISPR and CRISPR/Cas9 technology. Criteria for correct understanding of CRISPR/Cas9 are explained in Appendix A. Only students that demonstrated a basic understanding of CRISPR or CRISPR/Cas9 genome editing technology were included in my analyses $(n=331)$. Although this limited my sample size, it eliminated the confounding variable of content knowledge of CRISPR/Cas9 so I could ensure that all students regardless of level of genetics knowledge were writing and reasoning about the same genetic editing technology rather than genetic engineering in general. Fifty-two essays were eliminated because they were incomplete or failed to address the prompt, resulting in a final sample size of 279 essays. My sample population was $66 \%$ women, $34 \%$ men, $72 \%$ White, $28 \%$ Pell Grant eligible, and 19\% first-generation college students with a mean age of 20 years old (Table 1). Among the students that identified as an ethnicity/race other than White, 8\% were Black/African American, 5\% Hispanic, 2\% Middle Eastern, 8\% Asian, 3\% Multiracial, $1 \%$ Indian, and $<1 \%$ were Pacific Islander.

Federal Pell Grant eligibility was used as an indication of socioeconomic status (SES) since these grants are awarded to low-income students based on expected family contribution to college. First-generation students were defined as students that come from a family where neither parent graduated from college. First-generation students are a unique population. In general, first-generation students are mostly women, older than the average college students, from families with lower incomes, likely to work more hours in college, have more dependents, less involvement in on-campus activities, and less contact 
with other students (Mehta et al., 2011; Rubin \& Wright, 2014; Terenzini et al., 1996). I chose these particular demographic variables (gender, SES, and first-generation status) because they are known to be important in teaching and learning (Brickhouse, 2001; Freidus \& Noguera, 2017; Mehta et al., 2011). Pell eligibility, first-generation status, and race/ethnicity measures were self-identified by students in the demographic questionnaire (see Appendix A).

Table 1. Demographic data for the sample population.

\begin{tabular}{ccc}
\hline Social Factor & Category & Percentage \\
\hline Mean age & 20 years old & \\
Gender & & \\
& Women & $66 \%$ \\
Ethnicity & Men & $34 \%$ \\
& White & $72 \%$ \\
& Black/African American & $8 \%$ \\
& Hispanic & $5 \%$ \\
& Middle Eastern & $2 \%$ \\
& Asian & $8 \%$ \\
& Multiracial & $3 \%$ \\
& Indian & $1 \%$ \\
Pell Eligibility & Pacific Islander & $<1 \%$ \\
& & \\
& Yes & $28 \%$ \\
First Generation Status & No & $72 \%$ \\
& & $19 \%$ \\
& Yes & $81 \%$ \\
\hline
\end{tabular}

My sample was composed of students from three groups of courses that differed in science preparation and thus, level of genetics knowledge. I use the terms "content knowledge level" to represent the level of genetics knowledge. Content knowledge level was inferred based on three criteria: pre-requisites of the course in which the student was enrolled, number of previously completed science courses, and amount of dedicated 
genetics instruction provided to students in their enrolled course. To determine the amount of genetics-related material covered in classes, I examined syllabi and tabulated number of minutes devoted to genetics instruction.

Level 1 students were those enrolled in a standalone introductory biology course with no pre-requisites that met general education requirements, was intended for students not pursuing a STEM degree and included 300 minutes of instructional time devoted to genetics. On average, Level 1 students had completed only one college-level science class. Previous literature suggests that non-majors, like the students in Level 1, show lower performance, motivation, study habits, and incoming knowledge and skills (Cotner et al., 2017; Knight \& Smith, 2010) compared to science majors (who comprise levels 2 and 3).

Level 2 students had completed an average of four college science classes and were enrolled in an introductory biology course required by biology majors that devoted 525 minutes to genetics instruction. This course was one in a sequence of two courses and had pre-requisites related to student performance in science and math (e.g., minimum science ACT score of 24 or math SAT score of 540 or completion with a passing grade or enrollment in a department-approved biology course in a prior semester).

Level 3 students had completed on average 15 college science classes and were enrolled in an upper-level biology course for majors with the pre-requisite of two semesters of introductory biology, a 300-level course on cellular and molecular biology and 300-level genetics lecture and lab courses. Both upper level courses had at least 900 minutes devoted to genetics instruction. 
Level 1 and Level 2 were composed primarily of first- and second-year college students ( $86 \%$ and $82 \%$, respectively) whereas $98 \%$ of students in the Level 3 group were third or fourth year, post-baccalaureate, or graduate students (Table 2). The majority of Level 1 students were pre-nursing (31\%) and only $2 \%$ were intended biology majors who did not meet the pre-requisites to be in the introductory course for majors (Table 2). The remaining $67 \%$ of Level 1 students were from various majors, including but not limited to art, social work, psychology, education, dental hygiene, and exercise science. The majority of Level 2 students were biology majors (52\%; Table 2), 33\% were majors in bioengineering, chemical engineering, chemistry, biochemistry, exercise science, neuroscience, or identified as pre-medical without providing a specific academic major. The majority of Level 3 were biology majors (86\%; Table 2) with all other students having majors in biochemistry, chemistry, biology education, psychology, and microbiology. The average number of completed college science classes differed among all levels, Level 1 students the lowest and Level 3 students the highest (Wilcoxon-MannWhitney test, $\mathrm{p}<0.001$; Table 2).

These three groups of students did not differ in proportion of women $(65-69 \%$ women, $\left.\mathrm{p}=0.82, \chi^{2}=0.40\right)$ or proportion of students who were Pell eligible (22-34\%, $\mathrm{p}=0.18, \chi^{2}=3.40$ ). The proportion of first-generation students ranged from $15-33 \%$ and Level 3 (33\%) had a significantly higher proportion than Level 1 (16\%) and Level 2 $(15 \% ; \mathrm{p}<0.05$; Table 2). Based on course pre-requisites, amount of time devoted to genetics in the course, the average number of previously completed science courses and academic majors, I considered Level 3 students to have more genetics background 
knowledge than Level 1 and Level 2 students, and Level 2 students to have more genetics background knowledge than Level 1 students.

Table 2. Demographic information for students by academic level. This demonstrates academic and demographic differences between students in content knowledge levels: Level 1( $n=96)$, Level $2(n=125)$, and Level $3(n=58)$. Third year students and beyond included fourth-year, post-baccalaureate, and graduate students.

\begin{tabular}{lcccc}
\hline \multicolumn{2}{c}{ Academic or Social Category } & \multicolumn{3}{c}{ Percentages or Mean of Level } \\
\hline $\begin{array}{l}\text { Average number of completed science classes } \\
\text { Academic year }\end{array}$ & 1 & 2 & 3 \\
\hline & $\begin{array}{l}\text { First- and second-year } \\
\text { students } \\
\text { Third-year students } \\
\text { and beyond }\end{array}$ & $86 \%$ & $82 \%$ & $2 \%$ \\
Academic major & Biology majors & $2 \%$ & $18 \%$ & $98 \%$ \\
Ethnicity & White & & $52 \%$ & $86 \%$ \\
Gender & Female & $74 \%$ & $72 \%$ & $70 \%$ \\
Pell Eligibility & Yes & $69 \%$ & $65 \%$ & $66 \%$ \\
$\begin{array}{l}\text { First Generation } \\
\text { Status }\end{array}$ & Yes & $30 \%$ & $22 \%$ & $34 \%$ \\
\hline
\end{tabular}

Among the essays that were removed due to lack of CRISPR/Cas9 understanding (explained in Appendix A), 39\% were from Level 1, 33\% from Level 2, and 19\% from Level 3. The proportion removed from Level 3 was significantly lower than that of Level 1 and Level 2 ( $p<0.01$ and $p<0.05$, respectively) and there was a significant negative linear trend (Chi-squared test for trend in proportions; $p<0.01, \chi^{2}=9.88$ ) indicating that as content knowledge level increased, the ability to adequately describe CRISPR/Cas9 increased. There was no significant difference in proportion of responses removed (due to 
lack of CRISPR/Cas9 understanding) within levels from Pell eligible students ( $\mathrm{p}=0.09$, $\left.\chi^{2}=4.68\right)$ or first-generation students $\left(\mathrm{p}=0.60, \chi^{2}=1.02\right)$.

\section{Analysis of Essay Responses}

I applied quantitative methods to results from qualitative coding of student essays. I used content analysis (Weber, 1990) to analyze how students used moral reasoning in written discourse and then employed quantitative research methods to analyze patterns that emerged during my qualitative coding. I used open-coding (Saldaña, 2016) to develop themes that described the moral justification students used and then characterized these justifications as either principle- or consequence-based moral reasoning (Sadler \& Zeidler, 2003). Expressions were considered as consequence-based moral reasoning when a student used the outcome of a situation to justify their position. For example, one student displayed the use of consequence-based moral reasoning because they explicitly use the outcome (loss of diversity, a sub-category of eugenics) to justify why non-medical enhancement is unethical and should not be allowed:

"The use of CRISPR to genetically modify embryos is unethical because it would take away diversity in our population..."

The above example also demonstrates how the loss of diversity was an indirect outcome that was dependent upon a more direct outcome of eugenics. In contrast, expressions were considered principle-based moral reasoning when students used declarative statements about what is right or wrong based on their principles. For example, this student used principle-based moral reasoning (the principle of free will) to justify their position against non-medical enhancements in humans: 
"It all comes down to personal choice, and just like we cannot tell a woman what to do with her body we should not be able to decide on the specifics of our offspring's bodies."

Although Sadler \& Zeidler (2003) also identified when students used emotive or intuition-based moral judgements, I did not code for these because my dataset was composed of written responses as opposed to interviews and therefore emotion and intuition were difficult to gauge. All coding was performed using qualitative analysis software (NVivo version 11). My codebook is displayed in Table 3. Me and my advisor performed iterative rounds of coding until we reached an inter-rater reliability expressed as percentage match above $90 \%$. At that point, I coded the remaining essays. We conducted periodic inter-rater reliability checks to ensure that we maintained agreement over $90 \%$. I used themes that emerged from qualitative coding methods (Table 3 ) to analyze the patterns that emerged using the quantitative analysis methods described below.

I used logistic regression with forward selection to examine factors that influenced student use of most common consequence and principle-based arguments (>20\% of students used them; Table 3). Logistic regression was appropriate because my data was 0/1 (absence/presence) binary data (Evans \& Rosenthal, 2010), and it allowed me to determine what independent variables (e.g., content knowledge level, gender, SES) predicted the use of particular consequences or principles. I evaluated each individual model by performing a Wald test for variables and a likelihood ratio test comparing the chosen model to the next best model that had one less variable (Table 4). I used chisquared tests to compare expected and observed frequencies of students to determine 
differences among content knowledge levels (Evans \& Rosenthal, 2010), and when differences were significant, I performed pairwise comparisons of those proportions. All statistical analyses were performed using R. My results were used to indicate which populations of students are more or less likely to use particular types of moral reasoning and therefore provide insight into how these various populations of students reason morally about CRISPR/Cas9 non-medical enhancement.

\section{RESULTS}

Ninety-one percent of students argued against, $6 \%$ argued in favor, and $2 \%$ were conflicted over the use of non-medical enhancement. The proportion of students arguing against, in favor of, or expressing conflict was similar across the three content knowledge levels $\left(\mathrm{p}=0.70, \chi^{2}=0.71 ; \mathrm{p}=0.87, \chi^{2}=0.27 ; \mathrm{p}=0.37, \chi^{2}=1.98\right.$, respectively). I used only essays arguing against the use of non-medical enhancement in my statistical analyses because none of the arguments in favor of the use met the criteria of greater than $20 \%$ of students using it. Lack of the inclusion of these responses was related to sample size and was not meant as a judgement about their value. 
Table 3. Consequences and principles identified in student responses. Principles are bolded. Single asterisks denote sub-codes of the broader code it is listed under; see section 3.1 for full description. Double asterisks denote that the consideration was used only in arguments in favor of the use of non-medical genetic enhancement. Total $n=279$ but participants may be counted in more than one category.

\begin{tabular}{|c|c|c|c|c|c|}
\hline \multirow[t]{2}{*}{$\begin{array}{l}\text { Consequence or } \\
\text { Principle (n) }\end{array}$} & \multirow[t]{2}{*}{ Description } & \multirow[t]{2}{*}{ Example } & \multicolumn{3}{|c|}{$\begin{array}{l}\text { Percentage of } \\
\text { Students From } \\
\quad \text { Level }\end{array}$} \\
\hline & & & 1 & 2 & 3 \\
\hline Eugenics (192) & $\begin{array}{l}\text { The use of CRISPR for non-medical } \\
\text { enhancement is another form of } \\
\text { eugenics. This included discussions } \\
\text { about the creation of "ideal" } \\
\text { members of society and designer } \\
\text { children. }\end{array}$ & $\begin{array}{c}\text { "In this realm, gene editing via CRISPR can be } \\
\text { used as a "build-a-baby." You can essentially } \\
\text { choose your baby's eye color, hair color, } \\
\text { physique, and various mental advantages." - } \\
\text { Level } 1\end{array}$ & $55 \%$ & $78 \%$ & $71 \%$ \\
\hline $\begin{array}{l}\text { Loss of diversity } \\
\qquad(57)\end{array}$ & $\begin{array}{l}\text { If CRISPR is used in this way, there } \\
\text { will be a loss of diversity in general } \\
\text { and/or genetic diversity and/or } \\
\text { diversity among humans. }\end{array}$ & $\begin{array}{l}\text { "...the human race would probably become less } \\
\text { diverse because parents will most likely choose } \\
\text { the same features...If everyone has the same } \\
\text { desirable features there will be a loss } \\
\text { diversification in the human race hurting society } \\
\text { in many obvious ways." - Level } 1\end{array}$ & $14 \%$ & $28 \%$ & $16 \%$ \\
\hline $\begin{array}{l}\text { Precautionary } \\
\text { principle (176) }\end{array}$ & $\begin{array}{l}\text { If we do not know enough about } \\
\text { potential negative side effects or the } \\
\text { process of genetic modification } \\
\text { (with CRISPR/Cas9) in humans, it is } \\
\text { wrong to use it for this purpose. }\end{array}$ & $\begin{array}{l}\text { "CRISPR can have results that scientists cannot } \\
\text { predict, because it could accidentally work on the } \\
\text { wrong part of the DNA and is a risk not worth } \\
\text { taking for something non-medical." - Level } 3\end{array}$ & $66 \%$ & $60 \%$ & $66 \%$ \\
\hline
\end{tabular}


Increasing social

inequality (137)

Accessible to wealthy only*

(109)

Discrimination ${ }^{*}$
The use will result in increased inequality between the upper- and lower-classes. This inequality could include economic status, personal skills and opportunities, and/or other social inequalities.

If the technology is available, it will be accessible only to the upper-class individuals in society.

Using the technology will ultimately lead to the mistreatment or oppression of some social groups.
"Economically, no normal person will ever be able to compete with someone with perfect genes intellectually and that will negatively affect their ability to get educated, get jobs, and live their lives comfortably. Then those people who can't get good jobs because they weren't engineered won't be able to afford to have their children engineered, and the cycle will continue indefinitely. The rich at the top and the poor at the bottom, unable to move up in an unfair social

$$
\text { system." - Level } 2
$$

"...only the wealthy would be able to afford such a procedure, while the poor would never get the chance to have it." - Level 2

"It could also lead to a prejudice towards people who had their genes edited and those that did not. towards one side or the other." - Level 2 
Nature knows

best principle

(115)

Uniqueness

principle (55)
Nature or God designs the natural world for a reason (e.g., optimal fitness or God's image); interfering with that design is wrong.

Everyone is unique and differences among individuals are intrinsically

valuable; to compromise that uniqueness is wrong. (No mention of diversity.)

\section{Equality and fairness principle (44)}

"This act goes against the natural process of the world we were born into, and takes away from the 'naturalness' of life. ...we would have basically turned the aspect of life into a video game, treating our children, and even our own bodies as customizable avatars. In no way is this right." Level 2

"...our quirks and differences are what make us unique. These quirks, although sometimes detrimental, prove to also be our greatest strengths. Being obsessive, for instance, can be often unhealthy. It can lead to bad habits, and can lead to fixations that stop the person from normally participating in society. But, when properly cultivated, obsessiveness can lead a voracity of excellence, and a willingness to achieve." - Level 2

"If one group of people can create the perfect baby and edit their genes then everyone should be able to do this so that the world is fair and equal."

$$
\text { - Level } 2
$$

All humans should be treated equally and fairly; to interfere with equal treatment is wrong. This often included a declaration about something being unfair but no direct mention of social inequality.

\section{$13 \% \quad 31 \% \quad 7 \%$}




\section{Free will principle (38)}

\section{allocation principle (30)}

Resource
All humans are entitled to have free will and to interfere with that is wrong. This also included discussions about informed consent for embryos, fetuses, and/or children.

Money and resources should be used on life-saving advances; to use it for other purposes is wrong.

Identity conflicts

"It all comes down to personal choice, and just like we cannot tell a woman what to do with her body we should not be able to decide on the specifics of our offspring's bodies." - Level 1

"We need to make use of our money and spend it wisely. Imagine trillions and trillions of dollars being spent just on parents choosing to make their kids taller or have blonde hair and blue eyes instead of dark brown hair and eyes. This is a waster [sic] of time and money. There are so many things wrong with the world that must be changed and money should go to these types of things. Such things would be curing cancer or cystic fibrosis for the rest of eternity. Using nonmedical gene editing is a waste of time and money, people should be mature enough to understand that there are bigger problems in the world." - Level 1

"Just like the way in which intersex children

Individuals, whether genetically enhanced or not, will struggle with their sense of identity and selfworth. This included discussions of eventual conflict between an edited person and those who chose to do the editing. when grown may be upset and feel they have lost a part of themselves from when their parents decided their sex at birth, your child may also grow to resent you for destroying a part of them and choosing something for them that they would not have chosen for themselves." - Level 1 
Malicious uses

Animal

experimentation

Improve quality of life (11) ${ }^{* *}$

Enhance species fitness $(8)^{* *}$
The technology will be misused in some manner, including military misuse that will cause harm to other countries and the production of bioweapons.

There will be an increase in the amount of animal experimentation.

The technology would be used to improve the quality of life of some individuals.

The technology could result in the increase in species fitness of humans.
"This technology can be use [sic] to harm people and other species as well. CRISPR/Cas9 could be use [sic] as a bio-weapon, enhancing viruses [sic] deadly capabilities." - Level 1

"Finally, it could result in an explosion of animal experimentation and the abuse of said animals for the advancement of a non-essential medical science." - Level 2

"Surgery and working out wouldn't be needed anymore because the pathway to the perfect body is in the DNA. Altering DNA through CRISPR could let scientists make people stronger and more attractive, allowing for the person to be healthier and happier." - Level 1

"Some of these positive effects include forming a more genetically fit society, people may be able to live longer, and we would have children who are much more fit to survive in their environment." Level 1 
Contribute to overpopulation

Increase lifespans

$(2)^{* *}$

un $\begin{gathered}\text { Improve } \\ \text { knowledge }(3) * *\end{gathered}$
Because the technology can allow people to live longer and can correct defects that would usually result in shorter lifespans, it will contribute to overpopulation.

The technology will increase the lifespans of humans, and that is a good thing.

The use of CRISPR/Cas9 technology for non-medical enhancements will allow for more knowledge about the use and safety of the technology in general.
"This would create an even bigger overpopulation problem. People would no longer die of causes

esides organ failure, which means people would live a lot longer than they do now. This would lead to a problem of not having enough food to support the population, as well as further passing the carrying capacity which we've already done." - Level 1

"it [sic] could be used to make life better or may be even make us live a lot longer." - Level 3

“...extensive research by a variety of scientists medical research) would increase the knowledge about gene editing in humans. This would benefit the medical world because gene editing is likely to dominate much of the medical world as the $21^{\text {st }}$ century progresses. Being more knowledgeable on the subject would be highly beneficial to inevitably learn about the side effects of CRISPR and how to correctly address those problems." Level 1 
Impact job market It will indirectly result changes to the job market.

Capitalism (2)**

N
Use of the technology for nonmedical enhancements in humans will be good for the economy, and therefore good for members of society.

Safety principle $^{* *}(3)$
"The highest earning jobs are engineers, doctors, lawyers, entertainers, and pro sport players. So when given the opportunity parents would give their children the trait to make the most amount of money in order to be successful. This would cause a huge surge in white collar jobs while the service and blue collar jobs would suffer a

$$
\text { deficit." - Level } 3
$$

"Those who would want the treatment would have to pay enormous amounts of money for these type of procedures which would help stimulate the economy and put money back into the gene editing business/research." - Level 1

"With bodybuilding comes pain and injury; any injury can cause permanent damage and costs money. The same goes for plastic surgery. One slip of a scalpel and the patient's nerves could be permanently damaged or their face could have scars from the surgery. The possibilities of injury are endless. These exact reasons are why CRISPR technology could be used for different enhancements rather than medical. With CRISPR, we could make faces and bodies into anything the person desired without the pain." - Level 1 


\section{Consequence and Principle-Based Moral Reasoning}

Overall, students used a wider variety of consequences than principles in their reasoning. I identified 15 themes that were coded as consequence-based and seven as principle-based reasoning using definitions described by Sadler \& Zeidler (2003; Table

3). The most commonly used consequence-based moral reasoning arguments included: eugenics, increasing social inequality, inequitable accessibility, and loss of diversity (Table 3). Five of the 15 consequence-based reasoning themes were specific to students who argued in favor of or were conflicted about the use of CRISPR/Cas9 technology for non-medical enhancements in humans. The most commonly used principles were: the precautionary principle, nature knows best, uniqueness, equality and fairness, free will, and resource allocation principle (Table 3). One principle-based argument (safety) was unique to those in favor of using CRISPR/Cas9 technology for non-medical enhancement.

Some themes were further divided into sub-themes. For example, both accessibility and discrimination were sub-themes of increasing inequality, meaning that anything coded as accessibility or discrimination was also coded as increasing inequality, but not all increasing inequality events were coded as accessibility or discrimination. Diversity loss was a sub-code for eugenics.

Most students (73\%) used a combination of both principle-based and consequence-based reasoning; $15 \%$ used only principle-based and $9 \%$ used only consequence-based moral reasoning. A significantly higher proportion of students that argued against the non-medical use of CRISPR/Cas9 used principle-based moral reasoning $(93 \%)$ compared to consequence-based reasoning $\left(86 \% ; \mathrm{p}<0.05, \chi^{2}=5.39\right)$. 
There were no differences among content knowledge levels in the proportion of students using one or the other form of moral reasoning $\left(\mathrm{p}>0.09 ; \chi^{2}<3.36\right)$. Students that argued in favor of genetic enhancement or were conflicted about its use were equally likely to use consequence or principle-based reasoning $\left(\mathrm{p}=0.18, \chi^{2}=1.78\right.$ and $\mathrm{p}=0.49, \chi^{2}=0.48$, respectively).

\section{Arguments in favor of non-medical enhancement}

Themes specific to arguments in favor of non-medical enhancement of humans using CRISPR/Cas9 technology included consequence-based arguments: increasing lifespans, enhancing species fitness, improving quality of life, improving scientific and/or medical knowledge, and capitalism (Table 3). Of the students that argued in favor of using the technology for non-medical enhancement in humans, 39\% used the consequence-based argument that using the technology would enhance the fitness of the "human species". Similarly, 39\% of students argued that it would improve the human quality of life. Of those arguing in favor, $17 \%$ said that allowing the technology to be used for non-medical enhancement would lead to an increase in knowledge about genetics and CRISPR/Cas9 technology. Eleven percent said that it would increase lifespans of humans and $11 \%$ used a capitalism-based argument claiming that it would be good for the economy.

The only principle that was unique to arguments in favor of using the technology was the safety principle, the notion that we are obligated to use the safest procedure possible. This assumes that CRISPR/Cas9 technology is the safest option for altering non-medical related characteristics in humans. Overall, $11 \%$ of the students who argued 
in favor of non-medical enhancement in humans used this principle to justify their position (Table 3).

\section{Level and Social Factors Influence Moral Considerations}

\section{Consequences}

Eugenics was the most commonly invoked consequence (Table 3). In a logistic regression with presence or absence of the eugenics argument as a dependent variable and forward selection of independent variables (content knowledge level, gender, Pell eligibility, and first-generation status), the model that best explained variation in the use of eugenics included only one main effect, content knowledge level (Table 4). Level 1 students were 0.33 times less likely to use eugenics compared to Level 2 students, making them the least likely to do so ( $\mathrm{p}<0.001$; Figure 1). Given that arguing from the standpoint of negative consequences of eugenics was so common overall, and invoking eugenics is a common response to SSIs about genetic manipulation (Brokowski et al., 2015; Friedmann, 2019; Vizcarrondo, 2014), this suggests that students from Level 1 are missing a very important, socially relevant connection between nefarious uses of science in the name of genetics and use of CRISPR/Cas9. Although gender was not a significant predictor in the model, men were 0.62 times less likely to use the eugenics argument compared to women, indicating the potential for differences in how men and women reason about SSIs $(\mathrm{p}=0.08)$. 


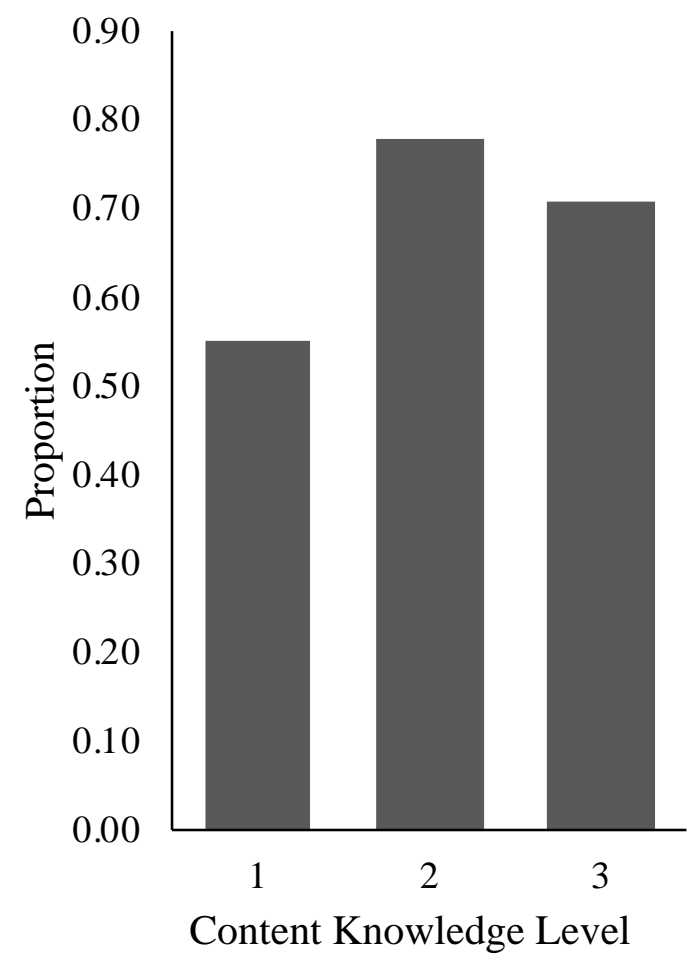

Figure 1. Proportion of students from each content knowledge level that discussed eugenics. Level 1 students were the least likely to consider eugenics in their responses $(\mathrm{p}<0.001)$.

Increasing inequality among social groups was the second most commonly used consequence (Table 3). Only one variable, content knowledge level, was significantly associated with use of this consequence (Table 4). The odds that a Level 1 student would invoke this consequence were 0.48 times less than that of a Level 2 student doing so, making Level 1 students the least likely to discuss increasing inequality ( $<<0.01$; Figure 2). Conversely, the odds that a Level 3 student would use increasing inequality were 2.30 times greater than that of a Level 2 student, making Level 3 students the most likely to invoke this consequence ( $\mathrm{p}<0.05$; Figure 2$)$. This suggests that students with different levels of genetics knowledge (content knowledge level) use different considerations regarding the social consequences of genetic manipulation with CRISPR/Cas9. 


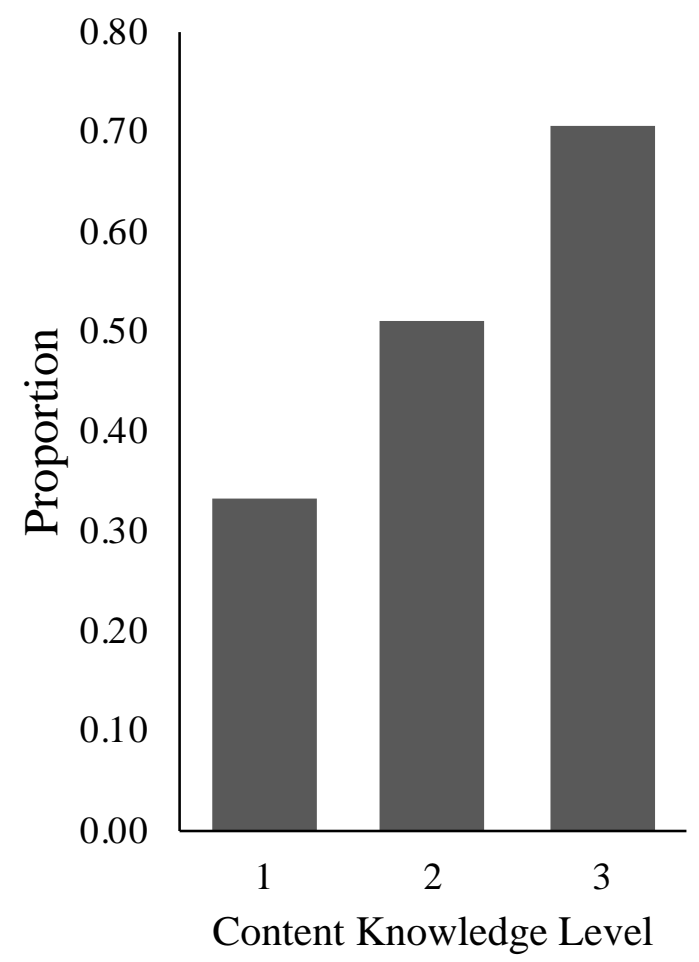

Figure 2. Proportion of students from each content knowledge level that discussed increasing inequality. Level 1 students were the least likely to discuss this outcome $(\mathrm{p}<0.01)$, while Level 3 were the most likely $(\mathrm{p}<0.05)$.

That CRISPR/Cas9 genome editing technology would be only available to the wealthiest in society, the accessibility consequence, was the third most commonly used consequence-based argument (Table 3). Eighty percent of the students that discussed increasing inequality specifically mentioned how limited accessibility would contribute to disparities regarding access to resources. Level was a significant predictor for this consequence, where the likelihood of a student using it increased as level increased (Table 4). All else being equal, Level 1 students were 0.52 times less likely to use this consequence compared to Level 2 students $(\mathrm{p}<0.05)$ while Level 3 students were 2.54 times more likely to invoke limited accessibility ( $<<0.01$; Figure 3 ). Again, indicating that genetics understanding may influence reasoning about SSIs. 


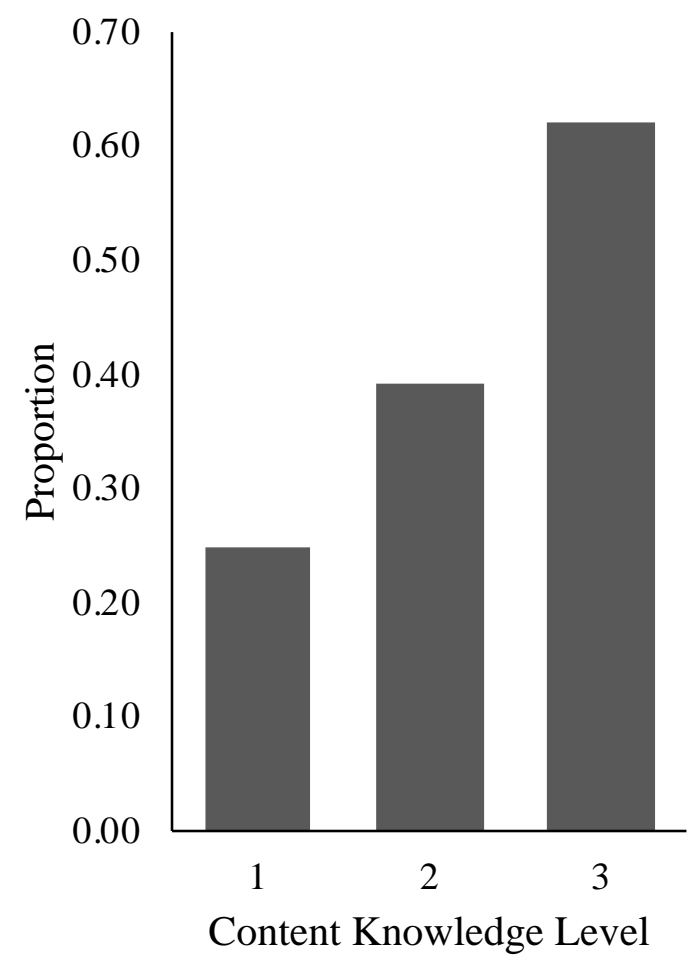

Figure 3. Proportion of students from each content knowledge level that discussed limited accessibility. Level 1 students were the least likely to discuss this outcome $(\mathrm{p}<0.05)$, while Level 3 were the most likely $(\mathrm{p}<0.01)$.

The fourth most commonly used consequence was diversity loss which was a subtheme embedded within eugenics (Table 3). Thirty percent of students who were concerned about eugenics specifically discussed how eugenic practices would lead to a loss of diversity. Content knowledge level, gender, and the interaction between the two were significant predictors of a student using this consequence (Table 4). Level 1 and Level 3 students were 0.25 and 0.28 times less likely to discuss the loss of diversity compared to Level 2 students ( $<<0.01$ and $\mathrm{p}<0.05$, respectively). Men on average were 0.28 times less likely to use this outcome compared to women ( $<<0.05)$, however, there was a significant interaction between content knowledge level and gender where women were less likely to discuss diversity loss compared to men at both Level 1 and Level 3, 
but not Level 2. Men in the Level 3 group were the most likely to use this outcome in their response, with men in the Level 1 group following closely behind them $(\mathrm{p}<0.05$; Figure 4).

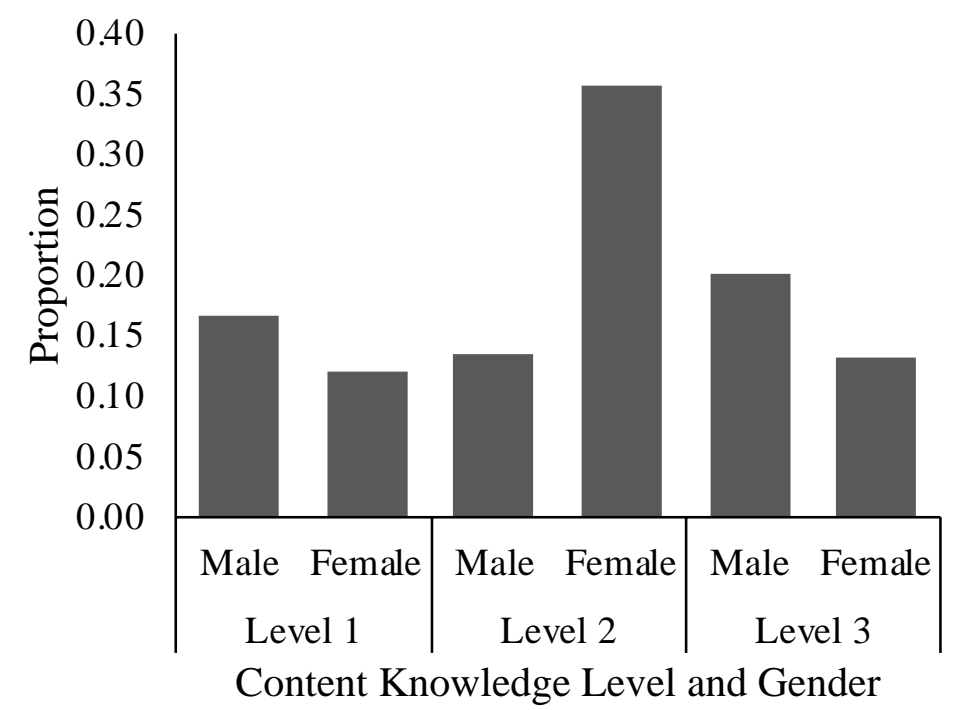

Figure 4. Proportion of students from each content knowledge level and gender that discussed the loss of diversity. Men on average were 0.29 times less likely to use this outcome compared to women $(\mathrm{p}<0.05)$. There was a significant interaction between content knowledge level and gender, where women were less likely to discuss diversity loss compared to men in both Level 1 and Level 3 groups, but not Level 2. Men in the Level 3 group were the most likely to discuss diversity loss $(\mathrm{p}<0.05)$. Principles

The most commonly used principle was the precautionary principle (Table 3) and gender was the only variable significantly associated with the use of this principle (Table 4). Men were 0.27 times less likely than women to use this principle ( $\mathrm{p}<0.001$; Figure 5). This adds to existing evidence that men and women may use different moral reasoning about SSIs (Siani \& Assaraf, 2015). 


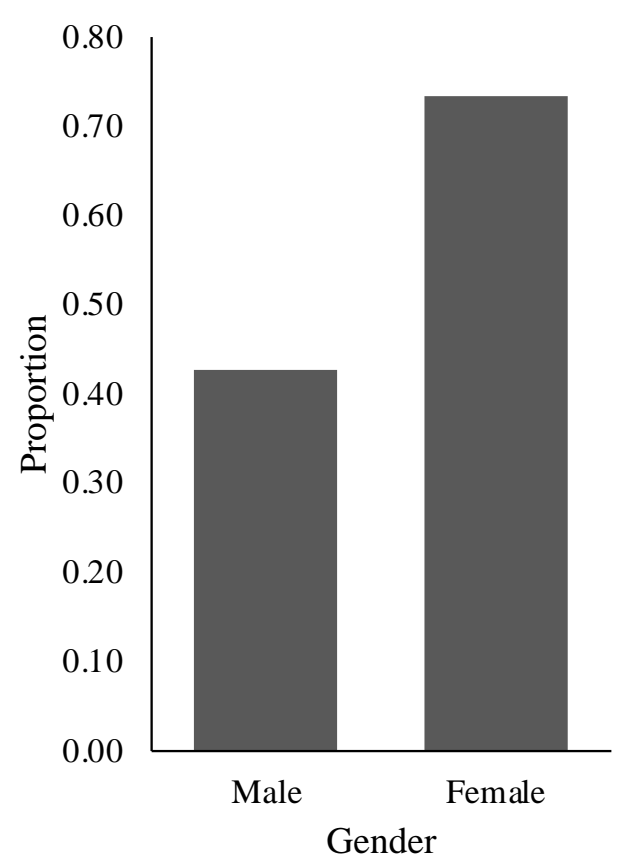

Figure 5. Proportion of students from each gender that used the precautionary principle. Males were less likely to consider this principle compared to females $(\mathrm{p}<0.001)$.

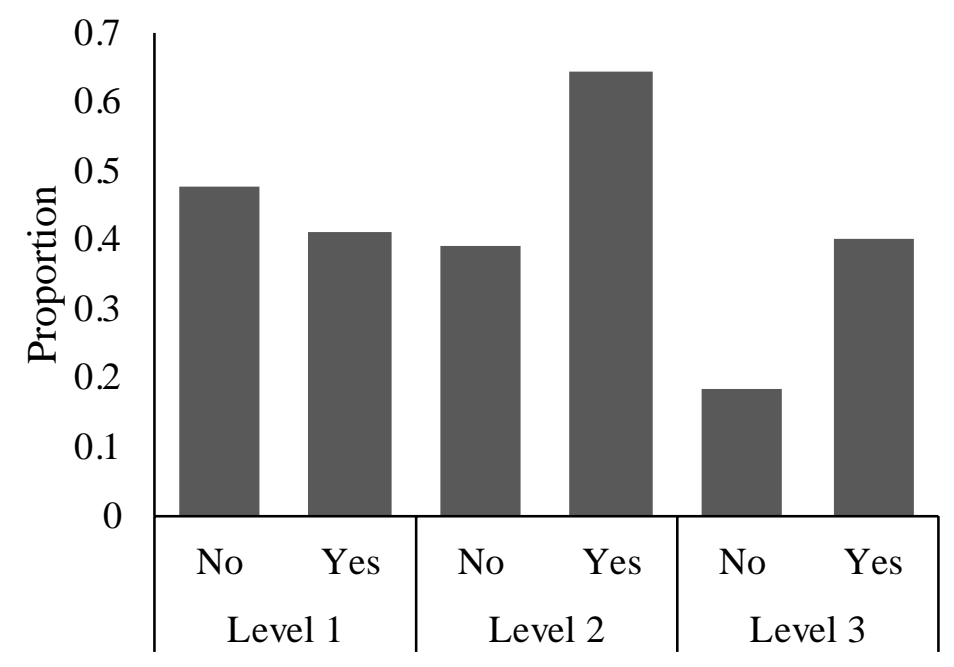

Content Knowledge Level and Pell Eligibility

Figure 6. Proportion of students from each content knowledge level and Pell group that discussed the nature principle. Pell students were more likely to invoke this 
principle except in the Level 1 group, where Pell eligible students were less likely to discuss the nature principle $(\mathrm{p}<0.05)$.

Content knowledge level, Pell eligibility, and the interaction between these variables were significantly associated with the use of the "nature knows best" principle, the second most commonly invoked principle (Tables 3 and 4). Students from Level 3 were the least likely to use this principle; they were 0.35 times less likely to consider this principle compared to students from Level $2(\mathrm{p}<0.05)$. Because this principle is closely related to the naturalistic fallacy (Daston, 2014), it is conceivable that students with more biology knowledge would be less likely to use it. Pell eligible students were 2.89 times more likely to invoke this principle compared to students that were not Pell eligible $(\mathrm{p}<0.05)$. However, Pell eligible students in the Level 1 group did not follow this pattern $(\mathrm{p}<0.05 ;$ Figure 6).

The uniqueness principle was the third most used principle in students' responses (Table 3). The best logistic regression model included two variables, content knowledge level and first-generation status (Table 4). First-generation students were 2.2 times more likely than non-first-generation students to invoke this principle ( $\mathrm{p}=0.04$; Figure 7). Students from Level 1 were 0.3 times less likely than students from Level 2 to invoke this principle ( $\mathrm{p}<0.01$ ), while students from Level 3 were 0.14 times less likely ( $<0.001$; Figure 8). This indicates that students with more genetics background are less likely to base their reasoning in individual intrinsic values but rather use larger, pervasive societal consequences, such as equality, accessibility and eugenics. 


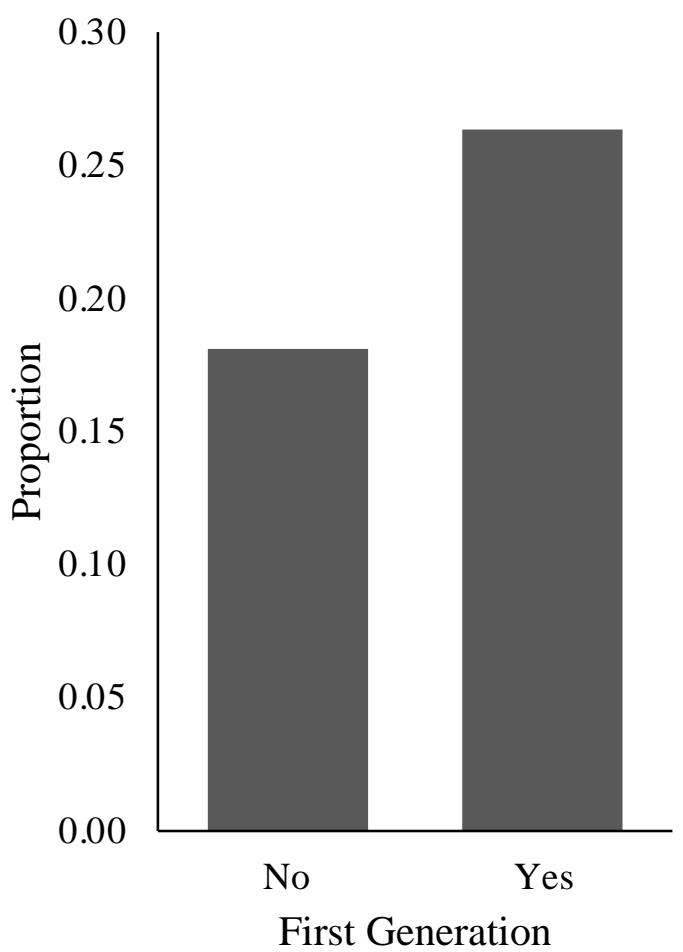

Figure 7. Proportion of students from each Pell group that discussed the uniqueness principle. Comparison of the proportion of first-generation and non-first-generation students that discussed uniqueness. First-generation students were more likely to use this principle $(\mathrm{p}<0.05)$. 


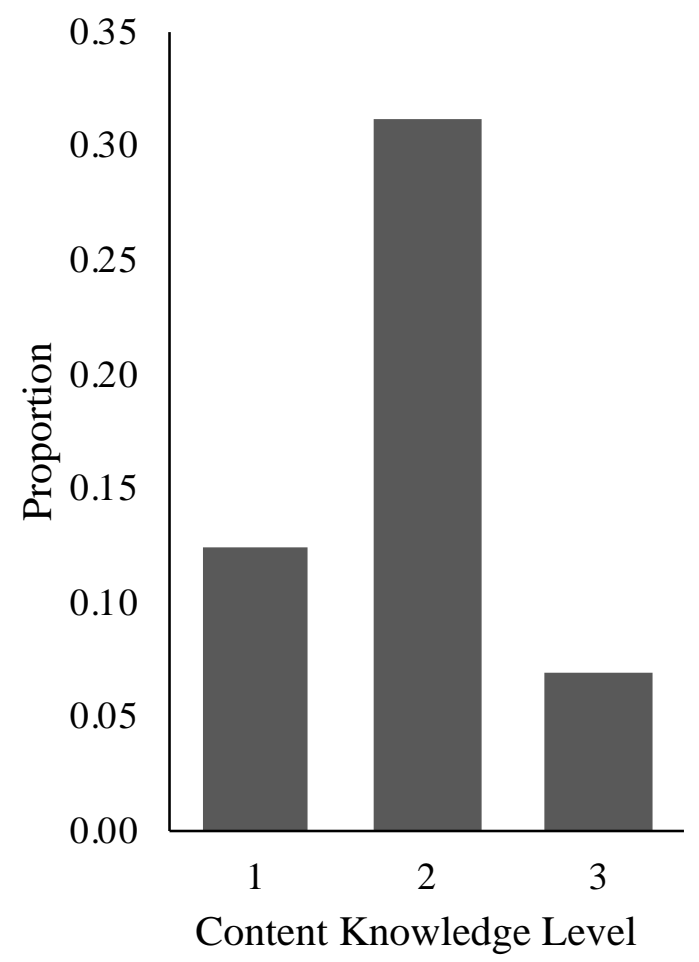

Figure 8. Proportion of students from each content knowledge level that discussed the uniqueness principle. Students from Level 2 were significantly more likely to use this principle compared to those from Level $1(\mathrm{p}<0.01)$ and Level $3(\mathrm{p}<0.001)$. 
Table 4. Logistic regression model evaluation for each of the six most common consequences and principles. LRT $=$ Likelihood ratio test. For gender, $0=$ female and $1=$ male; for Pell eligible and first-generation, $0=$ no and $1=$ yes.

\begin{tabular}{|c|c|c|c|c|c|c|c|c|c|c|}
\hline $\begin{array}{l}\text { Consequence or } \\
\text { Principle }\end{array}$ & $\begin{array}{c}\text { LRT } \\
\text { p-value }\end{array}$ & Predictor & & $\beta$ & $\begin{array}{c}\text { SE } \\
\beta\end{array}$ & $\mathbf{e}^{\beta}$ & $\begin{array}{c}\text { Logistic } \\
\text { regression } \\
\text { p-value }\end{array}$ & $\begin{array}{c}\text { Wald's } \\
\text { F } \\
\text { Statistic }\end{array}$ & $\begin{array}{c}\text { Wald's } \\
\text { p- } \\
\text { value }\end{array}$ & DF \\
\hline \multirow[t]{6}{*}{ Eugenics } & 0.08 & Level & & - & - & - & - & 6.93 & 0.00 & 2 \\
\hline & & & 1 & 1.11 & 0.30 & 0.3 & 0.00 & & & \\
\hline & & & 3 & 0.42 & 0.36 & 0.7 & 0.25 & & & \\
\hline & & Gender & & - & - & - & - & 3.01 & 0.08 & 1 \\
\hline & & & Male & 0.48 & 0.28 & 0.6 & 0.08 & & & \\
\hline & & Constant & & 1.47 & 0.25 & & & & & \\
\hline \multirow[t]{4}{*}{ Increase Inequality } & $2.60 \mathrm{E}-05$ & Level & & - & - & - & - & 9.76 & 0.00 & 2 \\
\hline & & & 1 & 0.74 & 0.28 & 0.5 & 0.01 & & & \\
\hline & & & 3 & 0.83 & 0.34 & 2.3 & 0.01 & & & \\
\hline & & Constant & & 0.05 & 0.18 & & & & & \\
\hline \multirow[t]{4}{*}{ Accessibility } & $2.8 \mathrm{E}-05$ & Level & & - & - & - & - & 9.83 & 0.00 & 2 \\
\hline & & & 1 & 0.66 & 0.30 & 0.5 & 0.03 & & & \\
\hline & & & 3 & 0.93 & 0.33 & 2.5 & 0.00 & & & \\
\hline & & Constant & & 0.44 & 0.18 & & & & & \\
\hline \multirow[t]{3}{*}{$\begin{array}{l}\text { Precautionary } \\
\text { Principle }\end{array}$} & $4.80 \mathrm{E}-07$ & Gender & & - & - & - & - & 24.48 & 0.00 & 1 \\
\hline & & & Male & 1.32 & 0.27 & 0.3 & 0.00 & & & \\
\hline & & Constant & & 1.02 & 0.17 & & & & & \\
\hline \multirow[t]{5}{*}{ Nature Principle } & 0.07 & Level & & - & - & - & - & 4.16 & 0.02 & 2 \\
\hline & & & 1 & 0.35 & 0.32 & 1.4 & 0.28 & & & \\
\hline & & & 3 & 1.05 & 0.47 & 0.4 & 0.02 & & & \\
\hline & & Pell Eligible & & - & - & - & - & 5.31 & 0.02 & 1 \\
\hline & & & Yes & 1.03 & 0.45 & 2.8 & 2.79 & & & \\
\hline
\end{tabular}




\begin{tabular}{|c|c|c|c|c|c|c|c|c|c|c|}
\hline & & Level by Pell & & - & - & - & - & 2.56 & 0.08 & 2 \\
\hline & & & $1 X Y e s$ & 1.29 & 0.63 & 0.3 & 0.04 & & & \\
\hline & & & $3 X$ Yes & 0.05 & 0.76 & 1.1 & 0.94 & & & \\
\hline & & Constant & & 0.44 & 0.21 & & & & & \\
\hline \multirow{6}{*}{$\begin{array}{l}\text { Uniqueness } \\
\text { Principle }\end{array}$} & 0.048 & Level & & - & - & - & - & 9.47 & 0.00 & 2 \\
\hline & & & 1 & 1.18 & 0.37 & 0.3 & 0.00 & & & \\
\hline & & & 3 & 2.00 & 0.57 & 0.14 & 0.00 & & & \\
\hline & & First generation & & - & - & - & - & 4.08 & 0.04 & 1 \\
\hline & & & Yes & 0.78 & 0.39 & 2.2 & 0.04 & & & \\
\hline & & Constant & & 0.92 & 0.21 & & & & & \\
\hline \multirow[t]{9}{*}{ Diversity Loss } & 0.04 & Level & & - & - & - & - & 6.55 & 0.00 & 2 \\
\hline & & & 1 & 1.40 & 0.44 & 0.3 & 0.00 & & & \\
\hline & & & 3 & 1.30 & 0.53 & 0.3 & 0.01 & & & \\
\hline & & Gender & & - & - & - & - & 6.45 & 0.01 & 1 \\
\hline & & & Male & 1.26 & 0.50 & 0.3 & 0.01 & & & \\
\hline & & Level by Gender & & . & - & - & - & 3.03 & 0.05 & 2 \\
\hline & & & $1 X$ Male & 1.63 & 0.79 & 5.1 & 0.04 & & & \\
\hline & & & 3 X Male & 1.76 & 0.89 & 5.3 & 0.05 & & & \\
\hline & & Constant & & 0.58 & 0.23 & & & & & \\
\hline
\end{tabular}




\section{DISCUSSION}

College student participants generally opposed non-medical enhancement with CRISPR/Cas9 technology and saw it as fraught with moral controversy primarily related to eugenics, equity, diversity, risk, and the authority of nature or the supernatural. My use of the SSI framework differs from that described by Zeidler et al. (2015) since students were not provided with a structured opportunity to engage in discourse with peers about their ethical considerations. Instead, students were asked to explain their personal reasoning in a writing assignment to explore individual moral perspectives of students from various cultural and academic backgrounds.

Since the proportion of students against, in favor of, or conflicted about the use of CRISPR/Cas9 for non-medical enhancements did not differ among content knowledge levels, I concluded that background knowledge in genetics was not associated with the moral judgement that students made, that is, if they chose to support or oppose the nonmedical uses of CRISPR/Cas9. However, content knowledge level and demographic factors (gender, SES and first-generation status) significantly predicted the moral considerations of students during their decision-making process, that is, the type of moral reasoning they used to justify their moral judgement. Interactions between content knowledge level and gender, and Pell eligibility suggest that there is a complex interplay between student demographics and level of genetics knowledge that may impact moral reasoning. My results also revealed that certain populations of students, such as men and those with less genetics knowledge, were less likely to consider eugenics when reasoning about this use of CRISPR and may indicate a lack knowledge about the history of science and how science has been used as an instrument of oppression. 


\section{How Students Use Moral Reasoning}

Students relied heavily on both consequences and principles in their responses, but they relied slightly more on principles. Based on Neo-Kohlbergian moral philosophy, this indicates that students were using the highest level of moral reasoning (Kohlberg, 1981), and this did not differ by content knowledge level, which is consistent with other findings (Siani \& Assaraf, 2015). My ability to compare stages of moral reasoning is limited because I did not specifically measure the level of moral reasoning using instruments designed for that task (i.e., DIT). However, it is heartening that students relied on principled moral reasoning because this is indicative of an openness to diversity (Gerson \& Neilson, 2014) and suggests that students will be receptive to a wide range of moral considerations when discussing SSIs.

Some of the consequences and principles that students invoked have been previously recorded as moral considerations in response to SSIs unrelated to CRISPR/Cas9 technology and in contexts other than education. For example, the most commonly used principle, the precautionary principle, has been used by policymakers to justify environmental and public health policies to limit negative impacts on human health and the environment when the risks are uncertain (Martuzzi \& Tickner, 2004). The principle has also been used to justify regulations on genetically modified organisms in agriculture (Tagliabue, 2016). In the case of CRISPR/Cas9 technology, students perceived the risk as associated with possible off-target effects and the consequences of those on human anatomy and health, indicating that students were thinking critically about the technical limitations of CRISPR/Cas9 technology as they applied their knowledge of the process to larger issues. However, I observed that some students made 
unfounded conclusions regarding the off-target effects of CRISPR/Cas9 technology and that these were often based on genetics misconceptions. For example, some students claimed that if the wrong gene was targeted, it would result in the loss of human anatomical structures (literally "an arm") and/or death.

Although few students were in favor of using CRISPR/Cas9 for non-medical enhancement, those that did were primarily concerned about increasing the quality of human life or the "fitness of the human species". These arguments are moral in that the students perceived the use of CRISPR/Cas9 technology as beneficial to members of society. Other studies have found similar moral arguments for using gene therapy to improve intelligence or other traits, such as eyesight (Sadler \& Zeidler, 2003). Kantian moral philosophy, which is focused on a duty to perfect oneself and to seek the happiness of others, has also been used to justify arguments for non-medical enhancement in humans (Gunderson, 2007). However, such arguments are deeply rooted in genetic essentialism, since they assume that we can modify any trait using CRISPR/Cas9 technology and that, in turn, will result in a better life for individuals and/or better fitness as a species. Genetic essentialism is the belief that you can infer what an individual's behavior or characteristics will be based on their genes alone (Dar-Nimrod \& Heine, 2011). Altering traits such as intelligence is not possible because the expression of these traits, and most others, are a result of the complex interaction between genes, the environment, and other factors such as epigenetics (Salk \& Hyde, 2012). The belief expressed by some students that it is possible to alter traits as complex as intelligence through pointed genetic manipulations available through CRISPR/Cas9 technology is a misconception based on genetic essentialism. It is more realistic that CRISPR/Cas9 
technology will be used to edit genes that influence a trait rather than guaranteeing a phenotypic change. It is extremely important that students from all academic backgrounds learn about how CRISPR/Cas9 may be misconstrued as having the ability to alter complex traits and how these ideas can be used to support unsavory policies that lean toward eugenics (Dar-Nimrod \& Heine, 2011).

\section{Level Influences Moral Reasoning and Interacts with Demographic Attributes}

I found that level of genetics knowledge significantly influenced how students used moral reasoning in their responses and that this was part of a complex relationship because it interacted with student demographic attributes. Only one consideration, the precautionary principle, was not impacted by content knowledge level. Eugenics and increasing social inequality were the most commonly used consequences and differed among content knowledge levels whereas nature, uniqueness, accessibility, and loss of diversity showed complex relationships between level and demographic attributes of students.

Level - Eugenics, Increasing Inequality, Accessibility, Uniqueness

Eugenics has traditionally been defined as applying science to "improve the genetic composition of a population through controlling reproduction" and has historically been associated with political agendas that violate human rights and promote social inequality based on wealth, mental capabilities, and race (Garver \& Garver, 1991; Subramaniam, 2014, p.46). The potential application of CRISPR/Cas9 technology to the manipulation of germline cells and embryos makes this new eugenics a realistic prospect (Cribbs \& Perera, 2017; Friedman, 2019; Vizcarronda, 2014), and I expected it to be discussed in students' responses. Although, the idea that non-medical enhancement 
smacks of a "new eugenics" resonated with students, fewer students in the Level 1 used eugenics in their arguments compared to Level 2 and Level 3 students (Vizcarronda, 2014).

Students from the Level 1 group were also less likely than Level 2 and Level 3 students to consider increasing social inequalities and limited accessibility as an outcome of non-medical genetic enhancement. Sadler and Zeidler (2003) found this to be a consequence considered by students in their study but used the term "social stratification" to describe it. It is of particular concern that Level 1 students, comprised of mainly nonmajors, are not discussing very obvious social inequity outcomes, such as similarities to eugenics, increasing inequality, and limited accessibility, that are related to CRISPR/Cas9 non-medical use in humans. One possible explanation for this is that students are not exposed to the history of science as it was used for oppressive and colonial purposes (Garver \& Garver, 1991; Subramaniam, 2014). This is especially applicable to the use of CRISPR/Cas9 technology such as how germline modifications are directly associated with eugenics and therefore may increase social inequity (Brokowski et al., 2015).

Use of the uniqueness principle is interesting in that Level 3 students were less likely to use it and first-generation students were more likely to invoke this principle. One explanation for the difference among levels is that, although my data is not longitudinal, students who hold this value are either leaving the biology program or their perceptions are changing as they move from lower-level majors courses to the upper level course. Also, this difference among levels could reflect developmental differences as older students may be more likely to have settled on an identity as opposed to being in a 
developmental stage in which identity exploration is paramount. Despite the explanation, the pattern is concerning because it suggests that our biology majors are likely leaving their undergraduate careers without a complete understanding of the value of uniqueness and individuality.

I recognize that level of genetics knowledge, as I describe it here, is confounded with other variables such as age, personal experience and psychological development that were not measured as part of this study. However, the patterns revealed in my data do not contradict previous findings that conceptual knowledge influences moral reasoning (reviewed in Sadler, 2004a). I add to this by showing that moral reasoning as related to content knowledge level is complicated by interactions with demographic attributes of the students.

Pell Eligibility - Nature Knows Best

Pell eligible students were more likely to use the "nature knows best" principle except in the Level 1 group. Again, SES as measured by Pell eligibility is confounded with other factors such as college preparedness (Titus, 2006) so, this relationship may be an artifact, since students self-reported Pell eligibility and could have done so incorrectly, or it could be indicative of how SES may influence moral reasoning. Use of this principle has been observed in other studies about student moral reasoning about genetic engineering (Sadler \& Zeidler, 2003) and the relationship of use of "nature knows best" with socioeconomic status has been recorded elsewhere. For example, in a study which found that upper class adults are more likely to use utilitarianism in moral dilemmas due to lower levels of empathy (Côté et al., 2013). Although it is difficult to make specific claims about SES and moral reasoning, this is an important outcome because the appeal 
to nature or the supernatural is rooted in the naturalistic fallacy that regards nature (or the supernatural) with an intrinsic value and authority that is inherently good (Daston, 2014). This thinking is problematic because it ascribes to "nature" the power of arbitration between what is and is not morally good; the principle has been used widely to justify everything from sexist and homophobic ideologies to charging higher prices for "natural" foods (Carter \& Braunack-Mayer, 2011; Daston, 2014; Sagoff, 2001). The experiences and challenges of students from lower SES backgrounds and how SES influences moral perspectives requires further investigation so that we can incorporate diverse moral perspectives into classroom discourse about SSIs.

Gender - Precautionary Principle

My results corroborated previous findings that men and women use moral reasoning differently in some instances (Gilligan, 1982; Siani \& Assaraf, 2015). Previous research has indicated that gender differences will impact how students arrive at ethical decisions due to differences in the values, ethics, and morals they hold (Beekun et al., 2010; Curtis et al., 2012; Jaffee \& Hyde, 2000). I found that men were less likely to use the precautionary principle in their response, which is in agreement with previous research in other disciplines indicating that women may be less risk tolerant and value risk-based information more than men (Byrnes et al., 1999; Powell \& Ansic, 1997; Taylor, 2011).

I also found that men were less likely to consider eugenics when reasoning and interpreted this as indication of implicit bias and lack of knowledge of their position of privilege that is reinforced by historical and social norms (Case et al., 2014; Parsons, 2001). For example, eugenics history is filled with instances of prejudice against women 
and children (Garver \& Garver, 1991). This highlights the importance of raising awareness of a positions of privilege to understanding the history and social implications of science and this can be directly impacted by teaching about dominant group advantage (Case et al., 2014).

\section{$\underline{\text { First Generation Students - Uniqueness }}$}

The reasons the uniqueness principle resonates more with first-generation students may be related to their position as a unique person in their family; the first to go to college. One study found that first-generation students had a positive view of their selfconcept which was dependent upon their unique experiences; this included being more appreciative of their opportunities to further their education, more self-reliant and independent, and more adaptable (Tate et al., 2015). My work adds to this body of knowledge since I found that first-generation students were more likely to consider the uniqueness principle in their responses compared to traditional students, suggesting they value uniqueness and individuality differently than other populations. First-generation students belong to a distinct population that may require special considerations to ensure equity (Mehta et al., 2011) in science classrooms. Further research may be useful for identifying why first-generation students hold these values and if this impacts their persistence in STEM fields (Allen et al., 2015).

\section{LIMITATIONS}

My study is an exploratory study, meaning that although I have discovered new and noteworthy patterns, more research is needed to uncover the reasons underlying these patterns. Additional limitations are found in demographic categories used. Students selfreported both Pell eligibility and first-generation status, therefore discoveries pertaining 
to those categories may contain errors and may impact the generalizability of my results. It is also not possible to distinguish between developmental maturity/age and content knowledge level. I also do not have information regarding the writing level of students, their experiences with previous persuasive writing assignments, or exposure to SSIs in or outside of their course. All of these factors could potentially impact the quality of student written responses. By categorizing students, I am making assumptions about particular groups and downplaying the variation that exists within these groups. Lastly, I cannot compare categories to one another in my study (i.e., comparing the results of eugenics to those of the precautionary principle) and instead have focused on exploring which categories were most important to particular student populations.

\section{IMPLICATIONS FOR SCIENCE EDUCATION}

Genetics knowledge and demographic factors likely impact how students use moral reasoning in response to an SSI about CRISPR/Cas9 and students evoked notions grounded in genetic determinism to support their claims. Bioethicists have found that many arguments regarding genetic modification are based on belief in genetic determinism (BGD), and therefore invalid arguments (Resnik \& Vorhaus, 2006). Since BGD is inconsistent with the current understanding of the role of genes on the expression of traits, it is vital that more attention is given to this subject.

The differences among groups of students in what arguments were employed to counter claims for the use of CRISPR/Cas9 in non-medical enhancement indicated that students lack foundational knowledge in the historic and social impacts of science that should serve as lessons about the potential use of science to promote social inequities and oppression of particular groups of people. This is especially pertinent to non-major 
students since these introductory biology courses are often their only experience with science at the college level. Incorporating the philosophy and history (e.g., eugenics) of science into introductory classes may help to emphasize social aspects of science, encourage students to consider diverse perspectives, and highlight the importance of understanding the humanity of science (Allchin, 2014; Kim \& Irving, 2010).

The differences among demographic groups of students highlights the importance of incorporating inclusive teaching techniques into science classes and encourages us to keep in mind the multidimensionality of diversity. The way instructors teach and present new knowledge to students in STEM fields, in particular, must change if instructors wish to foster learning in diverse classroom environments and reduce biases that may lead to marginalization of certain student populations (Dewsbury \& Brame, 2019). My results indicate that potentially marginalized students (e.g., low SES) may reason differently than non-marginalized students, and this knowledge underscores the importance of using a sociocultural perspective to understand how students are making meaning from moral dilemmas. Knowledge about diverse moral perspectives is important for instructors to be able to achieve this goal in the context of SSIs. As this is one of few studies investigating how culture and knowledge may influence moral reasoning, further research should be performed to investigate why particular moral perspectives may be important for certain populations. One type of study that may be useful for this investigation is a Funds of Knowledge (FoK) study using an ethnographic methodology to explore knowledge that students accumulate outside of their academic lives (Moll et al., 1992).

Negative interactions with diverse groups of peers thwarts moral development in unstructured classroom environments (Mayhew \& Engberg, 2010), therefore more 
studies are required to determine how best to incorporate pedagogical practices that promote moral development in science classrooms. Identifying diverse moral perspectives, as I have done in this study, is the first step to understanding a range of perspectives that can then be incorporated into science classrooms by instructors and used to encourage students to engage in transactional discourse, which involves understanding the perspectives of another, and is associated with gains in science learning (Berkowitz \& Simmons, 2003). Transactional discourse provides an opportunity for students to experience and engage in discourse with students that hold beliefs that may conflict with their own, thus providing an opportunity for students to evaluate their own pre-existing beliefs and reasoning (Zeidler et al., 2005). My research shows that it is crucial to consider both content knowledge and moral perspectives in teaching SSIs for a more inclusive science education. 


\section{CHAPTER TWO}

\section{GENETICS KNOWLEDGE INFLUENCES UNDERGRADUATE STUDENTS BELIEF IN GENETIC DETERMINISM}

\section{INTRODUCTION}

\section{Psychological Essentialism}

Essentialist thinking about biological phenomena, such as genes, is an important topic in science education, namely because targeting the conceptualization of genes may be an important educational intervention that can reduce negative societal biases associated with essentialism (Dar-Nimrod \& Heine, 2011) and impede student understanding of biological concepts. Essentialism is the belief that entities contain an underlying, unobservable essence which is responsible for categorization since it explains how the superficial features of members of that category are united (Newman \& Knobe, 2019; Wilkins, 2013). Psychological essentialism, a type of essentialism, is a phenomenon that occurs when people intuitively categorize organisms, including people, based on a perceived immutable essence shared by group members which is responsible for the characteristics that members of that group possess (Gelman, 2003; Gelman \& Rhodes, 2012; Yzerbyt et al., 1997). Essentialist thinking results in the perception that such categories are discrete and natural, and category membership is involuntary and fixed (Dar-Nimrod \& Heine, 2011; Prentice \& Miller, 2007). Previous studies have found 
that some human categories are more essentialized than others, with gender, ethnicity, and race being highly essentialized compared to other categories such as politics (Haslam et al., 2000).

Psychological essentialism of social categories is related to biological determinism, the concept that particular traits are a result of a biological essence (Bastian \& Haslam, 2006; Martin \& Parker, 1995). For example, someone may perceive members of the category man as having particular characteristics, (e.g., aggression, confidence, etc.), and these may be explained by the person doing the categorizing as the outcome of chromosomes or hormones. People may use an "essence placeholder", like genes, to help them make sense of a category and assist them in reaching conclusions about group members (Dar-Nimrod \& Heine, 2011; Prentice \& Miller, 2007) and thus, attribute similarities or differences in behaviors to chromosomes without a full understanding of the biology of chromosomes.

\section{Genetic Essentialism and Belief in Genetic Determinism}

When an individual draws conclusions about someone's characteristics based on what they perceive as a result of genes, it is called genetic essentialism and the gene is an essence placeholder (Dar-Nimrod \& Heine, 2011). Since genes are perceived as being natural, immutable, innate, and stable, they provide ideal essence placeholders (Lynch et al., 2018). In this case, a genetic similarity is extended to behaviors, ideologies, and other manifestations well beyond the control of a particular gene and insinuates that all individuals with this genetic similarity also share this suite of characteristics.

Conceptualizations about the essence, or essence placeholder (i.e., genes), are therefore related to intuitive essentialist beliefs. 
Genetic essentialism leads people to conceptualize genes as having a greater impact on character expression than is scientifically justified (Dar-Nimrod \& Heine, 2011; Stern et al., 2020). This has been termed belief in genetic determinism (BGD) and is characterized by the absence of environmental influences on character expression paired with the over-attribution of influence to genes (Gericke et al., 2017; Kampourakis, 2017; Stern et al., 2020; Tygart, 2000). As a result of this, BGD infers a deterministic, or causal relationship, between genes and characteristics such that genes directly determine a characteristic instead of effecting the probability or chance of developing it (Gericke et al., 2017).

The relationship between BGD and genetic essentialism is entwined in the conceptualization of genes. Genetic essentialism is argued to be related to four ways of thinking about genes: there is limited variability of genes among group members, genes are immutable, phenotypic outcomes of genes are natural, and genes are the single cause for characteristics (Dar-Nimrod \& Heine, 2011). A recent study found that Swiss secondary school students' conceptualizations of BGD was independent of the former two ways of thinking about genes, but overlapped with the latter two (Stern et al., 2020). Based on the definition I adopt, BGD overlaps with thinking of genes as single causes, and this has been used by other researchers as a way of exploring peoples' genetic essentialist views (Dar-Nimrod \& Heine, 2011; J. Keller, 2005) thus, I consider BGD as encompassing one dimension of genetic essentialism.

Both BGD and genetic essentialism negatively impact the ways in which members of society view outgroup members. A multitude of studies have investigated how BGD influences perceptions of race and gender (reviewed in Dar-Nimrod \& Heine, 
2011). Belief in genetic differences among races is associated with racial essentialism (i.e., perceiving members of different races as being distinct from one another; Haslam et al., 2006), which encourages prejudice and racism (Condit et al., 2004; Jayaratne et al., 2006; J. Keller, 2005). Genetic essentialist beliefs about gender can be associated with sexism and endorsement of gender stereotypes (Brescoll \& LaFrance, 2004; J. Keller, 2005).

Genetic essentialist beliefs can impact academic performance and bolster stereotype threat. For example, when women are provided with genetic explanations for differences in math performance, they perform worse on math tests (Dar-Nimrod \& Heine, 2006). Another recent study found that reading about genetic differences between sexes led to higher neurogenetic essentialism and the belief that science ability is an innate characteristic, and this effect was more significant for girls than for boys (Donovan et al., 2019b). Therefore, BGD may strengthen gender disparities in STEM fields.

Essentialist thinking hinders the conceptual understanding of biological phenomena in disciplines outside of genetics. For example, psychological essentialist assumptions encourage misconceptions about species and evolution such as the notion that species are stable, have strict boundaries, variability is low within species but high between species, and individuals are the source of evolutionary change (Gelman \& Rhodes, 2012; Shtulman \& Schulz, 2008). It is conceivable that genetic essentialism may likewise impact an individual's understanding of genetics. For example, it could promote the misconception that the presence of a gene guarantees the appearance of a characteristic or condition (Dar-Nimrod \& Heine, 2011). 


\section{Belief in Genetic Determinism and Genetics Knowledge}

Genetic essentialism and BGD are inconsistent with current understandings of genetics. Modern models of genes highlight that genes are not discrete, they produce products other than proteins (Gericke \& Hagberg, 2007; Kampourakis, 2017; Smith \& Adkison, 2010), and most human characteristics have very weak genetic explanations (Dar-Nimrod \& Heine, 2011). Current genetics studies also find that there can sometimes be hundreds of differences in DNA sequences that contribute to differences in a particular trait, that epigenetic and gene-by-environment interactions play an important role in the development of traits, and that an increasing amount of non-coding DNA previously identified as "junk DNA" has important gene regulatory functions (Falk, 2014; Salk \& Hyde, 2012; Smith \& Adkison, 2010). This new understanding of genes and the genome promotes a paradigm shift (E.F. Keller, 2005) that challenges the central dogma of onegene-one-enzyme genetics.

There are two lay conceptions of genes: Gene-P, defined by the phenotypic relationship, and Gene-D, defined by molecular sequence (Moss, 2008). For example, someone saying "the gene for cancer" is invoking the use of Gene-P, with the idea that the gene determines the phenotype. This perception of a gene is a direct result of concepts related to classical genetics and Mendelian inheritance (Moss, 2008; Smith \& Gericke, 2015), such as the view one gene will lead to one phenotypic characteristic (Gericke \& Hagberg, 2007; Kampourakis, 2017). The Gene-P conception is ripe for use as an essence placeholder because it offers a causal connection between genotypes and phenotypes (Dar-Nimrod \& Heine, 2011). I expected individuals that perceived genes as Gene-P to display higher levels of BGD than those who did not hold this conceptualization. 
The same cannot be said for a Gene-D conception, in which a gene does not determine the phenotype but only contributes to it, and therefore acknowledges developmental and environmental impacts on traits, and is more aligned with modern genetics models (Gericke \& Hagberg, 2007; Kampourakis, 2017; Moss, 2008). My overall hypothesis is that students with more genetics knowledge (i.e., those who have taken more genetics courses) should be more informed about Gene-D and modern genetics than those with lower genetics knowledge, and thus show lower BGD.

\section{Genetics Knowledge}

Belief in genetic determinism may be related to how genetics is presented in textbooks (Burian \& Kampourakis, 2013; Castéra, Bruguière, et al., 2008; Castéra, Clément, et al., 2008; Dar-Nimrod, 2012; Donovan, 2016; Gericke et al., 2013; Gericke et al., 2014; Gericke \& Hagberg, 2007, 2010a, 2010b; Santos et al., 2012; Smith \& Gericke, 2015). Some researchers suggest that inverting the genetics curriculum (i.e., presenting multifactorial examples of genetics as the rule and monogenic examples as the exception) could decrease BGD (Dougherty, 2009, 2010; Jamieson \& Radick, 2017). Jamieson and Radick (2017) compared the use of a Weldonian curriculum, which focuses on development and other impacts on phenotypes, to a Mendelian curriculum among undergraduate students in the United Kingdom and found that students who were exposed to the Weldonian curriculum had a decrease in their deterministic views. This indicates that changing curriculum, and the way information about genetics is presented to students, can be used to decrease BGD among students. However, this study did not directly investigate the link between genetics knowledge and BGD since, in their study, 
students from the Weldonian and Mendel treatments did not differ in their knowledge of genetics.

Studies from contexts outside of science education support the connection between genetics knowledge and BGD. In a study of how adults understand their results from commercial ancestry analysis using pre- and post-tests, individuals with higher genetics knowledge scores had decreased levels of racial essentialism after receiving their results, but for those with lower genetics knowledge, racial essentialist beliefs increased (Roth et al., 2020). White college-educated adults rated genetic make-up as being less important for the expression of traits compared to black and Latinx adults without college experience (Shostak et al., 2009). However, this study did not investigate college backgrounds or measure genetics knowledge among participants.

Gericke et al. (2017), investigated if higher level of genetics knowledge was correlated with lower BGD using a newly constructed and validated instrument, the Public Understanding of Genetics and Genomics (PUGGS) questionnaire, among Brazilian undergraduate students. However, they found no correlation between knowledge of genetics and BGD in their study but instead found that other factors, such as age, were more important determinants of BGD. Based on these studies, it is unclear if and how genetics knowledge impacts BGD among college students.

\section{Measuring Belief in Genetic Determinism}

There is no single accepted, validated measure of BGD that is readily used to study BGD among college students. It is a common practice to use Likert-scale surveys, that ask students to rate their agreement with a variety of statements, to measure psychological essentialism, essentialism of race, and genetic essentialism (Bastian \& 
Haslam, 2006; Donovan, 2014; Haslam et al., 2000; Haslam et al., 2002; Smiler \& Gelman, 2008; Yaylac1 et al., 2019) or to use implicit association tests to measure gender essentialism and genetic essentialism (Eidson \& Coley, 2014; Gould \& Heine, 2012). One study, specific to BGD, asked German undergraduate students to rate their level of agreement with 21 statements like, "I think that twins, because of the identical genetic predispositions, will be very similar in their behavior even if they were adopted and raised in different families" (J. Keller, 2005). However, this format of rating statements does not directly measure BGD as I defined it here (as attributing too much credit to genes for the development of a particular trait). Recent studies designed BGD measures that ask students to rate traits as being genetically determined, determined by genetics and the environment, or environmentally determined using 3-point or 5-point Likert scales, but these studies provided limited information about the conceptualization of BGD and how it relates to other concepts and/or the instruments had poor psychometric properties (Carver et al., 2017; Gericke et al., 2017; Stern et al., 2020).

I employed the use of a Likert-scale based BGD measure in combination with qualitative data to determine how BGD and genetics knowledge are related. There is limited research on the topic of BGD and characterization of which conceptualizations of genes are related to it in science education, specifically in the context of higher education. I used a combination of quantitative data and qualitative data (mixed methods) to measure and describe BGD and genetics knowledge and examine the relationships among BGD, genetics knowledge and conceptions of genes among college students. My guiding research questions were:

1) Do undergraduate students display BGD? 
2) How does BGD emerge in students' writing?

3) How is genetics knowledge associated with expression(s) of BGD?

Although the first two research questions were exploratory in nature, in accord with previous studies, I hypothesized that students with a greater genetics knowledge would display lower BGD.

\section{METHODS}

I employed a mixed methods design, using quantitative data from questionnaires and qualitative data from written responses, to evaluate students' belief in genetic determinism (BGD) and its relation to genetics knowledge. Students were required to complete all instruments and assignments used in the study using an online learning management system coupled with software that prevents access to other websites, browsers, and other applications (Lockdown Browser 4.0, n.d.).

\section{Participants}

Participants were undergraduate college students enrolled in science classes in a Midwestern, research-intensive university. Ethnicities were assigned to three categories: White, underrepresented minority (URM), and Asian or Middle Eastern student (hereafter non-underrepresented [non-UR]). URM students included those who self-identified as Black, Hispanic, Pacific Islander, or Native American. I used these three categories because they align with those used by National Science Foundation for URM groups (Glossary and key to acronyms, 2019). For gender categories, students were given the choices: female, male, prefer not to answer, or other. I used eligibility for receiving a federal Pell Grant as a metric of socio-economic status (SES). I requested identification of first-generation status because this population of students is known to encompass a 
unique population (Mehta et al., 2011). The sample population was $70 \%$ female, $70 \%$ White, 20\% URM, 24\% Pell eligible, and 21\% first-generation students. Table 5 displays this demographic information for all students who completed the quantitative and qualitative instruments used in the study.

Table 5. Demographic information for the PUGGS, essay, and students who completed both.

\begin{tabular}{|c|c|c|c|c|}
\hline & Social factor & $\begin{array}{c}\text { PUGGS } \\
\mathrm{n}=697\end{array}$ & $\begin{array}{l}\text { Essay } \\
\mathrm{n}=462\end{array}$ & $\begin{array}{c}\text { Both } \\
n=202\end{array}$ \\
\hline & Average age (years) & 20 & 20 & 19 \\
\hline & $\begin{array}{l}\text { Average number of previously } \\
\text { completed science classes }\end{array}$ & 5 & 4 & 2 \\
\hline \multirow[t]{3}{*}{ Gender } & Female & $72 \%$ & $66 \%$ & $71 \%$ \\
\hline & Male & $27 \%$ & $33 \%$ & $29 \%$ \\
\hline & Unknown & $1 \%$ & $1 \%$ & $0 \%$ \\
\hline \multirow[t]{6}{*}{ Year in college } & Freshman & $37 \%$ & $54 \%$ & $67 \%$ \\
\hline & Sophomore & $21 \%$ & $18 \%$ & $19 \%$ \\
\hline & Junior & $18 \%$ & $11 \%$ & $5 \%$ \\
\hline & Senior & $21 \%$ & $15 \%$ & $6 \%$ \\
\hline & Post-baccalaureate & $2 \%$ & $2 \%$ & $2 \%$ \\
\hline & Graduate & $1 \%$ & $0 \%$ & $1 \%$ \\
\hline \multirow[t]{3}{*}{ Ethnicity } & White & $72 \%$ & $69 \%$ & $69 \%$ \\
\hline & URM & $19 \%$ & $21 \%$ & $19 \%$ \\
\hline & non-UR & $9 \%$ & $10 \%$ & $11 \%$ \\
\hline \multirow[t]{2}{*}{ Pell eligibility } & Yes & $24 \%$ & $28 \%$ & $21 \%$ \\
\hline & No & $76 \%$ & $72 \%$ & $29 \%$ \\
\hline \multirow{2}{*}{$\begin{array}{c}\text { First } \\
\text { generation } \\
\text { status }\end{array}$} & Yes & $21 \%$ & $22 \%$ & $20 \%$ \\
\hline & No & $79 \%$ & $78 \%$ & $80 \%$ \\
\hline
\end{tabular}




\section{Data Collection}

\section{Quantitative Measures of BGD and Genetics Knowledge}

To investigate BGD and genetics knowledge, I recruited students enrolled in a variety of biology and nursing courses at my institution. Participants completed the Public Understanding and Attitudes towards Genetics and Genomics (PUGGS) questionnaire (Carver et al., 2017), at the end of the fall 2018 semester. The PUGGS includes a BGD section and two knowledge sections; it was developed for college-level students and validated using student populations in Brazil (Carver et al., 2017). In the PUGGS BGD section, students were asked to rate 17 traits on a scale from 1 to 5 where 1 indicated the student believed the trait was only influenced by the environment and 5 indicated that the student believed the trait was only influenced by genetics. I modified the PUGGS knowledge measure by combining the two knowledge sections into one and removing the first question of section 3 (knowledge about the complexity of geneenvironment interaction) based on my pilot data and recommendations of Gericke et al. (2017). I also used the Genetics Concepts Assessment (GCA; Smith et al., 2008), another independently developed and validated instrument, as a second measure of genetics knowledge.

I calculated Cronbach’s alpha (Tavakol \& Dennick, 2011) to measure internal consistency after using modal value imputation to replace missing values for the PUGGS BGD section, knowledge section, and GCA. Cronbach's alpha for the individual knowledge sections was 0.67 and 0.71 , respectively, and the combined section minus the one question was 0.77 . This supported my decision to combine the two knowledge sections of the PUGGS into one section for analyses. Unfortunately, results from the 
GCA indicated poor internal consistency $(\alpha=0.56)$ so, I did not include it in analyses as a measure of genetics knowledge. I report the information about GCA primarily because GCA is a widely used genetics concept inventory (Adams et al., 2016; Avena \& Knight, 2019; Briggs, 2019; Dougherty et al., 2011; Smith \& Knight, 2012; Strand \& Boes, 2019; Villarroel et al., 2012) and wanted to provide justification for why it was not used in my study as a measure of genetics knowledge. Cronbach's alpha for the BGD section $(\alpha=0.58)$ was lower than previously reported values ( $\alpha=0.67$, Gericke et al., 2017). The PUGGS is a relatively new instrument, developed in 2017, and therefore a lower measure of reliability (>0.6) is sometimes acceptable (Nunnally, 1978).

I distributed the PUGGS and GCA in six sections of introductory biology for nonbiology majors (hereafter, non-majors), two sections of introductory biology for biology majors, two sections of upper level nursing courses, and one section of each of the following courses: anatomy and physiology for pre-nursing students, cellular and molecular biology, evolutionary biology, biotechnology methods and endocrinology. Students enrolled in all course sections except for one (where students were required to complete the questionnaire for mandatory points) were provided with participation or extra credit points for completing both the PUGGS and GCA, and only those who consented to have their responses included in my study were used in analyses.

Overall, 1,013 students consented to have their PUGGS and GCA responses included in my study (54\% of students who were invited to participate). Of those students, 708 completed the GCA and 789 completed the PUGGS. A "test" question that instructed students what answer to provide was added to the BGD section of the PUGGS questionnaire and the GCA to ensure that I would only use responses from students who 
were thoroughly reading the questions. After removing students' responses who answered the "test" question incorrectly, made more than one attempt to submit responses, left demographic survey questions incomplete, were under 18 years of age, or completed the surveys in more than one course 703 PUGGS responses and 661 GCA responses remained.

To further enhance the quality of the dataset, I omitted outlier responses from students based on the duration it took them to complete the work. On average, students took 13 minutes and 51 seconds to complete the PUGGS ( $n=697)$. I converted durations to Z-scores (M=892.93 seconds, $\mathrm{SD}=846.99, \mathrm{n}=519)$ and student responses with Z-scores greater than 3 or less than negative 3 were removed $(n=5)$, resulting in a final sample size of 697 for the PUGGS. I had duration data for 11 sections and, overall, only $0.85 \%$ of student responses were removed using this method. This indicated that the lack of duration information for the other four sections did not compromise my dataset quality.

On average, students took 16 minutes to complete the GCA and duration data was available for 14 of the 15 course sections, resulting in a total of 645 GCA responses to be used for outlier removal methods. Based on z-scores of durations, I removed eight student responses (1.2\%), resulting in a final sample size of 651 for the GCA.

\section{Qualitative Measures of BGD}

I taught a lesson about CRISPR/Cas9 technology that varied in length from 30 to 75-minutes in the following courses: four sections of introductory biology for nonbiology majors, two sections of introductory biology for biology majors, two sections of microbiology for biology majors, and one section of an advanced genetics course for biology majors. During the lesson, I discussed what CRISPR is (its function in bacteria), 
how it can be used in scientific research and disease treatment, and some related ethical concerns. As part of the lesson, students were asked to read a news article (Pollack, 2014) about CRISPR/Cas9 that reiterated the topics taught by me and write a persuasive essay arguing for or against non-medical genetic modification in humans (defined as "the modification of genes not for the purpose of curing or preventing diseases"). The prompt asked students to address three things: 1) to describe CRISPR and how scientists are able to use CRISPR/Cas9 technology to edit genetic material, 2) to argue for or against its use for non-medical enhancement, and 3) to describe a dilemma about CRISPR/Cas9 technology that someone may experience (for full prompt, see Appendix A).

A total of 566 students agreed to have their written responses included in the study, but after removing outliers as described for PUGGS, the final sample size for analysis was 462 essays. I administered the writing assignment in a subset of the 15 course sections in which PUGGS and GCA were administered because the content was not applicable for all courses. In total, 202 students in four sections of introductory biology for non-biology majors and two sections of introductory biology for biology majors completed both the written assignment and the PUGGS.

\section{Measures of Belief in Genetic Determinism}

\section{PUGGS BGD}

I followed the methods used by previous researchers and used the average rating value for each of the 17 traits (named TT1-TT17) in the PUGGS BGD section to calculate indexed values using the equation: $n=(x-1) / 4$, where $x$ was the mean score and $n$ was the indexed value (Gericke et al., 2017; Table 8). Index values of 1 indicate the trait was described as entirely genetic. Gericke et al. (2017) used heritability estimates to 
categorize each trait as being primarily environmentally influenced $\left(h^{2}<0.4\right)$, genetically influenced $\left(h^{2}>0.6\right)$, or influenced by both environment and genetics $\left(h^{2}=0.4-0.6\right)$ based estimates in the literature. I updated heritability estimates and categorized five traits as primarily genetic, nine as influenced by both, and three primarily environmentally influenced. Four traits were updated based on my literature review: diabetes, political beliefs, ADHD, and asthma. Diabetes and political beliefs were moved to the both category from the environmental category (Avery \& Duncan, 2019; Klemmensen et al., 2012; Ksiazkiewicz \& Krueger, 2017; Willemsen et al., 2015), and ADHD and asthma were moved to the both category from the genetics category (Brikell et al., 2015; Doyle et al., 2005; Skadhauge et al., 1999; Thomsen et al., 2010; Ullemar et al., 2016).

Previous papers using PUGGS did not generate a BGD score useful for analyses (Carver et al., 2017; Gericke et al., 2017). In an effort to do so, I calculated a "BGD score" for each student based on how students rated traits that were categorized as both genetic and environmental or primarily environmentally influenced. I omitted scores for five traits considered primarily genetically influenced based on heritability estimates in the literature ( $>0.6$ heritability estimate): height, bipolar disorder, color blindness, schizophrenia, and blood group ( $\mathrm{ABO}$ ). By removing the traits known to be primarily influenced by genetics, I could assume that high "genetics" scores on the remaining 12 traits indicated that students had stronger belief that genes rather than environment or other factors influenced traits. I used the total score assigned to these 12 traits as a "BGD score" that could range from 12 to 60 . I divided the range into three and categorized BGD as being low (12-28), medium (29-44), or high (45-60). 


\section{BGD in Essays}

To further investigate the degree to which students held BGD, I used qualitative data from student essays about genetic modification. I used content analysis and descriptive, open-coding methods to characterize how BGD emerged in students' written responses (Saldaña, 2016; Weber, 1990). A research assistant and I developed a definition of BGD and then reviewed the essays for instances of BGD. I defined the expression of BGD as the belief that a trait or characteristic was dependent on genes only, without any mention of external factors, such as the environment or epigenetics, on the expression of that trait or traits. The two of us then examined a subset of essays to develop a codebook consisting of the 10 emergent BGD themes that reflected how students used BGD in their writing (Table 6). I summed the total number of students who used each theme, and the number of times each theme was used throughout all of the essays (Table 6). Students sometimes discussed themes in the specific sub-theme of creating designer babies (i.e., students referred literally to designer babies or described the genetic alteration of embryos to attain certain characteristics), and I used the sub-code “designer baby" to record these specific examples (Table 6). This included the use of terms such as "designer baby" or "build-a-baby.” A research assistant and I separately coded subsets of essays and used iterative coding, discussion, and modification until we reached a consistent $90 \%$ or greater agreement for BGD codes. After demonstrating a consistent $>90 \%$ agreement, the research assistant coded the remainder of the essays. Me and assistant periodically checked coding accuracy by discussing essays once a week to ensure there were no coding issues. I summed the number of times BGD manifested in an essay for a "BGD instances" measure. 
Table 6. Themes and contexts that BGD appeared in. BGD was coded for when a student attributed more credit to genes than is scientifically supported for traits/characteristics (Gericke et al., 2017) with no reference to outside factors on the expression of traits, such as the environment or epigenetics. Ten themes emerged from the essays and these were grouped into four larger context categories.

\begin{tabular}{|c|c|c|c|c|c|}
\hline Context $^{\mathrm{a}}$ & Theme & $\begin{array}{c}\text { Proportion } \\
\text { of } \\
\text { students }^{\mathrm{b}}\end{array}$ & $\begin{array}{c}\text { Total } \\
\text { frequency }\end{array}$ & Description & Representative examples ${ }^{\mathrm{d}}$ \\
\hline \multirow[t]{3}{*}{$\begin{array}{c}\text { Traits } \\
(n=316)\end{array}$} & Physical attributes & $49 \%$ & 236 & $\begin{array}{c}\text { Student uses specific } \\
\text { descriptors of physical } \\
\text { characteristics that can be } \\
\text { changed by altering gene(s) } \\
\text { or genetic material. } \\
\text { Examples include eye color, } \\
\text { hair color, height, and } \\
\text { muscle mass. }\end{array}$ & $\begin{array}{l}\text { "Changing genes that don't pose any } \\
\text { health threats is unnecessary and } \\
\text { should not be done by scientists. If } \\
\text { this became a reality, people would be } \\
\text { able to choose the way their babies } \\
\text { looked, almost as if they were hand } \\
\text { customizing their children from a } \\
\text { catalog. They would be able to pick } \\
\text { the hair and eye color along with the } \\
\text { height of their children." * }\end{array}$ \\
\hline & & & & & $\begin{array}{c}\text { "...we could use this technology for } \\
\text { non-medical enhancement in humans } \\
\text { to possibly modify genes that express } \\
\text { certain physical traits like hair color } \\
\text { or height." }\end{array}$ \\
\hline & Unspecified Traits & $26 \%$ & 101 & $\begin{array}{l}\text { Student describes how a } \\
\text { genetic change will result in } \\
\text { a trait or traits [sic] being } \\
\text { altered. This included } \\
\text { descriptions of achieving } \\
\text { "perfection" or creating }\end{array}$ & $\begin{array}{l}\text { “...I'd be lying if I said I didn't want } \\
\text { the ability to create a baby's features } \\
\text { and traits like I do on The Sims. It's } \\
\text { just not practical to give ourselves the } \\
\text { ability to unrestrictedly edit a } \\
\text { potential humans [sic] genome." * }\end{array}$ \\
\hline
\end{tabular}


"superhumans" through genetic modification.

Student describes how change of gene will cause or prevent disability or disorder [sic], which may or may not be specified.

Intellectual

capabilities
$12 \%$

Student discusses intelligence or increased mental capabilities caused by gene(s) or genetic changes.
"I do not believe it is ethical or right for human beings to pick and choose what genes and traits they want their offspring to possess." *

"If one group of people can create the perfect baby and edit their genes then everyone should be able to do this so that the world is fair and equal." *

“...we could see this technology being used in a selfish way, like some private company creating an army of super humans."

"The purpose of Crispr is to replace a "bad" gene with a good one in order to alter any "flaws" such as

disabilities in humans..."

"I definitely do not think CRISPR should be used to eradicate Autism or Down Syndrome. Both disorders are dear to my heart..."

"On the other hand, a person with significantly less money would never have the opportunity to edit their genes and they would stay less fortunate because they could never be as good as the person who edited their genes. This could also be true for 
Behavioral attributes

$9 \%$

32

g

Disease $^{\mathrm{e}} \quad$ Disease
$(\mathrm{n}=277)$

editing a gene to make people have better cognitive abilities."

"The biggest issue is similar to what I said before, which is people using it [CRISPR] to enhance babies for things such as intelligence..." *

“...an ethical board will have to decide what genes are turned off. Obviously the gene for Huntington's easily makes the list of targeted genes, but what about the one for gene(s) or genetic changes This includes aggression, emotion, personality, violence, etc.

Student attempted to explain how manipulating gene(s) could cure or prevent many diseases $[s i c]$, including complex diseases

like cancer.

$$
\text { addiction...?" }
$$

"Another way CRISPR could affect humans and future generations is the fact that this enzyme could ultimately cure some diseases. Getting rid of them all together and creating our genes to no longer carry the gene for that disease now and for future generations."

"CRISPR and Cas9 could be used to get rid of cancer, cystic fibrosis, Huntington's disease and many more horrible diseases that are caused by genes." 
Side

$$
\text { Side Effects }
$$

Effects

$(\mathrm{n}=83)$

\section{$\breve{o}$}

Identity
$(n=45)$
$\begin{gathered}\text { General belief(s) } \\ \text { about DNA and }\end{gathered}$

$40 \%$ gene(s)

Race
Student attempts to explain how CRISPR/Cas9 off target effects will lead to changes in complex characteristics or processes (i.e. growth deformities, development of cancer cells, development of disabilities).

Student provides generalized belief about genetic determinism without fitting into any of the categories previously coded for. This includes statements such as "DNA makes us who we are".

Student describes how a change in genes can change racial identity.
"If an individual is using Crispr and Cas 9 for non-medical use then the incorrect DNA segment may be sliced, creating a disabled individual who would have been able to survive without Crispr."

"... if the gene is improperly spliced and something goes wrong a horrible malformation or mutation could occur to the child, a kid could grow and extra arm or leg, the child could possibly develop a terrible disease such as cancer or diabetes..."

"DNA is the blueprint of whatever gene we make. DNA is behind your eye color, your skin color, your heart

size, your abilities, and your

disabilities. DNA is what makes you who you are.'

"When we alter the genome of a person, we change, in the most intense way possible, who that

person is."

"I could see a culture editing genes for skin color or hair and eye color to create a race that looks the same." 
Sex and gender

$9 \%$
"A dilemma that could arise from the improper use of CRISPR and Cas9 technology could be the use to get rid of races or ethnicities that are seen in society as less than. Although I personally do not identify with any minority groups it scares me that this technological advancement could be used to eradicate races or ethnicities."

"How would you feel if your race was changed before you were born due to being considered undesirable?"

"Although CRISPR has been a revolution in medicine and genetics I do not agree with it. I think it is unethical to decide your babies'

$$
\text { gender." * }
$$

“...CRISPR will one day be able to get to the point where it will be able to change the gender of an embryo in the womb."*

\footnotetext{
${ }^{a}$ The number of students that discussed BGD in each context is displayed under the context title, total $n=351 .{ }^{\mathrm{b}}$ The proportion of students that used each theme out of the total for that context. ${ }^{\mathrm{C}}$ Total frequency is the sum of the number of times each theme was present. ${ }^{\mathrm{d}}$ Asterisks indicate examples that were coded with the sub-theme designer baby. Words/phrases important for coding themes are bolded in the examples for

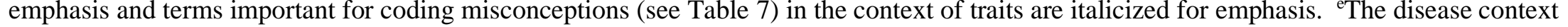
was excluded from BGD instances and further analysis because of conflict with the prompt.
} 
I grouped themes into four larger categories that described the context in which BGD arose: disease, traits, side effects, and identity (Table 6). Since the writing prompt implied that CRISPR/Cas9 technology could be used to cure or prevent diseases, I expected students to discuss it in their responses using those terms (cure or prevent), and thus, excluded the "disease" category from further coding, analysis, and discussion. To better understand how students were conceptualizing genes, I examined whether students used the terms "gene", "genes", "CRISPR", and/or "DNA" (Table 7) in conjunction with their descriptions that fit the trait's context. I used presence/absence, $0 / 1$, codes to indicate whether a student used any of the four terms in an expression of BGD in the context of traits. I assumed that students using "gene" in the context of trait were invoking a gene-P conceptualization. To investigate whether the use of the word gene (the gene-P concept) in the context of trait was associated with BGD, I used a t-test to test the hypothesis that students using the term in this context also had higher BGD scores than student not using the term.

Table 7. Statements used for characterizing terminology used in student's trait BGD instances.

\begin{tabular}{cl}
\hline Term code & Statements that qualify \\
\hline Gene & $\begin{array}{l}\text { Modifying one gene will change one trait, or multiple traits } \\
\text { Genes can be altered to change trait(s) [sic], or to alter a list of } \\
\text { individual traits provided by the student }\end{array}$ \\
DNA & $\begin{array}{l}\text { Altering DNA, genetic material, or genome will change trait(s) [sic], } \\
\text { or alter a list of individual traits provided by the student } \\
\text { CRISPR can be used to alter trait(s) [sic], or alter a list of individual } \\
\text { traits provided by the student }\end{array}$ \\
\hline
\end{tabular}

To further understand the extent to which students were or were not discussing multifactorial aspects of gene expression, I quantified how many students made references to the environment and/or epigenetics by searching the essays for the 
following terms: environment, epigenetic(s), Mendel (in the context of non-Mendelian genetics), complex, and interaction. Any word matches were read in full to ensure the student was describing outside factors that influence gene expression and not something unrelated.

\section{Measures of Knowledge}

I grouped students into three content knowledge levels based on the course in which they completed the essay: Level 1, Level 2, and Level 3. Level 1 students were non-science majors $(\mathrm{n}=180)$ enrolled in non-majors biology courses and had previously completed, on average, only one science course $(\mathrm{SD}=1.22)$. Level 2 students $(\mathrm{n}=207)$ were in the introductory majors course designed for students who planned to pursue STEM majors and, on average, had completed three science courses ( $\mathrm{SD}=4.12)$, and Level 3 students $(n=75)$ were in the microbiology and advanced genetics course and had completed 15 science classes $(\mathrm{SD}=6.99)$, on average. I compared the number of previously completed science classes for the three groups using ANOVA and Tukey's post-hoc analysis on log transformed values to ensure that the groups were distinct based on science course experience. Level 1, 2, and 3 students differed significantly in the number of previously completed science classes $(F(2,362)=244, p<0.0001$; Tukey's post hoc $p<0.001$ ), with Level 1 students having the least and Level 3 students having the most indicating that academic level correlated with exposure to background knowledge in biology. Based on these results, I chose to use content knowledge level as my measure of genetics knowledge when analyzing the essays.

I examined potential measures of genetics knowledge using number of science classes, year in college, and PUGGS knowledge scores for students who completed the 
PUGGS. I assumed the number of science classes completed would correlate with year in college and these should be correlated with PUGGS knowledge scores if these scores were a reasonable metric for genetics knowledge. I used Spearman's correlation to determine if year in college (an ordinal variable) and number of science classes were correlated. The number of previously completed science classes was strongly positively correlated with year in college $(R h o=0.74, p<0.001)$, so I used number of science classes, but not year in college, to evaluate the impact of background knowledge in biology on PUGGS knowledge scores using Pearson's correlation analysis and log transformed values $(\log (\mathrm{x}+1))$ to improve the normality.

\section{Analyses of BGD and Knowledge}

I examined how content knowledge level (genetics knowledge) impacted PUGGS BGD scores and/or BGD instances in essays. I used 202 students who completed both the PUGGS and the essays; they were from Level 1 and Level 2 groups. I used a student's ttest to show that the number of science classes and PUGGS knowledge scores were significantly different between these two groups. Level 1 students completed significantly fewer science classes than those in Level 2 (M=1, 3, respectively; $(t(195)=6.11, p<0.0001)$ and Level 1 students scored significantly lower on the PUGGS knowledge section $(\mathrm{M}=14.19, \mathrm{SD}=3.87)$ compared to those in Level $2(\mathrm{M}=15.91$, $\mathrm{SD}=3.68 ;(t(200)=3.22, p<0.01)$. This indicated that Level 2 students had more exposure to and greater genetics knowledge than Level 1 students. To evaluate the relationship between PUGGS BGD scores and BGD instances, I used Pearson's correlation. I performed two ANCOVAs using content knowledge level (Level 1, Level 2) as the independent variable, PUGGS knowledge scores as the covariate, and BGD scores or 
BGD instances as the response variable, to determine if either BGD scores or BGD instances would differ by content knowledge level when PUGGS knowledge scores were held constant and performed Tukey's post hoc test when differences were indicated.

Using those students who completed the essay $(\mathrm{n}=462)$, I performed an ANOVA and Tukey's post-hoc analysis to determine if number of BGD instances differed among Level 1, 2, and 3 students. For this, I used 0/1 codes for absence/presence of any example under each of the four categories in a students' response. For example, if a student used a BGD example about intellectual traits and gender, they would receive codes " 1 " for those categories but " 0 " for the other two. I performed three logistic regressions using content knowledge level as the predictor variable to determine if the use of any of the three BGD categories could be predicted by a student's content knowledge level, and therefore genetics knowledge. For each model, I performed likelihood ratio tests to evaluate the model fit. For students who completed the PUGGS (n=497), I used Pearson's correlation to determine if PUGGS knowledge scores were correlated with PUGGS BGD scores.

\section{RESULTS}

\section{Student Belief in Genetic Determinism - Quantitative Data}

\section{$\underline{\text { BGD Ratings, Indexed Values, Comparison to Heritability Estimates }}$}

Statistical analyses reported in this section included the 697 students who completed the PUGGS. Student BGD scores ranged from 20-47 (M=30.64, SD=3.64), indicating that students held a medium level of BGD. Students rated three traits as being primarily influenced by the environment $(\mathrm{M}<2)$ : interest in fashion, political beliefs, and religious beliefs. Two traits were rated as being primarily influenced by the genetics $(\mathrm{M}>4)$ : color blindness and blood group $(\mathrm{ABO})$. The remaining 12 traits were rated 
between $2-4$, meaning that students believed they were influenced by both the environment and genetics. The students weighted only one trait, breast cancer, as being more genetically influenced than scientific consensus suggests (Collins \& Politopouloas, 2011; Summa et al., 2017). They scored four traits, bipolar disorder (Lichtenstein et al., 2009; Uher, 2014), addiction to gambling (Agrawal et al., 2012; Lobo \& Kennedy, 2009; Slutske et al., 2010), political beliefs (Klemmensen et al., 2012; Ksiazkiewicz \& Krueger, 2017), and violent behavior (Frisell et al., 2012; Kendler et al., 2015), as being more environmentally weighted than current literature suggests (Table 8). These results suggest that students do not display strong BGD but are likely to rate traits as being more influenced by the environment than current literature suggests. Both of the PUGGS estimates of BGD as conceived here (indexed values and BGD scores) provide little information on degree or characteristics of BGD.

Table 8. Average BGD scores. Based on a scale from 1 to 5, with 5 indicating high BGD, standard deviation (SD), indexed values for each trait, and trait categorization based on heritability estimates in literature as environmentally influenced $(<0.4)$, genetically influenced (>0.6), or influenced by both $(0.4-0.6)^{\mathrm{a}}$.

\begin{tabular}{|c|c|c|c|c|c|}
\hline Trait & Average & $\mathrm{SD}$ & $\begin{array}{l}\text { Indexed } \\
\text { value }\end{array}$ & $\begin{array}{l}\text { My student } \\
\text { categorization }\end{array}$ & $\begin{array}{c}\text { Categorization } \\
\text { based on } \\
\text { heritability data }\end{array}$ \\
\hline TT1 Height** & 3.70 & 0.69 & 0.67 & Genetic & Genetic \\
\hline $\begin{array}{l}\text { TT2 Bipolar } \\
\text { disorder*** }\end{array}$ & 3.27 & 0.66 & 0.57 & Both & Genetic \\
\hline $\begin{array}{l}\text { TT3 Diabetes (type } \\
\text { 2) }\end{array}$ & 3.00 & 0.59 & 0.50 & Both & Both \\
\hline $\begin{array}{l}\text { TT4 Color } \\
\text { blindness** }\end{array}$ & 4.48 & 0.68 & 0.87 & Genetic & Genetic \\
\hline $\begin{array}{l}\text { TT5 } \\
\text { Schizophrenia** }\end{array}$ & 3.46 & 0.78 & 0.62 & Genetic & Genetic \\
\hline TT6 Alcoholism & 2.63 & 0.68 & 0.41 & Both & Both \\
\hline TT7 Breast cancer & 3.50 & 0.68 & 0.63 & Genetic & Environment \\
\hline $\begin{array}{l}\text { TT8 Interest in } \\
\text { fashion** }\end{array}$ & 1.61 & 0.66 & 0.15 & Environment & Environment \\
\hline
\end{tabular}




\begin{tabular}{lccccc}
$\begin{array}{l}\text { TT9 Addiction to } \\
\text { gambling }\end{array}$ & 2.25 & 0.78 & 0.31 & Environment & Both \\
$\begin{array}{l}\text { TT10 Political } \\
\text { beliefs }\end{array}$ & 1.48 & 0.64 & 0.12 & Environment & Both \\
$\begin{array}{l}\text { TT11 Intelligence } \\
\text { in adults }\end{array}$ & 2.75 & 0.63 & 0.44 & Both & Both \\
$\begin{array}{l}\text { TT12 Severe } \\
\text { depression }\end{array}$ & 2.90 & 0.56 & 0.48 & Both & Both \\
$\begin{array}{l}\text { TT13 Attention } \\
\text { deficit }\end{array}$ & 3.39 & 0.73 & 0.60 & Both & Both \\
$\begin{array}{l}\text { hyperactivity } \\
\text { disorder }\end{array}$ & 3.13 & 0.75 & 0.53 & Both & Both \\
$\begin{array}{l}\text { TT14 Asthma } \\
\begin{array}{l}\text { TT15 Violent } \\
\text { behavior }\end{array}\end{array}$ & 2.48 & 0.68 & 0.37 & Environment & Both \\
$\begin{array}{l}\text { TT16 Religious } \\
\text { beliefs }\end{array}$ & 1.52 & 0.73 & 0.13 & Environment & Environment \\
$\begin{array}{l}\text { TT17 Blood group } \\
\text { (ABO)** }\end{array}$ & 4.75 & 0.60 & 0.94 & Genetic & Genetic \\
\hline $\begin{array}{l}\text { aTraits that students weighted more genetically than the literature suggests are bolded, } \\
\text { more environmental are italicized. A single asterisk indicates traits that I could not find }\end{array}$
\end{tabular}

\section{Characterization of BGD from Essays}

The following results were based on analysis of the students who completed the writing assignment $(n=462)$. Overall, $76 \%$ of students used BGD in at least one of the contexts in their written response at least one time. Instances of BGD in a single student essay ranged from 0-12 (+/- 2.09 SD) with a mean of 2 instances per essay. There was no statistically significant correlation between BGD scores (from the PUGGS) and BGD instances in essays $(R=-0.12, p=0.09)$.

Overall, each of the three context categories were discussed in the sub-theme of "designer babies"; the terms designer baby and build-a-baby were used 187 times. A very small number of students ( $\mathrm{n}=7$, or $2 \%$ of students) referenced outside factors related to 
gene expression. Only two of those students discussed epigenetics or environmental impacts on gene expression, while five considered the complexity of genes and/or how they may interact with one another. This suggests that students are not considering factors other than genes in the context of genetic modification.

Traits - Physical, Behavioral, Intellectual, Disability

The BGD context traits was the most common in student responses, with $90 \%$ of students that displayed BGD explaining that traits such as height, hair color, emotions, intellect, and those associated with "disabilities" [ sic], could be controlled by altering genes alone, with no mention of the influence of outside factors such as the environment, epigenetics, or control of gene expression. Of these students, the most common theme was physical attributes (49\% of students), and the second most common was unspecified traits (26\%; Table 6). Less common themes were intellectual capabilities (12\%), disabilities (12\%), and behavioral attributes (9\%; Table 6). Fifty-seven percent of students described traits being altered in the sub-theme of "designer babies". Two examples demonstrating BGD in the "trait" category follow; the first is in the sub-theme of designer babies and both are from Level 1 students:

“...brown eyes are a dominant trait. However, you want your child to have blue eyes, the recessive trait. This gene can be edited into the childs [sic] genome." “...someone can abuse this system and alter genes that promote HGH or other anabolic hormones, allowing mass and strength growth that normal people would deem impossible or unnatural."

Only $9 \%$ of students used "gene" in their trait BGD instances. The largest proportion of students that used the term were Level 1 students and the smallest were from Level 3 (Figure 9), indicating that students with lower genetics knowledge were 
more likely to invoke the use of a Gene-P conceptualization. Students who used "gene" in the context of trait in their response had significantly higher BGD instances ( $M=4.68$, $\mathrm{SD}=2.74)$ compared to students who did not use "gene" $(\mathrm{M}=3.76, \mathrm{SD}=1.84 ; \mathrm{t}(314)=3.55$, $p=0.0002$ ), reinforcing my interpretation of the use of gene in this context being indicative of a gene-P conceptualization. In contrast, 33\% of students used "genes", $38 \%$ used "DNA", and 44\% of students used "CRISPR" terms. The use of "genes" indicates those students may have an understanding of polygenic traits, but it could also be purely vernacular.

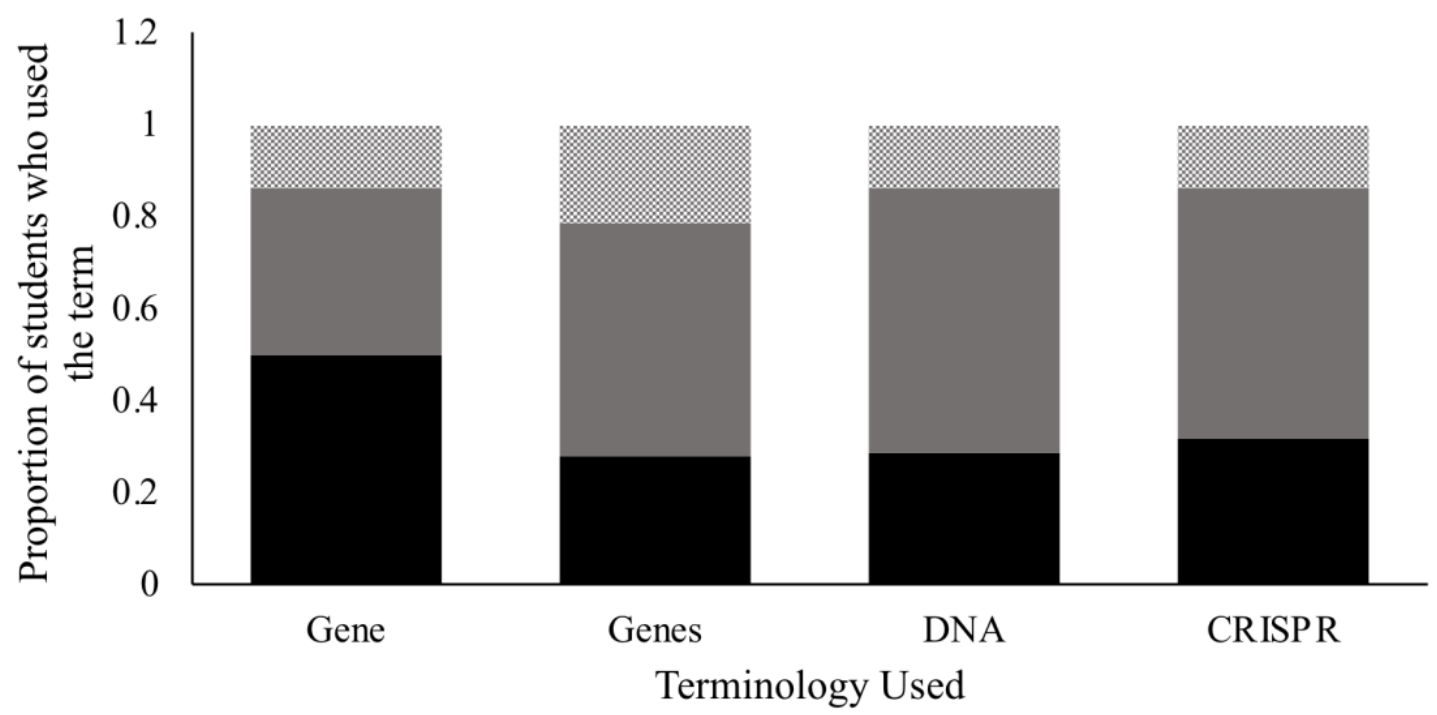

Figure 9. Severity of BGD proportions by academic level. The proportion of students that used one of these four terms grouped by academic level. Black represents Level 1 students, gray represents Level 2 students, and light gray checkered represents Level 3 students.

\section{$\underline{\text { Side Effects }}$}

Some students described extreme side effects in their responses (24\% of students that displayed BGD; Table 6). Fourteen percent of these students described such 
outcomes in the sub-theme of designer babies. This was very specific to CRISPR/Cas9 technology and involved students explaining that off-target effects (i.e., targeting the wrong gene(s), which are legitimate concerns about CRISPR/Cas9 technology) from this genetic modification process could lead to extreme outcomes, such as growth deformities and/or death. However, the extreme nature of the side-effects (i.e., loss of limbs, growth of extra body parts, zombification of humans) in several cases indicated that students were attributing undue power to a gene and ignoring other factors that influence expression of complex traits. Two examples of extreme side effects from Level 2 students follow:

“...if perhaps the human body rejects the DNA editing and sends our bodies into shock or if the scientist messes up and all the sudden $[\mathrm{sic}]$ you're growing another tongue."

"Starting a zombie apocalypse is something I always thought scientists would start, with their so many experiments. Since CRISPR/Cas9 can cut up a gene sequence that was not it's [sic] target, the repair could cause a possible combination that was needed for the zombification of the whole DNA gene."

Identity

Some participants (13\% of students that displayed BGD) expressed BGD in relation to identity in general or specifically, race or gender. These were characterized as identity since both are essential concepts that work in concert with other variables to impact a person's identity (Holvino, 2008; Rogers \& Meltzoff, 2017; Zaytoun, 2005). Responses in the most common theme, general beliefs (40\% of students that used BGD this context; Table 6), included statements about DNA or genes making "people who they are" or "controlling everything about who a person is". The second most common theme was race $(31 \%)$, while gender was the least common (9\%; Table 6). Out of all students who used BGD in the identity context, over a quarter of them (27\%) discussed these 
beliefs in the sub-theme of designer babies. Two examples from Level 1 students, the first about identity in general and the second about gender, follow:

"Genes control someone's entire life and they truly determine what a person's life truly is. Everything that makes one person unique is due to genetics and DNA so why should technology be able to alter that?

'I think it is unethical to decide your babies' [sic] gender. It takes the natural process way of life away. You should not decide the babies' [sic] gender creating the "designer baby" like they are toys."

\section{Genetics Knowledge Assessments}

The average score for the PUGGS knowledge section was 15/24, or $63 \%$

( $\mathrm{SD}=4.23)$. A majority of students answered most of the questions correctly, with students scoring the lowest ( $<50 \%)$ for Q13- Q15 and Q17-Q21 (see Carver et al., 2017 for questions; Figure 10; Table 9). These questions were originally categorized as "knowledge of modern genetics and genomics" and the lower scores for these questions are in agreement with previous research (Gericke et al. 2017), suggesting that students' knowledge about these concepts in both United States and Brazilian undergraduate student populations is lacking.

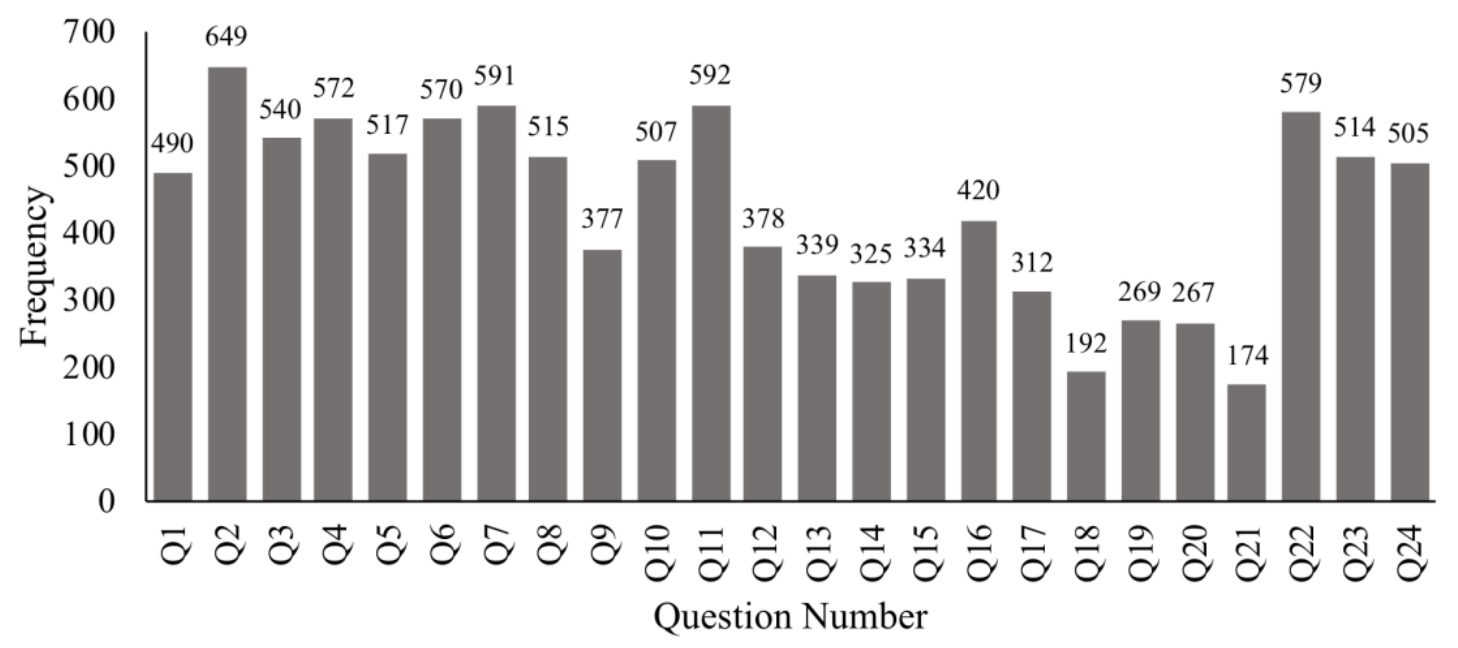

Figure 10. Frequency of students who scored correctly for each genetics knowledge 
question of the PUGGS. The exact number of students who scored correctly for each question is displayed above its respective bar.

Table 9. The average score and standard deviation (SD) for each of the knowledge questions from the PUGGS.

\begin{tabular}{ccc}
\hline Question Number & Average Score & SD \\
1 & 0.70 & 0.46 \\
2 & 0.93 & 0.25 \\
3 & 0.77 & 0.42 \\
4 & 0.82 & 0.38 \\
5 & 0.74 & 0.44 \\
6 & 0.82 & 0.39 \\
7 & 0.85 & 0.36 \\
8 & 0.74 & 0.44 \\
9 & 0.54 & 0.50 \\
10 & 0.73 & 0.45 \\
11 & 0.85 & 0.36 \\
12 & 0.54 & 0.50 \\
13 & 0.49 & 0.50 \\
14 & 0.47 & 0.50 \\
15 & 0.48 & 0.50 \\
16 & 0.60 & 0.49 \\
17 & 0.45 & 0.50 \\
18 & 0.28 & 0.45 \\
19 & 0.39 & 0.49 \\
20 & 0.38 & 0.49 \\
21 & 0.25 & 0.43 \\
22 & 0.83 & 0.37 \\
23 & 0.74 & 0.44 \\
24 & 0.72 & 0.45 \\
\hline
\end{tabular}

\section{Knowledge and Belief in Genetic Determinism}

In an analysis with log-transformed scores using students who completed the PUGGS, the number of previously completed science classes was weakly positively correlated with PUGGS knowledge scores $(R=0.22, p<0.0001, \mathrm{n}=670)$, indicating that as background knowledge in science increases, students perform better on the PUGGS genetics knowledge questions. There was no significant correlation between PUGGS knowledge scores and BGD scores $(R=0.03, p=0.47, \mathrm{n}=697)$. Taken together, this 
suggests that genetics knowledge does not impact BGD scores as measured by the PUGGS.

Among students that completed both the PUGGS and the essay (n=202), my ANCOVA results indicated that PUGGS BGD scores $(F(1,199)=1.42, p=0.24)$ did not explain the variation among academic levels, but BGD instances from essays did. Level 2 students had significantly higher BGD instances $(M=1.64)$ than Level 1 students $(\mathrm{M}=1.13 ; p=0.02 ; F(1,199)=5.72, p=0.02)$. Thus, in contrast to the data from the PUGGS (knowledge and BGD scores), when BGD is quantified as the number of instances of BGD occurrence in essays, genetics knowledge influences BGD but not in the direction predicted. Level 1 students had lower BGD than Level 2 students who had completed more science classes.

Among all the students who completed the essays, the number of BGD instances differed among the three academic levels $(F(2,459)=7.34, p<0.01)$; Level 1 students had significantly fewer BGD instances $(\mathrm{M}=1.44, \mathrm{SD}=2.08)$ compared to Level 2 students $(\mathrm{M}=2.55, \mathrm{SD}=2.03 ; p<0.01)$ and, although only marginally significant, than Level 3 students $(\mathrm{M}=2.41, \mathrm{SD}=1.93 ; p=0.06)$. Level 2 and Level 3 students did not differ $(p=0.88 ;$ Figure 11). 


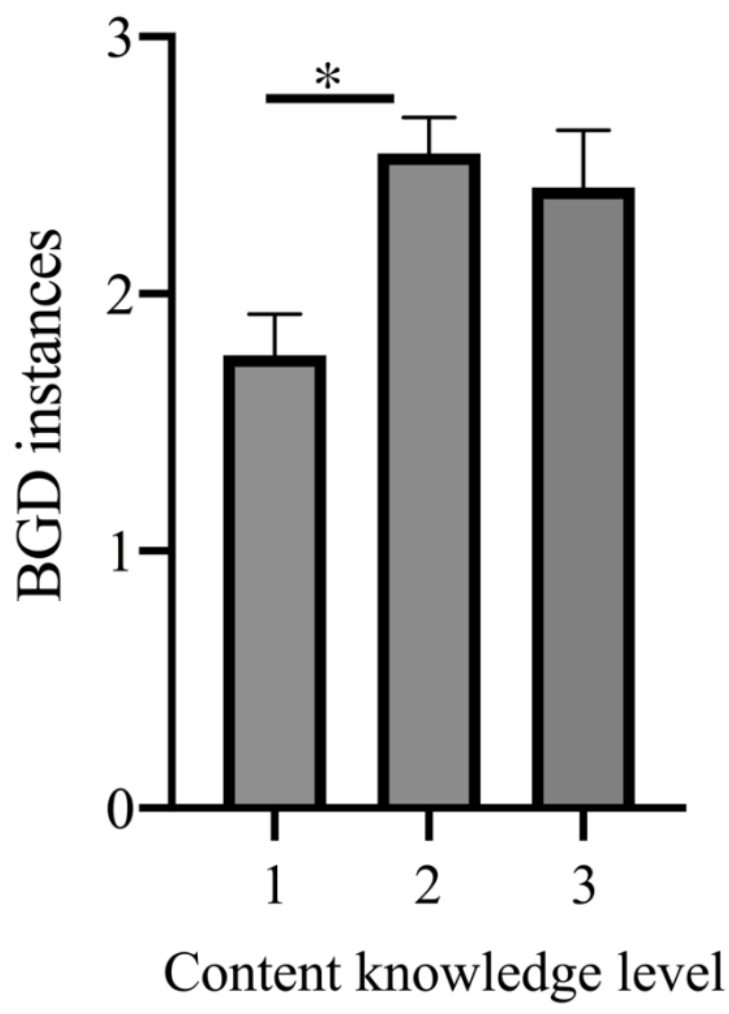

Figure 11. Average number of BGD instances for each content knowledge level \pm SEM. An asterisk indicates $p<0.01$ (Tukey's post-hoc analysis).

Although Level 1 students used fewer instances of BGD overall, there were differences in the context in which students from the three academic levels used BGD. In the most common context, traits, Level 2 students were 2.59 times more likely $(p<0.001)$, and Level 3 students were 2.3 times more likely to $(p<0.01)$ to express BGD compared to Level 1 students (Table 10; Figure 12). 


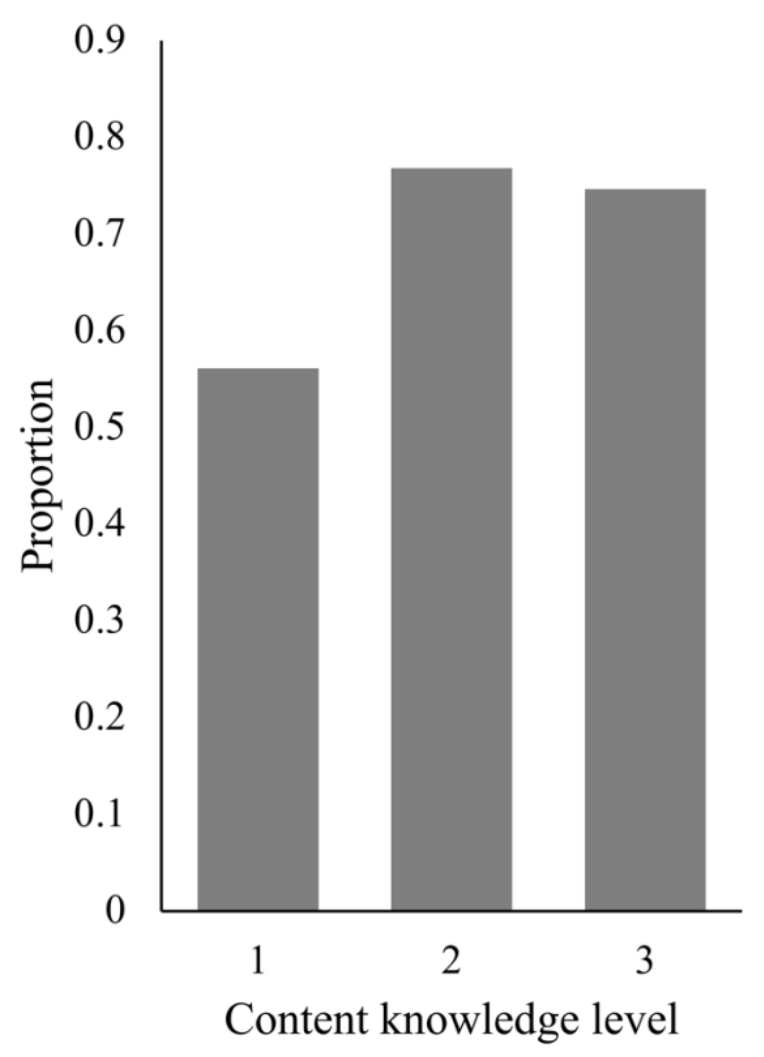

Figure 12. Proportion of students from each content knowledge level that used at least one instance of BGD in the context of "traits".

Students from all academic levels were equally likely to discuss identity and side effects in their responses (Table 10) that exhibited BGD. However, these results are limited since likelihood ratio tests (LRT) for identity and side effects indicate the model was not a good fit; this was no doubt influenced by small sample sizes for the categories in each academic level (Table 10). 
Table 10. Logistic regression model statistics for each of the three BGD categories. Content knowledge level was the predictor variable with 3 levels (Level 1, 2, and 3). LRT=Likelihood ratio test.

\begin{tabular}{|c|c|c|c|c|c|c|c|c|}
\hline $\begin{array}{c}\text { BGD } \\
\text { category }\end{array}$ & $\begin{array}{l}\mathrm{LRT} p \text { - } \\
\text { value }\end{array}$ & $\begin{array}{c}\text { McFadden's } \\
\text { R-squared }\end{array}$ & Level & Presence $n^{\mathrm{a}}$ & $\beta$ & SE $\beta$ & $e^{\beta}$ & $\begin{array}{l}\text { Logistic } \\
\text { regression } p \text { - } \\
\text { value }^{b}\end{array}$ \\
\hline Traits & $<0.0001$ & 0.03554 & $\begin{array}{c}2 \\
3 \\
\text { Constant }\end{array}$ & $\begin{array}{c}159 \\
56 \\
101\end{array}$ & $\begin{array}{l}0.9529 \\
0.8352 \\
0.2547\end{array}$ & $\begin{array}{l}0.2229 \\
0.3050 \\
0.1502\end{array}$ & $\begin{array}{c}2.591 \\
2.305 \\
-\end{array}$ & $\begin{array}{c}<\mathbf{0 . 0 0 0 1} \\
\mathbf{0 . 0 0 6} \\
0.1019\end{array}$ \\
\hline Side effects & 0.7026 & 0.0016 & $\begin{array}{c}2 \\
3 \\
\text { Constant }\end{array}$ & $\begin{array}{l}39 \\
11 \\
33\end{array}$ & $\begin{array}{c}0.0335 \\
-0.2671 \\
-1.494\end{array}$ & $\begin{array}{l}0.2621 \\
0.3790 \\
0.1926\end{array}$ & $\begin{array}{c}1.034 \\
0.7656 \\
-\end{array}$ & $\begin{array}{c}0.8982 \\
0.4810 \\
<0.0001\end{array}$ \\
\hline Identity & 0.4442 & 0.0055 & $\begin{array}{c}2 \\
3 \\
\text { Constant }\end{array}$ & $\begin{array}{c}24 \\
7 \\
14\end{array}$ & $\begin{array}{l}0.4415 \\
0.1993 \\
-2.473 \\
\end{array}$ & $\begin{array}{l}0.3530 \\
0.4848 \\
0.2783\end{array}$ & $\begin{array}{c}1.555 \\
1.221 \\
- \\
\end{array}$ & $\begin{array}{c}0.2110 \\
0.6809 \\
<0.0001\end{array}$ \\
\hline
\end{tabular}

aPresence $n$ is the number of students from each level that used each category, where Level 1 numbers are adjacent with constant. ${ }^{\text {bSignificant }}$-values associated with Level 2 and Level 3 students are bolded for emphasis. 


\section{DISCUSSION}

Quantitative measures of BGD were indicative of an accurate understanding of genetics and low-to-medium BGD among students, but BGD was widespread in students' writing. Students expressed BGD in the context of changing genetic material to alter traits, how altering the wrong gene could lead to disastrous anatomical consequences, or how aspects of identity were rooted in one's DNA. Students held outdated understandings of genes and did not reference environmental, developmental or epigenetic influences on the expression of human characteristics. The contexts in which BGD was expressed and the prevalence of BGD in student writing differed by content knowledge level (and, thus, genetics knowledge) where Level 2 students were the most likely to express BGD and it was most likely to be in the context of altering superficial traits. Although the least likely to express BGD, Level 1 students were more likely to display monogenic views of genetics in their BGD statements than biology students.

\section{Measures of Belief in Genetic Determinism}

Interpretation of the PUGGS BGD measures, as described in Gericke et al. (2017), had limited use for quantifying and characterizing BGD. Although the instrument had an acceptable internal consistency in the original study performed in Brazil (Gericke et al., 2017), here it displayed low internal consistency which may be indicative of differences between the Brazilian and the United States undergraduate populations. The original BGD measure from the instrument was the average BGD score for each student and did not provide an accurate measure of BGD since it was Likert-scale data and contained a variety of weakly and strongly determined traits; therefore, most students' averages were around three. Summing the scores resulted in a similar issue. I modified 
the BGD score of each student to overcome these limitations and using that interpretation, I found that my students displayed low-to-medium levels of BGD.

Students were less likely to rate traits as being more genetically influenced than current science suggests and more likely to rate them as being more environmentally influenced; in other words, they believed that most traits were only weakly genetically determined.

My results were similar to those of Gericke et al. (2017), where students rated seven traits (including two of the four traits from my sample population: bipolar disorder and violent behavior) as being more environmentally influenced and two traits (including breast cancer) as being more genetically influenced than current science supports. In both studies, students displayed lower levels of BGD than expected. It was suggested that this is due to students being more likely to rate biological traits (i.e., breast cancer, bipolar disorder) as genetically determined than social traits (i.e., violent behavior; Gericke et al., 2017). My results do not support this hypothesis since bipolar disorder (a biological trait), was rated as being more environmentally influenced but the three other social traits were rated by students as more environmentally influenced. Gericke et al. (2017) suggest including more biological traits that are heavily influenced by the environment and more social traits that are strongly genetically determined to better evaluate students' BGD. I agree that this should be considered for future use of the PUGGS.

I am not the only researcher that has struggled with measuring BGD. Stern et al. (2020) found that their BGD measure was also less informative than anticipated since only social traits loaded onto one factor together in a principal component analysis, whereas the biological traits did not. In that study, Cronbach's alpha was low (0.53) as were expected correlations between BGD and other measures (genetic teleology and 
genetic essentialism). Therefore, they concluded that their genetic determinism measure provided limited information about BGD. Their results were similar to those of Gericke et al.'s (2017) in that it confirmed that BGD varies based on the trait being measured (i.e. social or biological) and that BGD is low for social/mental traits. Therefore, although my modified interpretation of PUGGS results indicated that students had an adequate understanding of genetic and environmental influences on traits, this was a relatively coarse measurement and did not provide detailed information about student thinking in terms of BGD.

\section{Qualitative Measures}

Despite the characterization of relatively low BGD from the PUGGS instrument, almost all students displayed at least one instance of BGD in their essay response. Students did not discuss outside factors, such as gene-environment interactions or epigenetics, and the impacts they have on the expression of traits. This, coupled with the limited use of the PUGGS BGD measure, suggests that using mixed methods is a better approach is to examine the complexity of students' BGD.

\section{Emergence of BGD in Essays}

Given that the writing prompt focused on the use of CRISPR/Cas9 technology for non-medical enhancement, I expected responses related to the manipulation of human traits. However, I expected students to be critical of the possibility of these uses on the basis that genes are not the sole determinant of traits, and I expected discussions of polygenic traits, environmental influences (such as development and epigenetics) on human traits, or the complexity of trait expression that would indicate a multifactorial view of genetics (Gericke \& Hagberg, 2007). 
A multifactorial view of genetics aligns with modern genetics and is indicative of a Gene-D conceptualization (Gericke \& Hagberg, 2007; Moss, 2008; Smith \& Adkison, 2010). This view was rare in my population, with only a handful of students acknowledging environmental aspects on expression of traits. The absence of discussing environmental impacts of trait expression, coupled with a description of altering genes to change characteristics, was considered a more simplistic Gene-P conceptualization rooted in Mendelian or classical genetics (Gericke \& Hagberg, 2007; Moss, 2008; Smith \& Adkison, 2010). For example, students who discussed traits in a BGD framework stated that complex traits could be altered by editing a gene or genes. Therefore, students revealed a Gene-P conceptualization: that genes control traits in the absence of any environmental or developmental influences. This is consistent with how BGD is conceptualized in the PUGGS, where acknowledgement of environmental aspects of trait expression is associated with lower BGD.

Monogenic and Polygenic Views of Genetics

A monogenic view of genetics (that one gene is the sole determinant of one trait), which has been found to be the exception rather than the rule (Falk, 2014; Gericke \& Hagberg, 2007; Kampourakis, 2017; Salk \& Hyde, 2012), stems from Mendelian and classical gene models, which emphasize a causal relationship between genes and traits (“a gene determines a trait”; Gericke \& Hagberg, 2007).

I considered the use of this terminology to be equivalent to a Gene-P conceptualization and indicative of genetic essentialism (Dar-Nimrod \& Heine, 2011; Moss, 2008). Students with less background in genetics were more likely to use this Gene-P conceptualization compared to those with more background (i.e., more genetics 
courses taken), and students that held monogenic, Gene-P conceptualizations about superficial traits, such as physical, behavioral, and intellectual capabilities, were also more likely to express higher levels of BGD in their essay. This underscores the need for explicit instruction regarding environmental (and other) impacts on trait expression, especially in non-majors biology courses.

Close to one-third of students used "genes" in their descriptions of how traits could be modified. To the extent that the use of the plural represents an understanding that of polygenic traits, this conceptualization falls short of a modern, multifactorial view of genetics. Even when students used relatively ambiguous language, (including vernacular uses of "genes"), they did not express an understanding that complex characteristics and diseases cannot be altered and determined by genetic factors alone.

\section{CRISPR/Cas9 Side Effects}

BGD related to CRISPR/Cas9 side effects was the third most common category that was used by students. Since students were instructed about the possibility of offtarget effects in the CRISPR lesson it was not surprising that they discussed possible side effects. What was surprising, however, was the extreme nature of the side effects discussed. For example, one student described "loss of a limb" as a potential side effect of targeting the wrong gene during CRISPR modification. This particular example may be related to a lack of understanding of developmental processes and timing of gene editing; e.g., embryos versus adults. Although the samples were not completely overlapping, PUGGS knowledge results suggest that students should be aware of the complexity of gene expression since almost three-quarters of students answered question 10 ("Cells, tissues, and organs differ because they have different sets of genes that are 
activated ("turned on") and deactivated ("turned off") correctly), indicating that they have a basic understanding of cell differentiation but that they are not transferring this knowledge from one context to another (i.e., the context of specialized cells for organs to the context of development).

\section{Genetic Essentialism}

The least frequent category, identity, consisted of students who displayed beliefs about DNA, or genes, as personal destiny. This idea that genes control our fate, and there is nothing that can be done to change that fate (except, presumably, to change our genes), is termed genetic fatalism and is linked to strong beliefs in genetic determinism (Resnik \& Vorhaus, 2006). Someone who perceives gender and/or race as being genetically determined (and therefore immutable) may also be more likely to view inequity related to gender/race as non-problematic, which promotes gender and race stereotypes (J. Keller, 2005). Stereotype threat results when these stereotypes are internalized and this is associated with poor academic performance and behaviors, and higher attrition rates for underrepresented groups in STEM fields (Dar-Nimrod \& Heine, 2006; Morton \& Parsons, 2018; Steele, 1997). Being made aware of how race and gender are both socially constructed, and not genetically determined, can decrease these negative impacts on student learning and reduce stereotypes (Dar-Nimrod \& Heine, 2011).

Genetic essentialism and BGD are associated with negative social ideologies such as eugenics (Dar-Nimrod \& Heine, 2011). In our population, it was common for students to use "genes" or "DNA" as an essence placeholder and to express the belief that changing that essence will also alter their categorical classification, for example, the belief that changing genes will change gender from male to female. This is important 
because one defining feature of the essence is that it is unalterable (Dar-Nimrod \& Heine, 2011; Gelman, 2003; Gelman \& Rhodes, 2012; Yzerbyt et al., 1997), and genome editing technology offers the ability to change this fundamental property. This is especially problematic since the genome editing technology the students were asked about, CRISPR/Cas9, has recently raised concerns about "designer babies" and a new era of eugenics (Dar-Nimrod \& Heine, 2011; Vizcarrondo, 2014). Technologies that offer the ability to "better people's lives" are harmful in that they support the idea that genes determine our characteristics and that modification of those genes will solve "problems" someone believes that they or their offspring have, whether they are medical or nonmedical (i.e., superficial traits; Dar-Nimrod \& Heine, 2011). It is clear from the widespread use of BGD in the context of editing human characteristics that our population of students exhibit genetic essentialist views.

\section{BGD and Knowledge}

There was no correlation between genetics knowledge scores and BGD scores based on quantitative data, which is similar to previous results (Gericke et al., 2017), but this is limited based on previously discussed limitations of the BGD measure from PUGGS. However, qualitative data revealed that academic level impacted the frequency and context of BGD examples used in student writing. Level 2 students, who displayed the highest prevalence of BGD in their writing, were in a traditional introductory biology, large lecture course that relied primarily on didactic instruction. Level 3 students were in advanced classes and had significantly more college biology experience, indicating that BGD persists as students progress through the curriculum, even though instruction about the complexity of trait expression presumably increases. In contrast to Level 3 and 2 
students, Level 1 students were enrolled in an introductory biology course, "Issues and Applications", in a classroom designed to encourage active learning. These results align with those from another study which found that essentialist reasoning about biological phenomena was associated with agreement with essentialist biological misconceptions for biology majors but not non-majors (Coley \& Tanner, 2015). Both of these results indicate that a more "traditional" education in science which focuses on learning concepts via memorization, such as that received by majors, may reinforce essentialist beliefs, such as BGD. Neither study directly tested this hypothesis and thus, more studies are needed to investigate how differences in instruction, specifically, impacts BGD.

Quantitative data from the PUGGS knowledge section indicated that a majority of students did not understand concepts related to "modern genetics and genomics", which included statements about epigenetics and challenged the central dogma (i.e., that DNA leads to products other than RNA that produces protein). Taken together, these results underline the [previously mentioned] need for teaching about complexity of genes and incorporating more of the "new" genetics into all biology courses.

\section{$\underline{\text { BGD as a Barrier to Paradigm Shift }}$}

Geneticists are in the midst of a paradigm shift that challenges the central dogma and moves away from one-gene-one-trait conceptualizations towards a much more complex understanding of the "gene" (Kampourakis, 2017; J. Keller, 2005; Meyer et al., 2013; Salk \& Hyde, 2012). This paradigm shift is coupled with a call to transform genetics education to better represent modern genetics and de-emphasize Mendelian and classical genetics (Gericke \& Hagberg, 2007; Meyer et al., 2013; Smith \& Adkison, 2010; Smith \& Gericke, 2015). 
BGD and genetic essentialism act as barriers to this paradigm shift since they can impede conceptual understandings of modern genetics. Science education research about evolution has found that individuals who display essentialist beliefs about species hold misconceptions about evolution and natural selection (Gelman \& Rhodes, 2012;

Shtulman \& Schulz, 2008), and these essentialist beliefs are hypothesized to transcend biological disciplines and include misconceptions about genes (Coley \& Tanner, 2012; Stern et al., 2020). Although essentialist thinking has been found to be associated with biological misconceptions (Coley \& Tanner, 2015), there are limited studies investigating this link between genetic essentialism and misconceptions about genes. My results begin to fill this gap in the literature since the presence of genetic misconceptions ("gene" and "genes" terminology) was common among students who displayed BGD. Taken together, this supports the hypothesis that genetic essentialist biases, as measured by BGD, are associated with misconceptions about genes, but warrants further research using studies designed to specifically investigate this association.

\section{LIMITATIONS}

The quantitative data gathered from the PUGGS BGD measure had several limitations. For example, the instrument had low internal consistency and did not supply a clear BGD measure that could be used to compare student populations. My comparisons to heritability estimates are limited in that BGD and heritability estimates are not equal measures (Dar-Nimrod \& Heine, 2011; Gericke et al., 2017); that is, heritability is not a measure of BGD and measures of heritability are not necessarily accurate representations of environmental or genetic influence because heritability is tied to the population, environment, and time of the population in which it is measured. Thus, 
although helpful in examining the use of PUGGS data, it is difficult to draw conclusions about students BGD based on this comparison.

In the analysis of written responses to evaluate the types of genetic terminology used by students who displayed BGD, there was a large proportion of students that used ambiguous language in their responses, such as "edit DNA" or "use CRISPR" to edit trait(s) or cure/prevent disease(s), which makes it difficult to draw conclusions about their degree of BGD. Likewise, I cannot be sure that students use of the term "genes" always indicated an understanding of polygenes, because it may also have been vernacular. I also could not draw any conclusions about BGD in the context of disease due to the wording used in the writing prompt. Additionally, any discussion of how students' BGD may change as they progress through the biology curricula are speculative in their nature, because my data are not longitudinal.

\section{RECOMMENDATIONS FOR SCIENCE EDUCATION RESEARCH}

BGD has clear societal and educational impacts, so it is vital that more research be performed to develop a reliable instrument that can measure BGD in various populations, allowing researchers to make generalizable claims about BGD and its relation to students' knowledge about genetics. Future studies using PUGGS in the United States may need to modify the traits used in the instrument to optimize measures of BGD in their populations. More studies are required using diverse populations to determine the reliability and generalizability of the instrument results, but my results match with past researchers in that BGD is difficult to measure and compare and should be coupled with other measures for a more complete understanding of the phenomenon (Carver et al., 2017; Gericke et al., 2017). 
Changing genetics curricula to emphasize human genetic variation can decrease students' perception of genetic differences within and between races (genetic essentialism), and in turn reduce prejudice (Donovan, 2016, 2017; Donovan et al., 2019a). Likewise, emphasizing the developmental aspects of trait expression instead of Mendelian genetics also decreases BGD (Jamieson \& Radick, 2017). There is a clear need for more explicit instruction regarding the environmental impacts on gene expression and development of characteristics, especially in non-majors biology courses where this will be one of the only experiences students have with genetics curricula. Instructors can use carefully chosen examples of complex characteristics previously described as exclusively monogenic that are impacted by multiple genes and/or environmental factors (i.e., cystic fibrosis and phenylketonuria (PKU); Schechter, 2011; Fitzgerald et al., 2000), to decrease these beliefs and foster discussion about eugenics.

It remains unclear if using Mendelian models in genetics as simplified models, and building upon complexity from that, is better for students' understanding of genetics compared to beginning with complex models of genes (Smith \& Gericke, 2015). Different instructional models need to be evaluated in their effectiveness to teach modern genetics to students, without completely disregarding Mendel's contributions to the history of science. One study found that when students where taught about molecular genetics prior to Mendelian genetics, it did not impact their exam scores and thus indicates that changing the method of teaching genetics is not harmful to students' ability to learn basic genetics (Deutch, 2018). Future research should be performed to evaluate how changing the presentation of genetic material to college students impacts their understanding of genetics and BGD. 
Geneticists may be aware of the complexity of the modern gene concept, but this is not being adequately taught to our undergraduate population of students, including biology majors that often aspire to find careers in medical fields. Although I did not test it, my results indicate that biology majors, who receive more "formal" or "traditional" instruction regarding biological concepts, are more likely to harbor essentialist beliefs about genes. This should be explored by other researchers to more fully understand how and why biology students differ from non-major students in this way.

Further research should be conducted to investigate the association between a multitude of biological misconceptions, including those about genes, and essentialist thinking. If essentialist thinking is found to be associated with misconceptions about genes and other biological phenomena, it makes sense to target instruction at decreasing essentialist thinking in general. Conceptual change theory (CCT) may be useful to consider in deciphering how best to decrease students' essentialist thinking as a way of reducing the presence of biological misconceptions (Posner et al., 1982). However, instead of using CCT to target the misconception that one gene controls the expression of one trait, instructors could target essentialist thinking that transcends disciplines by encouraging students to use metacognitive skills important for learning to think more deeply about their essentialist thinking and how they apply to various biological misconceptions, such as those present in evolution, natural selection, and genetics (Coley \& Tanner, 2012; Leonard et al., 2014). 


\section{CHAPTER THREE}

\section{USING A CRISPR/CAS9 SOCIOSCIENTIFIC ISSUE TO TEACH UNDERGRADUATE STUDENTS ABOUT BIOETHICS}

\section{INTRODUCTION}

Promoting scientific literacy for all students is an imperative of science education (American Association for the Advancement of Science, 1990; National Research Council, 1996). Though various meanings of "scientific literacy" have been adopted (Sadler, 2004b), I use the one from National Science Education Standards (1996) which defines scientific literacy broadly as:

“...the knowledge and understanding of scientific concepts and processes required for personal decision making, participation in civic and cultural affairs, and economic productivity." (National Research Council, 1996, p.22) Being scientifically literate involves being able to make informed decisions about issues related to science and technology that exist in ones' everyday life and have societal impacts (Sadler, 2004b; Sadler et al., 2006), and these have been coined socioscientific issues (SSIs; Zeidler et al., 2002). Socioscientific issues involve the use of scientific concepts, require the consideration of ethical concerns to resolve them, are relevant/meaningful to students, and are controversial and open-ended dilemmas (Zeidler and Nichols, 2009). Examples include matters such as stem cell research, environmental 
issues (i.e., global warming), genetically modified organisms, and, most recently, human genetic engineering (Cinici, 2016; Sadler, 2004b; Sadler \& Zeidler, 2003; Sadler et al., 2006; Widiyawati, 2020).

SSIs centered around human genetic engineering are especially important since a new technology, CRISPR/Cas9, has revolutionized the field of genetic modification (Cribbs \& Perera, 2017). CRISPR/Cas9 technology is simple and affordable compared to past genome editing technologies, and this has contributed to its rapid and widespread use and made it a dominant form of genetic engineering in just a few years (Cribbs \& Perera, 2017; Wollert, 2020). The superiority of CRISPR/Cas9 genome editing technology has reignited bioethical conversations related to human genetic modification, making it imperative for students pursuing careers in science to be taught about bioethics related to CRISPR/Cas9 in particular (Wollert, 2020).

Bioethics involves considering ethics related to the research methods and conduct (Bird, 1996), how the results of the research will be used (Kitcher, 2004), the consequences that the research findings will have on members of society (Johansen \& Harris, 2000), and personal moral/ethical considerations that are influenced by sociocultural factors (discussed in Chapter 1). There are several bioethical issues related to CRISPR/Cas9 technology in particular (Cribbs \& Perera, 2017). First, there are concerns about how the technology will be used in the future. For example, there are safety concerns related to possible off-target effects and how these may impact human subjects and future generations of modifying germline cells. The latter prospect of altering germline cells also brings up issues regarding informed consent because future generations cannot consent to the alterations. 
Although few would argue against the use of CRISPR/Cas9 for medically related purposes (Cribbs \& Perera, 2017; Ledford, 2019), it is difficult to ascertain where the line is between medical uses and enhancement of humans. This leads to serious concerns about its use to promote eugenic ideology (Cribbs \& Perera, 2017). All of these concerns highlight the need to consider the risks and determine if the benefits outweigh them, and these are dependent upon the context in which the technology is used.

Although there is general consensus that bioethics should be incorporated into science curricula, instruction in this area remains minimal in biology undergraduate courses (Booth \& Garrett, 2004; Johansen \& Harris, 2000; Loike, et al., 2013; Zaikwoski $\&$ Garrett, 2004). Several reasons for this have been proposed: science instructors may feel ill-equipped to teach students about ethical/moral ramifications of science and technology (Downie \& Clarkeburn, 2005), and this may be influenced by a belief that scientific knowledge is an objective truth (Johansen \& Harris, 2000; Sadler et al., 2006). Instruction focused on the bioethical standards of scientific research are particularly important for biology majors who plan to pursue medical and/or research careers (Loike, 2013; Martin et al., 2020). Thus, it is important to develop lessons known to promote the understanding of bioethics that can be easily incorporated into science curricula, which was one of my objectives.

I used a socially relevant, recent case involving CRISPR/Cas9 to teach students about bioethics related to human genetic modification. In this case, researchers recently claimed to have modified human embryos to be HIV-resistant, and these embryos were implanted into the uterus of at least one woman and carried full-term, resulting in the birth of the first alleged CRISPR/Cas9 babies (Li et al., 2019; Raposo, 2019). This case is 
an ideal SSI to use in undergraduate biology courses. First, it involves the application of scientific concepts. For example, students must understand CRISPR/Cas9 technology and how it can modify genetic material, what germline cells are, and how HIV susceptibility can be genetically modified. Second, the case brings up a multitude of important bioethical issues: there are concerns about the methods employed (i.e., clarity of the informed consent, safety and lack of follow-up procedures), justification of the research (i.e., the medical need to alter HIV resistance), and future uses such as modifying other characteristics in germline cells (Cyranoski, 2019; Ledford, 2019; Li et al., 2019; Raposo, 2019; Shaw, 2020). The case is controversial, meaningful, and relevant to students because it discusses human genetic modification, and students will be required to make decisions about it as scientifically literate members of a democratic society.

Since resolution of SSIs involves the application of scientific concepts (Sadler, 2004b), it is important that students understand and apply genetics knowledge appropriately. Most character expression is influenced by more than one gene and those genes may also interact with the environment to impact expression (Gericke \& Hagberg, 2007). Knowledge about this multifactorial view of genetics is a domain-specific type of scientific literacy, recently referred to as standard genomics literacy (Donovan et al., 2020). Previous research indicated that students invoke belief in genetic determinism (BGD) when reasoning about an SSI concerning CRISPR/Cas9 genetic modification of humans (Chapter 2). BGD is characterized by an excessive attribution to genes in influencing character expression along with a lack of consideration for environmental factors (Gericke et al., 2017; Kampourakis, 2017; Stern et al., 2020; Tygart, 2000). Aside from being inconsistent with the current understanding of genetics (Donovan et al., 2020; 
Gericke \& Hagberg, 2007; Kampourakis, 2017; Smith \& Adkison, 2010), BGD is also associated with racism and prejudice against members of society (Condit et al., 2004; Jayaratne et al., 2006; J. Keller, 2005) and endorsing gender stereotypes (Brescoll \& LaFrance, 2004; J. Keller, 2005). Content knowledge and the presentation of genetics concepts may influence BGD (Jamieson \& Radick, 2017; Chapter 2).

\section{Form of Instruction - Active Learning}

There is a need for STEM education to implement active learning approaches in place of traditional didactic lecturing (Bauerle et al., 2011; Henderson et al., 2011), which is a common and persistent form of instruction in college classrooms (Klionsky, 2004; Miller et al., 2013). I define active learning to be a student-centered teaching technique designed to engage students in classroom activities and discussions and promote participation in their own learning (Freeman et al., 2014; Miller et al., 2013; Prince, 2004). This approach is more impactful to students learning and results in more positive attitudes towards science compared to traditional didactic lecturing (Freeman et al., 2014; McConnell et al., 2003). For example, undergraduate students enrolled in STEM courses with traditional didactic instruction are more likely to fail the course compared to students with some form of active learning in their class (Freeman et al., 2007; Freeman et al., 2014).

There are many approaches and techniques that can be used to implement active learning (discussed in Gleason et al., 2011). Cooperative learning is one approach and it is defined by intentional group work aimed at enhancing learning through the use of teamwork (Kaufman et al., 1997; Keyser, 2000; Johnson et al., 1991). This technique shifts responsibility from the instructor to the student and encourages application of 
scientific concepts and critical thinking about scientific evidence (Eberg-May et al., 1997; McConnell et al., 2003). Cooperative learning promotes interdependence among learners, development of interpersonal skills, discourse among learners, and accountability (Kaufman et al., 1997).

One cooperative learning technique is a jigsaw activity. This technique has two parts. The first step involves placing students into "expert groups" that are assigned one part of a larger issue (i.e., one of several readings discussing content relevant to the main issue), so that each student can become an "expert" on their assigned portion. In the second step, students meet with experts of the other portions and share their expertise with the non-experts and learn about the other experts' portions (Amador \& Mederer, 2013; Baken et al., 2020; Kaufman et al., 1997; Keyser, 2000). In a study comparing performance of students enrolled in a Vertebrate Biology laboratory course using jigsaw activities versus traditional lecture-style, students from the jigsaw sections had significantly higher quiz scores (Baken et al., 2020). The National Institutes of Health (NIH) recommends using this activity, among others, to teach bioethics to high school students (Gandhi et al., 2009), but studies evaluating the use of this technique to teach college students about bioethics are lacking.

\section{Objectives}

The purpose of this study was to develop, implement, and assess a jigsaw activity designed to promote biology students' understanding and application of bioethics by evaluating a socially relevant, real-life research study about human genetic modification with CRISPR/Cas9 technology. I intentionally designed the lesson so I could evaluate if 
students invoked BGD afterwards. Student learning outcomes and assessments for each are displayed in Table 11.

The main student learning goals were:

1. Identity and apply biological concepts and bioethical considerations important for scientific research.

2. Describe the expression of human characteristics as influenced by both genes and the environment.

Table 11. Student learning outcomes and associated assessments

\begin{tabular}{l}
\hline Learning Outcome \\
Effectively examine literature discussing a \\
CRISPR/Cas9 SSI and identify \\
biological and bioethical concepts \\
discussed
\end{tabular}
Assessment

Answer four pre-assignment clicker questions about CRISPR, CRISPR/Cas9 technology, and the twin study

Complete reading guide questions for assigned reading

Complete summary sheets

Evaluate a socially relevant, current CRISPR/Cas9-related socioscientific issue by applying bioethical guidelines

Recognize that the scientific justification of research cannot be separated from human values and/or ethics

Apply ethical policies to make a decision about if the research upheld ethical standards and justify using evidence from literature

Describe HIV infection and how modification of an important coreceptor could lead to HIV-resistant cells

Apply principles of bioethics to make a decision about if the research was justified and justify using evidence from literature

Discuss an SSI about genetic modification of human characteristics using CRISPR/Cas9 without invoking belief in genetic determinism

Assess the genetic contribution of characteristics when determining the ability to use CRISPR/Cas9 technology to influence their expression 


\section{METHODS}

\section{Participants}

This study was performed in an introductory biology course designed for biology majors. Overall, 99 students were invited to participate in the study, and 82 provided consent to include their answers in the study. The activity was implemented as a regular lesson in the course, but all assignments were completed for extra credit. Of the total population of students that participated in one or more parts of the lesson, $61 \%$ selfidentified as female, $59 \%$ identified as white and $23 \%$ identified as an underrepresented minority (Black, Hispanic, Indian $[s i c]$ ) in an open-ended demographic question. A majority of students were in their first year of college (80\%) and had completed one prior course in natural science at the college level. Most students (43\%) were biology majors, $28 \%$ were majoring in other STEM or health-related fields (chemistry, engineering, nursing, neuroscience), and $22 \%$ were majoring in a wide variety of fields (economics, English, exercise science, Spanish, psychology, public health).

\section{Pre-Assignment}

Prior to the in-class jigsaw activity, students were asked to review eight slides on CRISPR and CRISPR/Cas9 technology and read part of an article that provided a description of a recent research study that resulted in the first alleged "CRISPR babies" (Appendix B; Kolata \& Belluck, 2018). This study will hereon be referred to as the "twin study". Students were given two attempts to answer four multiple-choice questions on Blackboard assessing their understanding of the pre-assignment materials (Appendix B). Using each student's last attempt of the two ( $n=49$ for use of the second attempt; total n=73), I quantified the proportion of students who answered each of the four questions 
correctly as a measure of student engagement in the pre-assignment. At the beginning of class, I used Clickers to review the questions with students and address questions to ensure that everyone had some understanding of CRISPR/Cas9 technology and the twin study before they began the jigsaw activity, described in detail below.

\section{Instructional Intervention}

After discussing the answers to the four pre-assignment questions, students were asked to participate in a jigsaw activity. Students were split into jigsaw groups of 4-5 students and each was assigned a letter A-D that represented the reading that they were assigned. Each reading had its own reading guide that students were asked to complete individually on Blackboard during the class period. Reading guides were designed to draw attention to important concepts and to aid students in staying on task during the activity. Four topics were discussed in the readings and associated reading guides: HIV infection and resistance, responsible conduct of research and informed consent, germline modification and criteria, and bioethics (Appendix C). Students were given 20 minutes to read and fill out the reading guides and then 10 minutes to discuss the reading with their “expert group" (composed of other students that were assigned the same reading).

Students were then asked to join their jigsaw groups and present the main information from their reading to group members. Listening members were encouraged to ask questions for clarification and were expected to provide 1-2 sentences from each reading in a summary sheet (Appendix D).

I used the proportion of students that answered each question correctly as a measure of reading comprehension, and the average score for each reading guide was used to measure student engagement during the activity. Students who either did not 
complete at least half of the reading guide ( $\mathrm{n}=1$ for reading $\mathrm{A}, \mathrm{n}=3$ for reading $\mathrm{B}$ ) or clearly did not put forth an effort based on the quality of their answers ( $n=1$ for reading C; score of 0.29) were excluded from this number and any subsequent analyses for the reading guides. I scored students $0 / 1$ (incomplete/complete) for the summary sheets to provide another measure of student engagement.

\section{$\underline{\text { Selection of Readings }}$}

I chose readings that highlighted a range of bioethical considerations specific to CRISPR/Cas9 genetic modification of humans and the twin study in combination with readings that taught students about HIV infection. Additionally, all readings were four pages or less and were at an appropriate reading level. This was indicated by their intended audience which was the general public (since they were News articles) or was students and researchers (for reading B). The readings and their associated reading guides are in Appendix C. Below I provide a brief description and justification for using each reading.

The first reading (A) was an article titled, The Man Who Was Cured of HIV (Jamie, 2011), which detailed the story of Timothy Ray Brown, the first person to be fully cured of HIV and presumably the justification for scientists editing the genes they did in the twin study (Shaw, 2020). The article described how HIV infects immune cells by binding to receptors and subsequent co-receptors to allow fusion with the cell membrane and revealed that some individuals have a natural mutation for one of the coreceptors which results in resistance to HIV infection. As noted in the article, this does not result in complete immunity since some forms of HIV can infect immune cells using a different co-receptor. In Brown's case, he received a bone marrow transplant from a 
donor who contained this natural mutation and doing so cured him of both HIV and cancer. Reading guide questions discussed the receptors involved, the results of the transplant, and the fact that other HIV variants could still infect Brown, thus emphasizing the biology of HIV infection and environmental influences.

The second reading (B) contained sections of Introduction to the Responsible Conduct of Research that highlighted protection of human subjects and ethical issues related to the conduct of research (Steneck, 2004). Students were also given the informed consent provided to the twin study participants (which can be found at https://web.archive.org/web/20181128061149/http:/www.sustcgenome.org.cn/source/pdf/Informed-consent-women-English.pdf). In a couple of the associated reading guide questions, students were asked to answer questions about a specific section of the informed consent. In the reading, the author recounted several historical cases which led to the development of ethical codes and standards (e.g., World War II, the syphilis study). The Nuremberg Code was included in the reading along with a description of the Common Rule and emphasis on research subjects which require special considerations (e.g., pregnant women, human fetuses, neonates, prisoners, and children). Ethical issues included those related to informed consent (i.e., someone else must provide consent for embryos), risk/benefit ratios, and the right to withdraw from research. The reading guide, paired with the informed consent, was designed to draw attention to the adequacy of the informed consent by asking if it included necessary explanations of certain risks, and if the description of the research aligned with the actual procedures. I expected students to recognize that the two did not align since the project description stated that the twin study was being used to develop a vaccine against HIV, 
but the research that was actually performed focused on genetic modification to prevent HIV.

Reading $\mathrm{C}$ contained the rest of the article that was provided before class, Why Are Scientists So Upset About the First CRISPR Babies? (Kolata \& Belluck, 2018). The reading discussed the relation of germline editing to the CRISPR twin study and brought up questions regarding informed consent and project description misalignment. It also described four criteria that the scientific community uses when deciding if such modification is appropriate or not and how these criteria fit into the twin study. These included: it must correct a serious genetic disorder that causes disease/disability, the benefits must outweigh the risks, there should be no other alternatives, and there should be a plan in place to follow the edited children throughout their life. The reading guide was designed to emphasize the risks of editing embryos (increased risk of contracting diseases, genetic mosaicism) and have students evaluate if the above criteria were met or not in the twin study.

The fourth reading (D) was the article Beyond Safety Questions, Gene Editing Will Force Us to Deal with a Moral Quandary, discussed bioethics related to how the technology may be used in the future and the societal issues it brings up (Josephine, 2018). These include ethical considerations regarding germline modification, such as how it may impact future generations, if it is morally justifiable to perform, and when it is appropriate to do so. The article compares CRISPR/Cas9 genetic modification of embryos to in vitro fertilization (IVF), preimplantation genetic testing, and prenatal testing. It also brings up an important ethical consideration of where the line between disease and "designer" baby characteristics lies. The reading guide associated with this 
article contained questions that emphasized the impact on future generations, comparisons between genetically modified embryos to IVF, and where to draw the line between medical and non-medical genetic modification.

\section{Assessment Questions - Design and Analysis}

\section{Questions 1 and 2 - Ethical Considerations}

The first assessment question encouraged students to discuss the ethical considerations that they and their group members read about during the jigsaw activity. I asked students:

"Was the research Dr. He performed in accordance with the ethical scientific policies you have learned about today? Justify your position by providing your reasoning in 3-4 sentences. Reference the information that you read and the information that your group members shared with you in your justification."

This question was a Bloom level six question since students needed to evaluate the case and defend their position (Crowe et al., 2008). There was no "right" or "wrong" answer for this question, but students were expected to accurately use the bioethical principles from the readings to justify their position. I expected students to justify their position by citing the adequacy of the informed consent (including if the project description was accurate), the potential risks to the babies and future generations (including increased susceptibility to certain diseases and unknown off-target effects), criteria used by NASEM to justify germline editing (and information related to the necessity to treat HIV with genetic modification), and principles related to the Nuremberg Code.

I quantified the proportion of students who answered yes, no, or somewhat and then used open coding methods to identify what ethical considerations students discussed by students (Table 13). The list of ethical considerations was grouped into categories 
based on common themes, and some of these were based on information from the readings. For example, all ethical considerations that came from the Nuremberg Code were grouped into one "Nuremberg Code" category and these all came from one reading, but all ethical considerations about informed consent were grouped into one broad "Informed Consent" category (Table 13). The purpose of coding the ethical considerations was to determine if students were on task and engaged during the activity. In particular, I wanted to know if students were using information from the readings they were assigned and what other considerations they came up with on their own. To do this, I quantified the proportion of students who referenced at least one ethical dilemma and the average number of different ethical considerations per student. I calculated the proportion of students who mentioned each ethical consideration to determine which considerations were the most common.

To measure if students were applying ethics learned about from other experts during the jigsaw activity, I identified which ethical considerations came from each reading (Table 13). I determined what proportion of the students who referenced ethics from the readings also referenced ethics present in readings they were not assigned. This provided a measure of both understanding and student engagement (since they were specifically asked to use information from a different reading).

The second assessment question was designed to evaluate if students would separate the "science" behind the study and the ethical standards of the scientific community. I asked students,

"From a scientific standpoint, if you ignored any ethical dimensions such as those that you discussed in question 1, was Dr. He's research justified? In other words, did he have a rational scientific reason for editing what he did in the embryos? Defend your position by providing your reasoning in 3-4 sentences. Reference the 
information that you read and/or the information that your group members shared with you to come up with your justification."

Similar to the first assessment question, this one was also a Bloom level six question (Crowe et al., 2008). I wanted students to demonstrate an understanding of HIV infection and resistance and to explain that genetic modification of an important co-receptor (CCR5) could lead to HIV-resistant cells. This mutation would lead to immunity against most forms of HIV. To be able to identify how many students provided this answer, I identified the most common justifications that were used. I found the proportion of students who answered with the target answer, the proportion that discussed ethical considerations from Table 13, and the proportion of students who discussed other justifications in their responses (e.g. having "good intentions", treating disease, advance science knowledge, and being "logical"). I considered treating disease to be an ethical consideration not described by students in response to the first assessment question because students displayed a concern for the wellbeing of others (that is, they believed that treating disease would benefit members of society). I found the proportion of students who said yes, no, or that it was complicated in response to whether the research was scientifically justified and described the most common justifications provided by each group of students. Chi-squared tests were performed in R to determine if groups different in proportions.

\section{Question 3 and Clicker Activity-Belief in Genetic Determinism}

After responding to the first two assessment questions during class time, students participated in a clicker activity. This activity asked students to rate their level of agreement with the following statement: "If I found out that my child had one of the 
genes associated with [insert characteristic] I would choose to use CRISPR/Cas9 to genetically disable it and reduce their chances of having an [insert characteristic]." Four characteristics were used: cystic fibrosis, addiction, deafness, and autism spectrum disorders (ASD). Ratings ranged from 1-5, with one representing the strongest level of agreement and five representing the lowest level of agreement. I chose these characteristics because they are topics to which the general population has likely been exposed (e.g., addiction, deafness, ASD), or commonly discussed in genetics courses (e.g., cystic fibrosis). Additionally, they represent a range of characteristics with wellknown genetic and/or environmental components. For example, cystic fibrosis is commonly taught in the context of monogenic traits (Dougherty, 2009), thus I considered it to be the most genetically determined of the four traits. In contrast, addiction is a wellknown characteristic that is impacted by both genetics and environment. I expected students to have the highest level of agreement for altering cystic fibrosis since it is the most genetically determined. I expected to see a lower level of agreement for the other characteristics because they are more complex (i.e., they have genetic and environmental impacts). I averaged the scores for each of the four characteristics to generate an average level of agreement for editing each of the four characteristics ( $n=73$; Figure 3$)$. The results from this question, coupled with the third assessment question, was used to measure the degree to which students displayed BGD.

The third assessment question was a Bloom level six question designed to assess the degree to which students invoked BGD after the lesson (Crowe et al., 2008). I asked the students:

"You are a NIH researcher and you have just received a million-dollar grant to use CC9 to genetically edit human cells. You have 3 years and your career 
depends on you being successful. You can choose from among the following characteristics: cystic fibrosis, addictive behavior, deafness, or autism spectrum disorders (ASD). You should choose the characteristic that you believe is the most likely to be manipulated by CC9. Which ONE of the four would you choose to work with? Explain why you chose that characteristic as being the one that will be successfully manipulated by CC9. Explain why you thought the others would not be successfully manipulated by CC9. Be sure to mention each of the four characteristics at least once in your explanations. Your response should be at least one paragraph long."

CC9 was shorthand for "CRISPR/Cas9" during the lesson. I expected students to choose cystic fibrosis more frequently than the other three characteristics on the basis that it would have the highest chance of being successfully genetically altered without environmental influences impacting its expression. Choosing one of the other three characteristics indicated the student thought it could be easily genetically altered and therefore indicated a higher degree of BGD. To characterize the degree of BGD students displayed, I coded using the same methods as Chapter 2 (i.e., identifying when students referenced "gene", "genes", or environmental influences) in the context of each of the four characteristics, with the exception that I removed "genes" references that were ambiguous (i.e., the student did not specify "many" genes or a synonymous term before "genes"). I determined the proportion of each "gene", "genes", or environmental reference in each of the four contexts and overall. I used Chi-squared tests in R to determine if there was a difference in how often each was referenced among the four contexts (characteristics).

\section{RESULTS}

\section{Student Engagement}

I used the pre-assignment, reading guides, and the first assessment question to gauge student engagement in the jigsaw activity. A majority of students answered the 
four pre-assignment questions correctly. The first two questions, which focused on differentiating between the CRISPR system in bacteria and the CRISPR/Cas9 genome editing technology, were the most difficult with $68 \%$ and $77 \%$ of students answering them correctly, respectively (total $n=73$ ). A higher proportion of students answered the two questions related to the CRISPR twin study correctly (questions three and four, 90\% and $92 \%$, respectively; total $\mathrm{n}=73$ ). Thus, most students came to class with some understanding of CRISPR, CRISPR/Cas9 genome editing technology, and the CRISPR twin study.

On average, students scored above $85 \%$ on the reading guides (Table 12) and all students who submitted a completed reading guide also submitted a completed summary sheet $(n=71)$, indicating that these students were actively participating in the jigsaw activity. Students scored the lowest on the reading guide for reading B, which focused on responsible research conduct and informed consent, with the average score ranging from 0.50 to 1.00 (with 1.00 being the total possible score; Table 12). The two questions that students scored the lowest, $2 \mathrm{C}$ and $3 \mathrm{C}$, asked about risks specific to human embryos (i.e., mosaicism) and the project description in the informed consent. On average, only $75 \%$ and $55 \%$ of students, respectively, answered these questions correctly.

Table 12. Descriptive statistics for each of the reading guides. Average score, SD, and range are in proportions.

\begin{tabular}{ccccc}
\hline & $\mathrm{A}(\mathrm{n}=21)$ & $\mathrm{B}(\mathrm{n}=20)$ & $\mathrm{C}(\mathrm{n}=15)$ & $\mathrm{D}(\mathrm{n}=15)$ \\
\hline Average score & 0.96 & 0.85 & 0.92 & 0.86 \\
SD & 0.07 & 0.14 & 0.08 & 0.15 \\
Range & $0.71-1.00$ & $0.50-1.00$ & $0.71-1.00$ & $0.56-1.00$ \\
Total points & 7 & 8 & 7 & 8 \\
\hline
\end{tabular}

The origin of five of the main ten ethical dilemmas could not be determined: scientific or clinical trial rationale, reporting results, embryo editing and treatment, 
increase social disparities, and playing God (Table 13). One of the main ethical considerations, designer babies, was discussed in reading $\mathrm{D}$ but has also been shown to be a common ethical concern (Chapter 1) and thus could have been spontaneously cited by the student (Table 13). Information about two broad ethical categories could have come from one reading only: NASEM criteria was only discussed in reading $\mathrm{C}$ and the Nuremberg Code was only mentioned in reading B. I could not discern where the information for two of six considerations in the informed consent category came from. The other four considerations in this category could have come from reading $\mathrm{B}$, reading $\mathrm{C}$, and/or the before class article (Table 13). For the safety and/or risk category, which contained six specific considerations, I could not determine where the information from two of the considerations came from due to their unspecific nature. Two of the considerations, however, were only mentioned in reading C (incomplete resistance, increase risk of disease), one was mentioned in both the reading B reading guide and reading $\mathrm{C}$ (mosaic embryos), and the last one (future generations) was discussed in reading $\mathrm{C}$ and $\mathrm{D}$, but also could have been brought up by the student spontaneously (Chapter 1).

\section{Application of Ethical Considerations}

\section{Assessment Question 1 - Ethics}

A majority of students (94\%) said that the research performed in the twin study was not performed in accordance with current scientific ethical standards; only $3 \%$ of students said it upheld these standards and another 3\% said it somewhat did. Ninety-nine percent of students discussed at least one ethical consideration in their justification, and 93\% of those students specifically referenced information from the readings and did so in 
a plausible manner. The most common ethical categories (used by $>15 \%$ of students) were informed consent, germline editing criteria provided by the National Academies of Science, Engineering, and Medicine (NASEM), concerns about safety and/or risk of the procedures, and guidelines from the Nuremberg Code (Table 13).

In particular, students expressed concerns about the general adequacy of the informed consent (43\% of students who discussed informed consent) and an insufficient description of risks (38\% of students who discussed informed consent; Table 13). Of students mentioning NASEM criteria, 59\% discussed the requirement that genome editing should only be performed to help treat or prevent a genetic disorder and $50 \%$ described the need for there to be no other alternatives, for the benefits to outweigh the risks, or the need to follow the edited children long-term (Table 13). Forty percent of students concerned about safety and/or risks made general statements about the unknown safety and/or risks, and $69 \%$ of students who referenced the Nuremberg Code did so using general statements about if the guidelines were upheld or not (Table 13). Other ethical considerations were less common and these included a lack of research in embryos to justify the study, vague reporting of the results, the production of designer babies, the treatment/editing of embryos, the possibility of increasing social disparities, and the researchers "playing God" by performing the research (Table 13).

The number of ethical considerations mentioned in a student's response ranged from $0-6$, with students referencing three, on average $(\mathrm{SD}=1.18)$. I found that $59 \%$ of students that referenced ethical considerations from the readings referenced ones that were present in their group members readings indicating most students were applying 
both the knowledge they learned in their reading and that they acquired by discussing the readings with their group.

\section{Assessment Question 2 - Scientific Justification}

A majority of students (54\%) said that the research performed on the twins was justified if ethics were put aside. Forty percent said that it was not, and $6 \%$ said it was complicated. Application of ethics from Table 13 was significantly more common among those who thought the research was not justified (96\%) compared to those who believed it was $\left(27 \% ; \mathrm{p}<0.001, \chi^{2}=27.7\right)$. However, most students from the latter group used treating diseases in their reasoning $(65 \%, \mathrm{n}=37)$. Since I considered treating to disease to be an ethical consideration, these results demonstrate that all students were applying ethical considerations even when asked specifically not to, indicating they recognized that the "science" could not be separated from ethical considerations.

Most students $(59 \%, \mathrm{n}=40)$ used ethical considerations from Table 13 to justify their answer (other students used treating disease or did not use any). The most common considerations included: a concern about not knowing the risks (40\% of these students), treatment of embryos (33\%), experimental background (33\%), and non-specific adequacy of the informed consent documents (18\%; Table 13). This indicated that students understood and applied ethical considerations that they learned about during the activity. 
Table 13. Ethical considerations that students used in responses to assessment questions. The reading from which the information came from is indicated. A single asterisk denotes ethical considerations that may have been spontaneously discussed or which their origin could not be determined, a double asterisk denotes ethical considerations that were discussed in the reading students were asked to read before class. Total $n=70$ for the first assessment question, and $n=40$ for the second assessment question, but students could be counted in more than one ethical consideration category. $\operatorname{Pr}=$ proportion.

\begin{tabular}{lcc}
\hline $\begin{array}{l}\text { Ethical } \\
\text { category }\end{array}$ & $\begin{array}{c}\text { Ethical } \\
\text { consideration }\end{array}$ & Description \\
\hline $\begin{array}{l}\text { Informed } \\
\text { consent } \\
(n=42)\end{array}$ & $\begin{array}{c}\text { Adequacy, } \\
\text { general }\end{array}$ & $\begin{array}{c}\text { Insufficient or sufficient } \\
\text { informed consent was present in } \\
\text { the paperwork provided to the } \\
\text { parents of the edited embryos, } \\
\text { but no specific topic mentioned }\end{array}$ \\
& &
\end{tabular}

$\begin{array}{cc}\text { Risks } & \begin{array}{c}\text { Risks to the mother(s) and/or } \\ \text { unborn children were not } \\ \text { adequately stated in the } \\ \text { informed consent }\end{array} \\ \begin{array}{c}\text { Misaligned } \\ \text { project } \\ \text { description }\end{array} & \begin{array}{c}\text { There was a discrepancy } \\ \text { between the project description } \\ \text { in the informed consent } \\ \text { documents and what was } \\ \text { actually performed }\end{array} \\ \text { Transparency } & \begin{array}{c}\text { The informed consent was very } \\ \text { detailed and contained all of the } \\ \text { necessary information or did not } \\ \text { provide enough detail or }\end{array}\end{array}$

$\mathrm{B}, \mathrm{C}$, or ** “...he didn't include all the risks when asking for consent."

$\mathrm{B}$ or $\mathrm{C}$

"The purpose of Dr. He's $8 \quad 3 \%$ research (as stated in Reading B's informed consent) was to develop an HIV/AIDS vaccine. However, this was clearly not the outcome of the experiment (as genome editing was used)."

"...he did not necessarily include 5 $0 \%$ all of the details in his consent form that should have been included." 
transparency regarding the procedures

Accountability

National

Academies

of Science,

Engineering,

and Medicine

(NASEM)

N Criteria

$(n=34)$

\section{consent \\ Embryos}

Genetic

disorder
Proper or improper liability was present in the informed consent documents

Genome editing should only be applied when used to correct a serious genetic disorder that causes disease or disability

\section{Embryos could not provide consent to undergo the procedure}

B or $*$

No Genome editing should only be alternatives

Benefits outweigh risks

Monitor children longterm used when there are no other alternative treatments available

The benefits should clearly outweigh the risks before genome editing is used

There must be a plan in place to follow the edited children before editing is performed
C

"...his group in the informed

consent papers were all accountable for the mother in and out of the project."
"The children would not have been able to consent to the procedure..."

"According to the national academies of science,

engineering, and medicine issued a report saying it was only ethical to modify human embryos if it would be used to correct a serious genetic disorder that causes disease or a disability."

"The four guidelines are that editing should be used in the case of...no other alternatives are present..."

"There would have to be good $17 \quad 0 \%$ evidence that the benefits would outweigh the risks..."

C
"He also didn't have many plans to follow up with the children after the experiment." 
General

Safety and/or risk $(\mathrm{n}=25)$ benefits, general
The four guidelines were not upheld properly, but none specifically mentioned

The risks of editing embryos were unknown because there is a lack of knowledge concerning CRISPR/Cas9

$\begin{array}{cc}\text { Mosaic } & \text { Mosaic embryos were used, } \\ \text { embryos } & \text { which posed a danger to the } \\ \text { mentioned } & \text { edited children }\end{array}$

Risks The risks were greater than the outweigh

Incomplete resistance

Future generations benefits, but no specific risks/benefits described; not discussed in the context of NASEM criteria from above in the embryos due to issues regarding the successfulness of the experiment (e.g. only one allele was altered)

The risk to future generations was unknown
"There were 4 criteria for ethical purposes which he did not

$$
\text { follow." }
$$

"There is concern that we don't know enough about CRISPR gene editing to use it on humans."

B or C

"The use of mosaic embryos was also a red flag, due to it being dangerous, but was ignored by

$$
\text { Dr. He." }
$$

"There were many risks for the children being born-- some of which came with consequences that modern science and technology can't make up for."

"There is concern that the genes he edited weren't fully expressed in the babies."
"Another, more important

C, D, or * oncern, is the possible effects of genome editing on our future population." 


\section{Increase risk \\ Increased the risk of certain} of disease diseases (i.e., West Nile Virus)

in the edited children

\section{Nuremberg}

Code $(n=13)$

Experimental background

Reporting results

\section{General}

The experiments violated the Nuremberg Code, but no specific region of it described

Sufficient animal testing

Voluntary withdrawal

There should be sufficient moving onto human trials but in this case not possible, animal testing performed before

Withdrawal should be an option, since the children underwent genetic modification and were, therefore, permanently altered

There is not enough scientific research on embryonic genetic modification to justify

performing the experiment

Results from the experiment are too vague/unclear
"It was absolutely not [in

$18 \%$ accordance with scientific ethical policies] because he ... only caused vulnerability to different diseases..."

"Dr. He also violated the

$9 \quad 0 \%$ Nuremberg Laws."

"There was also not even enough $7 \quad 8 \%$ tests on animals to see the actual long-term effects."

"According to the

Nuremburg code, it's required for the human subjects to have the liberty to bring the experiment to an end at any time, this was not possible for the twin babies who were being experimented on."

"There was also not that much research showing that this experiment would actually work so there was not enough research to make this experiment safe or credible."

“Dr. He didn't post his findings on the embryos tested on. There is no proof of them actually 
Designer

babies

Treatment

of embryos

Increase

social

$\stackrel{N}{\perp}$

disparities

"Playing

God"
The technology may be used to produce "designer babies", and the line between treating disease and "designing" babies is ambiguous

Embryos were unethically edited or mistreated in the experiment

The use of CRISPR/Cas9 technology may lead to more disparities between socioeconomic classes

The researchers were "playing God" by using CRISPR/Cas9 technology on embryos surviving birth or if the alterations worked."
D or *

"This experiment also leads to the ethical question if all babies should be "designed" to meet

parents needs and wants."

"Dr. He surely had failed subjects before his success, implying that he discarded the embryos not suited for CRISPR, snuffing out their potential for human life."

"...it has the potential to increase disparities between

socioeconomic classes with "designer babies."

$*$
"There is concern that Dr. He is playing God." 
Other justifications that students used included: it will help treat diseases (43\%), the researchers had good intentions (12\%), it will advance scientific knowledge (9\%), and it was "logical" or "made sense" (6\%; Figure 13). Only $12 \%$ of students provided the target answer: by editing HIV using CRISPR/Cas9 technology to alter the CCR5 receptor, the researchers could produce HIV-resistance embryos (Figure 13). Of these students, $(n=8), 38 \%$ also referenced ethics from Table 13.

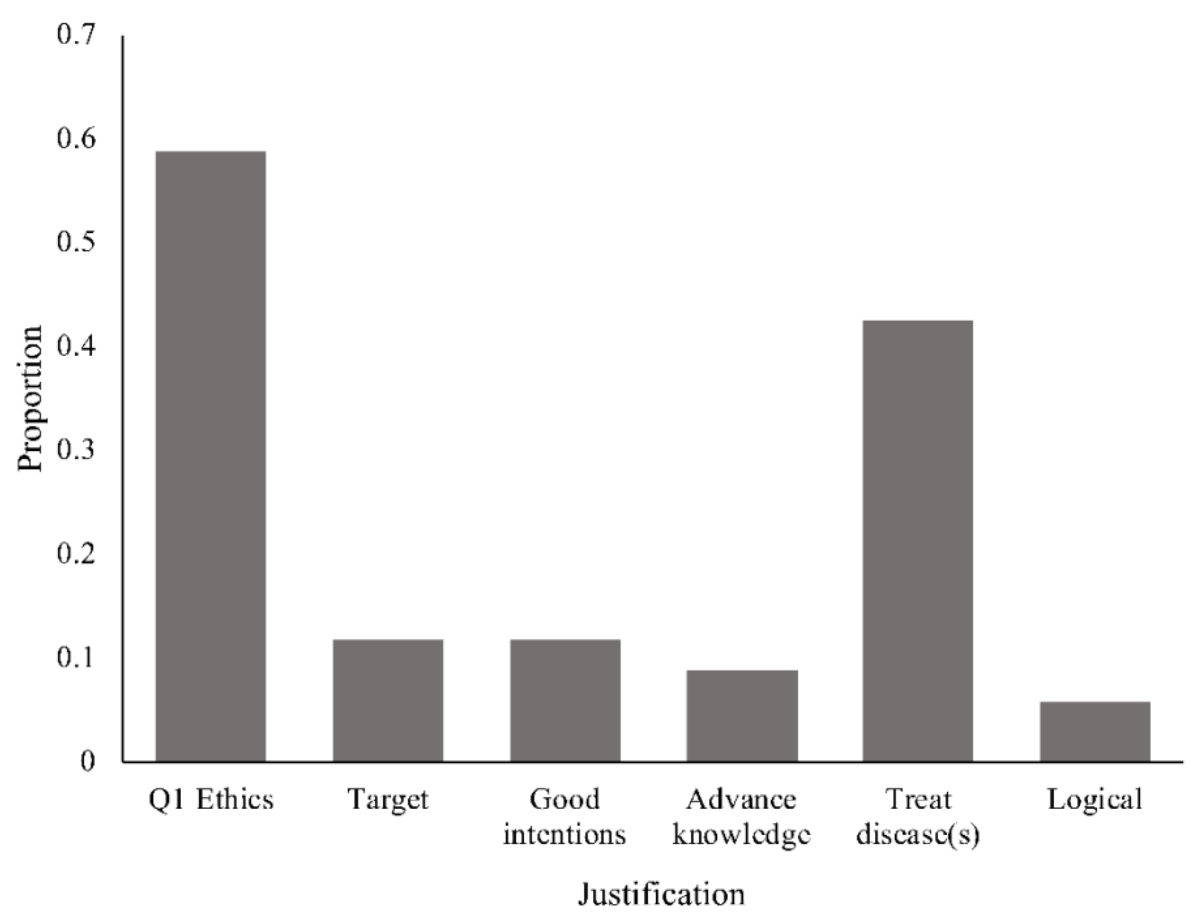

Figure 13. The proportion of students who used each type of justification for the second assessment question. Most students (59\%) referenced ethical considerations that were also discussed in response to the first assessment question. The second most common consideration was the treatment of diseases (43\%). Fewer students answered with the target answer (12\%), stated the researchers had "good intentions" (12\%), claimed the research would advance knowledge of science $(9 \%)$, or the research was "logical/made sense" $(6 \%)$. Total $n=68$. 


\section{Belief in Genetic Determinism}

\section{Assessment Question 3}

Most students (95\%) said that they would choose to work with cystic fibrosis, and this was significantly higher than the proportion of students that chose addiction $(0 \%)$, deafness $(2 \%)$, or ASD $(3 \% ; \mathrm{p}<0.001)$. Thirty-one percent of students used "gene" in the context of at least one the four characteristics (cystic fibrosis, addiction, deafness, or ASD), but most students $(82 \%)$ used "gene" in the context of cystic fibrosis. For example, the following students explained why they would choose cystic fibrosis and referenced "gene" in their response:

"I would choose cystic fibrosis. Cystic fibrosis is caused by a single gene that has to be inherited by multiple parents, or mutated..."

"I would manipulate cystic fibrosis with CC9. Cystic fibrosis is controlled by one gene and its either you have it or you don't. Cystic Fibrosis is when many of the digestive liquids like mucus and sweat become more sticky, which can clog many tubes in our body. It involves many severe symptoms such as difficulty breathing and lung infections..."

Significantly fewer students used "gene" in the context of deafness $(9 \%)$, addiction $(5 \%)$, or $\operatorname{ASD}(5 \% ; p<0.001 ;$ Figure 14$)$. Although references to "gene" imply a deterministic view of genetics, it is not surprising that students used it in the context of cystic fibrosis since it was taught as such in the textbook that was used in the class, even though it can be more complex (Dougherty, 2009).

Overall, $36 \%$ of students made references to a characteristic being influenced by many "genes", but there was not a significant difference in the proportion of students that referenced "multiple genes" in the context of cystic fibrosis (18\%), addiction (25\%), deafness (21\%), or $\operatorname{ASD}\left(25 \% ; \mathrm{p}=0.68, \chi^{2}=1.52 ;\right.$ Figure 14). Thus, few students demonstrated knowledge of 
polygenic traits for each of the four characteristics. One student said the following about addiction, deafness, and ASD:

“...Addictive behavior can be inherited from many different genes... Deafness can also be caused by many different genetic loci going wrong. Autism spectrum disorder is even less certain, with many genes that are associated with it..."

A majority (86\%) of students referenced environmental factors, which included

references to environment, epigenetics, hearing aids, therapy and/or rehab to alter addictive behaviors, and therapy to help individuals with ASD. The following passages are from students that demonstrate the variety of environmental influences that students described:

“...I think addictive behavior can be helped by many other methods. For example, if a person had an alcohol or drug addiction, it can [be] helped through rehab and many people who go to rehab never get involved in that addictive behavior. Deafness is also a very terrible situation because there really isn't any "cure" for deafness yet. If people are partly deaf, there are many technologies that help create or project the surrounding sound into the person's ear..."

“...Addictive behavior, for example, could occur in a person whether or not they are prone to addictive behavior because of the environment they are living in or the addictive substances they are or are not exposed to... Deafness can also be influenced by external factors. While some causes are hereditary and babies are born deaf from birth, others causes can include disease, or loud or traumatizing environments... ASD is tricky because while it is gene-linked, the gene mutation is different depending on the severity of the autism, not to mention the external factors that could induce or elevate the severity of autism..."

Most environmental references were in the context of addiction (52\%), and this proportion was significantly higher than references in the context of deafness $(26 \%, \mathrm{p}<0.01)$ and ASD $(22 \%$, $\mathrm{p}<0.001)$. None of the students referenced the environment in the context of cystic fibrosis (Figure 14). These results indicate that students did not hold deterministic views about addiction. 


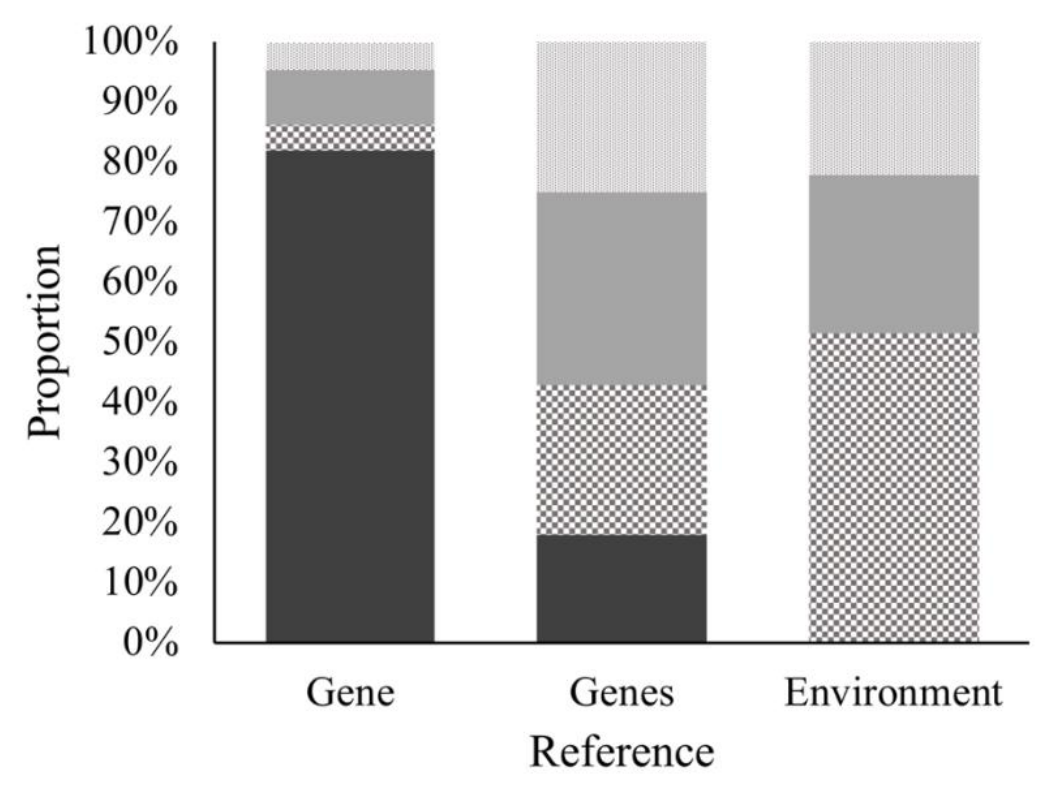

Figure 14. The proportion of gene, genes, and environmental references that were in the context of each of the four characteristics. A significantly higher proportion of the "gene" references were in the context of CF compared to the other three characteristics $(\mathrm{p}<0.001)$. A significantly lower proportion of the environmental references were in the context of CF compared to the other three characteristics $(\mathrm{p}<0.001)$, and a significantly higher proportion were in the context of addiction compared to deafness $(\mathrm{p}<0.01)$ and ASD $(\mathrm{p}<0.001)$. Black represents cystic fibrosis, checkered is addiction, gray is deafness, and ASD is dotted.

Clicker Activity - Cystic fibrosis, addiction, deafness, and ASD

Students exhibited the highest level of agreement for modifying cystic fibrosis $(\mathrm{M}=3.58$, $\mathrm{SD}=1.17$ ) compared to the other characteristics (Figure 15). They demonstrated the lowest level of agreement for modifying addiction $(\mathrm{M}=2.26, \mathrm{SD}=1.28$; Figure 15$)$. This mirrored the results from the third assessment question, where cystic fibrosis was chosen to be modified in a majority of cases, and addiction was never chosen, indicating students may have been considering the 
genetics of the four characteristics during the Clicker activity, before the assessment question was asked.

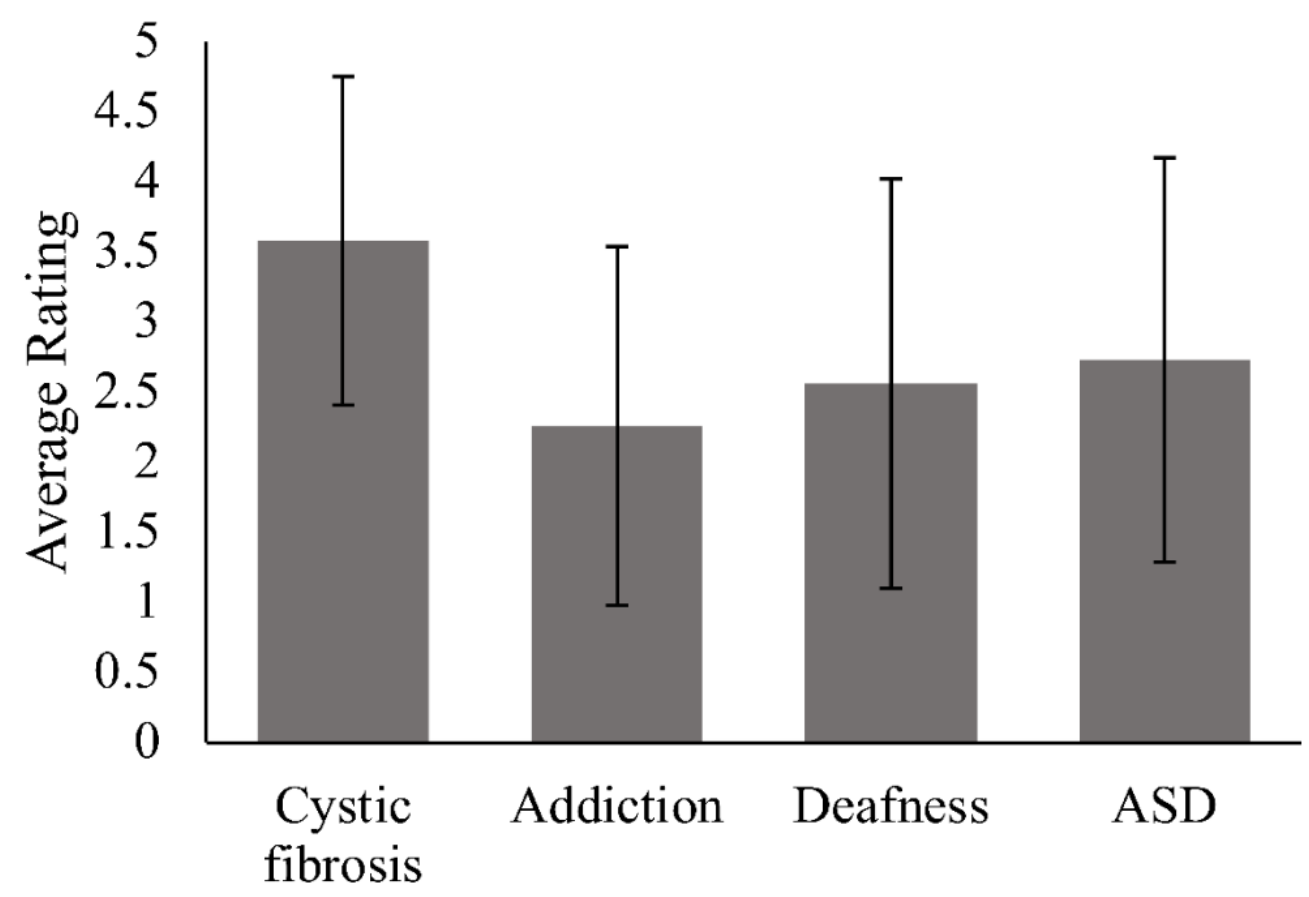

Characteristic

Figure 15. The average rating for each characteristic \pm SD. The lowest level of agreement $=1$, highest $=5 ; \mathrm{ASD}=$ Autism Spectrum Disorders. Students displayed the highest level of agreement for altering the gene(s) to decrease the chances of their child developing cystic fibrosis and the lowest level of agreement for altering gene(s) to decrease the risk of their child developing addiction. 


\section{DISCUSSION}

The active learning, student-centered jigsaw activity described here effectively emphasized bioethics related to an SSI concerning CRISPR/Cas9 human genetic engineering. High scores on the pre-assignment questions and reading guides indicated that students effectively examined the literature about the twin study and understood the concepts discussed. They were able to reason from evidence, meaning they used the literature as evidence to justify their position, which is a higher order thinking skill (Crowe et al., 2008). Students successfully evaluated a real-life, current CRISPR/Cas9related SSI by applying principles of bioethics that they learned in their reading and by discussing the readings with their group, indicating that they were engaged with the material and stayed on task during the activity. Furthermore, they displayed a low level of BGD after the lesson which was indicated by the high proportion of students who chose cystic fibrosis because it was a single gene modification and a high proportion that acknowledged environmental impacts on the expression of complex characteristics. Taken together, I believe that the activity described here, a CRISPR/Cas9-related case, is an ideal active learning lesson that instructors can use to help students understand how to apply principles of bioethics and argue from evidence.

\section{Limitations and Recommendations for Reading Guides}

Overall, most students demonstrated that they understood the information from their assigned reading. However, students scored the poorest on two questions from reading guide $\mathrm{B}$. This reading discussed the protection of human subjects and bioethical issues related to the conduct of research. It is difficult to ascertain why students struggled with these questions in particular since I did not gather data from students asking for 
feedback after the lesson. However, using my experience during the activity, I offer some conjectures for why they may have scored lower on these questions along with recommended changes for future use. First, I heard students that were assigned to reading B express concern about finishing their reading guide on time. I would recommend removing some of the questions from this reading guide, and/or cutting out some of the information provided in the reading to give students more time to read and answer their reading guide to address this possible issue. Additionally, many of the students who considered the adequacy of the informed consent (predominantly discussed in reading B) or the Nuremberg Code (only discussed in reading B) used statements such as "the informed consent was inadequate" or "the study did not follow the Nuremberg Code". The lack of detail in these responses may also be indicative of students being overwhelmed with the amount of information in reading B and the time constraint. I would recommend removing some of the questions from this reading guide, and/or cutting out some of the information provided in the reading, to give students more time to read and answer their reading guide and address this issue.

The question students performed the poorest on asked them to compare the project description presented in the twin study's informed consent form with the research that had been described. In a prior question, students were instructed to look up what a vaccine was to ensure that they had an understanding of what one was before being asked if the twin study was used to develop one. I believe that the exact wording, repeated below, may have been confusing for students:

"Does the research described in the article before class and in the class discussion before the activity appear in line with Dr. He's description of the project you found in part A? Explain." 
Students often answered this question vaguely, so it is possible that they did not know to which "part A" referred. I recommend changing the wording to read: "Do you think the research study you learned about today aligned with the project description (which you found in $3 \mathrm{~A})$ ? Keep in mind the definition of a vaccine (found in 3B)." Another option would be to include the project description from the informed consent into the question.

The second question that students performed poorly on asked about if the risks specific to editing human embryos were mentioned in the informed consent $(2 \mathrm{C}$; Appendix C). The students were directed to a particular section of the informed consent document so they did not have to search, and they were provided with an example of a risk specific to editing human embryos (e.g. genetic mosaicism). One reason students may have struggled with this question could be due to a lack of knowledge about mosaicism. Although students could have used outside resources to look up what genetic mosaicism is, the time constraint may have unknowingly pressured them not to take the extra time to look it up. I recommend including the definition in the question or incorporating it in lessons prior to the activity to ensure students understand the scientific concept before being asked to answer a question about it. Additionally, I believe students struggled with the option to answer "No" (the correct answer in this case) to open-ended questions, so informing them that "No" is an acceptable answer in some cases prior to beginning the activity may be helpful as well.

\section{Use of CRISPR/Cas9 "Twin Study" as an SSI}

One key characteristic of SSIs is that they are controversial science-related topics (Zeidler and Nichols, 2009). A majority of students believed the research was not performed in accordance with present-day bioethical standards, but they were divided 
when deciding if the twin study was scientifically justified or not. In both cases, students used a wide variety of ethical considerations both from the readings and that they came up with on their own. I highlight some of the most common and least common of these considerations so future instructors can be prepared for discussions and guide them appropriately.

It may be useful for instructors to prepare for discussions about these considerations specifically, however, they should be aware that students also use ethical considerations that they come up with on their own (Chapter 1). In this study, some considerations that were "spontaneously" derived by students included transparency of the informed consent, lack of experimental background, and lack of clarity of the results. Being aware of these possible, self-derived considerations is important so instructors can encourage respectful classroom discourse from a variety of students and engage them in the activity further.

Students discussed information from some ethical categories vaguely without referencing specific considerations. I recommend that instructors emphasize specific considerations from these topics when guiding discussion. For example, when students are in their "expert" groups discussing informed consent or safety and/or risk, instructors could draw attention to the inability of future generations to provide consent. This is a CRISPR/Cas9 and twin study specific bioethical issue because there may be unforeseen consequences of editing germline cells in those generations, but it was rarely discussed in student responses (Cribbs \& Perera, 2017; Ledford, 2019; Li et al., 2019). This is just one example from the twin study of a bioethical issue that has no clear solution and that students may hold a variety of opinions about. Guiding "expert” group discussions about 
broad bioethical categories is therefore an ideal method for promoting students to think deeper about these categories and apply specific considerations.

I expected some ethical considerations specific to CRISPR/Cas9 genome editing technology to be discussed by students more frequently, such as designer babies and the misuse of power ("playing God"). Both of these were prevalent moral reasoning themes found in a previous study (Chapter 1), were discussed in the readings, and represent serious concerns that bioethicists and others have about the technology being used on germline cells in the future (Cribbs \& Perera, 2017; Locke, 2020). In future implementations of the activity, instructors should emphasize these specific bioethical issues since students will be asked to make judgements about them as active members of a democratic society.

I expected students to express concern about some bioethics related to the twin study in particular at a higher frequency than what was observed. For example, I predicted that students would discuss the misalignment of the project description, which was highlighted in reading guide B and reading C, however, it was only discussed by a few students. Likewise, I expected students to describe specific risks that the babies were subjected to, which were discussed in reading $\mathrm{C}$. These included the possibility that the implanted embryos contained mosaic cells, that both babies may not be resistant to HIV infection due to incomplete resistance, and that altering the gene CCR5 may result in an increased susceptibility to other diseases. There may represent topics (informed consent) and science concepts that students have difficulty understanding and therefore applying to the CRISPR/Cas9 case. 


\section{Standard Genomics Literacy}

My results demonstrated that most students held a non-genetic deterministic view of complex characteristics such as deafness, addiction, and ASD. This was evident not only in open-ended responses, but also by clicker responses in which students displayed a high agreement for altering a traditionally monogenic trait (cystic fibrosis) compared to the other, more complex characteristics.

Although BGD (represented by the use of "gene") was uncommon in the responses, when it did appear, it was most frequently in the context of altering cystic fibrosis and was therefore appropriate. Of the four characteristics, I expected cystic fibrosis to be referred to as monogenic the most frequently since it is often taught as an example of a simple, monogenic trait in the context of Mendelian genetics (Dougherty, 2009). It is also commonly used as an example of how CRISPR/Cas9 may be used for therapeutic purposes (Cribbs \& Perera, 2017; Ledford, 2019; Wollert, 2020). This could be problematic because teaching genetics by highlighting monogenetic, Mendelian genetics examples may unknowingly reinforce genetic determinism (Dar-Nimrod \& Heine, 2011; Donovan, 2016; Dougherty, 2009). Since students demonstrated nondeterministic views about three of the characteristics, I believe this activity is a useful method for emphasizing a multifactorial model of genetics.

\section{Scientific Literacy and the Nature of Science}

Previous research has found that students use ethics and moral reasoning as decision-making factors when resolving SSIs (Chapter 1; Sadler \& Zeidler, 2003), and my work adds to this body of knowledge. Students recognized that the biological processes that rationalize research procedures must be considered in the context in which 
they are being employed. That is, the science cannot be used as the sole justification for research and it must be considered along with relevant bioethical considerations.

SSIs may be an ideal method to teach students about the Nature of Science (NOS; Simmons \& Zeidler, 2003). The twin study SSI activity presented here could be used in the future to highlight aspects of the Nature of Science (NOS). NOS includes ideas such as: scientific knowledge is subject to change upon the discovery of new knowledge, based on empirical evidence, theory-laden and value-laden, socially/culturally influenced, and a product of human creativity (Bell, 2003). The twin case SSI that I used emphasized several of these NOS aspects, most notably the idea that science is value-laden and therefore includes ethics, which students acknowledged. Instructors may want to use this SSI activity, therefore, to encourage students to think about the NOS. 


\section{REFERENCES}

Abd-El-Khalick, F. (2003). Socioscientific issues in pre-college science classrooms: The primacy of learners' epistemological orientations and views of nature of science. In D. L. Zeidler (Ed.), The role of moral reasoning on socioscientific issues and discourse in science education. Dordrecht: Kluwer Academic Publishers.

Adams, A. E. M., Garcia, J., \& Traustadóttir, T. (2016). A quasi experiment to determine the effectiveness of a "partially flipped" versus "fully flipped" undergraduate class in genetics and evolution. CBE-Life Sciences Education, 15(2). https://doi.org/10.1187/cbe.15-07-0157

Agrawal, A., Verweij, K. J. H., Gillespie, N. A., Heath, A. C., Lessov-Schlaggar, C. N., Martin, N. G., Nelson, E. C., Slutske, W. S., Whitfield, J. B., Lynskey, M. T. (2012). The genetics of addiction — a translational perspective. Translational Psychiatry, 2(7). https://doi.org/10.1038/tp.2012.54

Allchin, D. (2014). From science studies to scientific literacy: A view from the classroom. Science \& Education, 23(9), 1911-1932. doi: 10.1007/s11191-013$9672-8$

Allen, J. M., Muragishi, G. A., Smith, J. L., Thoman, D. B., \& Brown, E. R. (2015). To grab and to hold: Cultivating communal goals to overcome cultural and structural 
barriers in first-generation college students' science interest. Translational Issues in Psychological Science, 1(4), 331-341. doi: 10.1037/tps0000046

Amador, J., \& Mederer, H. (2013). Migrating successful student engagement strategies online: Opportunities and challenges using jigsaw groups and problem-based learning. Journal of Online Learning and Teaching, 9, 89-105.

American Association for the Advancement of Science. (1990). Science for all Americans. New York: Oxford University Press.

Avena, J. S., \& Knight, J. K. (2019). Problem solving in genetics: Content hints can help. CBE_Life Sciences Education, 18(2). https://doi.org/10.1187/cbe.18-06-0093

Avery, A. R., \& Duncan, G. E. (2019). Heritability of type 2 diabetes in the Washington State twin registry. Twin Research and Human Genetics, 22(2), 95-98. https://doi.org/10.1017/thg.2019.11

Balgopal, M. M., Wallace, A. M., \& Dahlberg, S. (2016). Writing from different cultural contexts: How college students frame an environmental SSI through written arguments. Journal of Research in Science Teaching, 54(2), 195-218. doi: $10.1002 /$ tea. 21342

Barrangou, R., Fremaux, C., Deveau, H., Richards, M., Boyaval, P., Moineau, S., Romero, D. A., Horvath, P. (2007). CRISPR provides acquired resistance against viruses in prokaryotes. Science, 315(5819), 1709-1712.

doi:10.1126/science. 1138140

Bastian, B., \& Haslam, N. (2006). Psychological essentialism and stereotype endorsement. Journal of Experimental Social Psychology, 42(2), 228-235. doi:10.1016/j.jesp.2005.03.003 
Bauerle, C., DePass, A., Lynn, D., O'Connor, C., Singer, S., Withers, M., Anderson, C. W., Donovan, S., Hoskins, S. G., Labov, J., Lopatto, D., McClatchey, W., VarmaNelson, P., Pelaez, N., Poston, M., Tanner, K., Wessner, D., White, H., Wood, W., \& Wubah, D. (2011). Vision and change in undergraduate biology education: A call to action. (C. A. Brewer \& D. Smith, Eds.). American Association for the Advancement of Science.

Beekun, R. I., Stedham, Y., Westerman, J. W., \& Yamamura, J. H. (2010). Effects of justice and utilitarianism on ethical decision making: a cross-cultural examination of gender similarities and differences. Business Ethics: A European Review, 19(4), 309-325. doi: 10.1111/j.1467-8608.2010.01600.x

Bell, R. (2003). Exploring the role of NOS understandings in decision making. In D. L. Zeidler (Ed.), The role of moral reasoning on socioscientific issues and discourse in science education. Dordrecht: Kluwer Academic Publishers.

Berkowitz, M. W., \& Simmons, P. (2003). Integrating science education and character education: The role of peer discussion. In D. L. Zeidler (Ed.), The role of moral reasoning on socioscientific issues and discourse in science education. Dordrecht: Kluwer Academic Publishers.

Bird, S. J. (1996). The role of science professionals in teaching responsible research conduct. BioScience, 46(10), 783-786. https://doi.org/10.2307/1312856

Booth, J. M., \& Garrett, J. M. (2004). Instructors' practices in and attitudes toward teaching ethics in the genetics classroom. Genetics, 168(3), 1111-1117. https://doi.org/10.1534/genetics.103.023077 
Brescoll, V., \& Lafrance, M. (2004). The correlates and consequences of newspaper reports of research on sex differences. Psychological Science, 15(8), 515-520. doi:10.1111/j.0956-7976.2004.00712.x

Brickhouse, N. W. (2001). Embodying science: A feminist perspective on learning. Journal of Research in Science Teaching, 38(3), 282-295. doi: 10.1002/10982736(200103)38:3<282::aid-tea1006>3.0.co;2-0

Briggs, D. C. (2019). Interpreting and visualizing the unit of measurement in the Rasch Model. Measurement, 146, 961-971. https://doi.org/10.1016/j.measurement.2019.07.035

Brikell, I., Kuja-Halkola, R., \& Larsson, H. (2015). Heritability of attention-deficit hyperactivity disorder in adults. American Journal of Medical Genetics Part B: Neuropsychiatric Genetics, 168(6), 406-413. https://doi.org/10.1002/ajmg.b.32335

Brokowski, C., Pollack, M., \& Pollack, R. (2015). Cutting eugenics out of CRISPRCas9. Ethics in Biology, Engineering and Medicine: An International Journal, 6(3-4), 263-279. doi: 10.1615/ethicsbiologyengmed.2016016260

Burian, R. M., \& Kampourakis, K. (2013). Against "genes for": Could an inclusive concept of genetic material effectively replace gene concepts? In K. Kampourakis (Ed.), The philosophy of biology: A companion for educators (pp. 597-628). Dordrecht: Springer.

Byrnes, J. P., Miller, D. C., \& Schafer, W. D. (1999). Gender differences in risk taking: A meta-analysis. Psychological Bulletin, 125(3), 367-383. doi: 10.1037/00332909.125.3.367 
Caravita, S. C., Giardino, S., Lenzi, L., Salvaterra, M., \& Antonietti, A. (2012). Socioeconomic factors related to moral reasoning in childhood and adolescence: The missing link between brain and behavior. Frontiers in Human Neuroscience, 6. doi:10.3389/fnhum.2012.00262

Carter, D., \& Braunack-Mayer, A. (2011). The appeal to nature implicit in certain restrictions on public funding for assisted reproductive technology. Bioethics, 25(8), 463-471. doi: 10.1111/j.1467-8519.2011.01925.x

Carver, R. B., Castéra, J., Gericke, N., Evangelista, N. A., \& El-Hani, C. N. (2017). Young adults' belief in genetic determinism, and knowledge and attitudes towards modern genetics and genomics: The PUGGS questionnaire. Plos One, 12(1). doi:10.1371/journal.pone.0169808

Case, K. A., Hensley, R., \& Anderson, A. (2014). Reflecting on heterosexual and male privilege: Interventions to raise awareness. Journal of Social Issues, 70(4), 722740. doi: $10.1111 /$ josi. 12088

Castéra, J., Bruguière, C., \& Clément, P. (2008). Genetic diseases and genetic determinism models in French secondary school biology textbooks. Journal of Biological Education, 42(2), 53-59. doi:10.1080/00219266.2008.9656111

Castéra, J., Clément, P., Abroughui, M., Nisiforou, O., Valanides, N., Turcinaviciene, J., Sarapuu, T., Agorram, B., Calado, F., Bogner F., Carvalho, G. (2008). Genetic determinism in school textbooks: A comparative study conducted among sixteen countries. Science Education International, 19(2), 163-184. 
Cinici, A. (2016). Balancing the pros and cons of GMOs: Socio-scientific argumentation in pre-service teacher education. International Journal of Science Education, 38(11), 1841-1866. https://doi.org/10.1080/09500693.2016.1220033

Cobern, W. W., \& Loving, C. C. (2000). Defining "science” in a multicultural world: Implications for science education. Science Education, 85, 50-67.

Colby, A., Kohlberg, L., Gibbs, J., Lieberman, M., Fischer, K., \& Satzstein, H. D. (1983). A longitudinal study of moral judgment (Vol. 48). Chicago, IL: University of Chicago Press for the Society for Research in Child Development.

Coley, J. D., \& Tanner, K. (2015). Relations between intuitive biological thinking and biological misconceptions in biology majors and nonmajors. CBE_Life Sciences Education, 14(1). https://doi.org/10.1187/cbe.14-06-0094

Coley, J. D., \& Tanner, K. D. (2012). Common origins of diverse misconceptions: Cognitive principles and the development of biology thinking. $C B E$ - Life Sciences Education, 11(3), 209-215. https://doi.org/10.1187/cbe.12-06-0074

Collins, A., \& Politopoulos, I. (2011). The genetics of breast cancer: risk factors for disease. The Application of Clinical Genetics, 11. https://doi.org/10.2147/tacg.s13139

Condit, C. M., Parrott, R. L., Harris, T. M., Lynch, J., \& Dubriwny, T. (2004). The role of "genetics" in popular understandings of race in the United States. Public Understanding of Science, 13(3), 249-272. doi:10.1177/0963662504045573

Côté, S., Piff, P. K., \& Willer, R. (2013). For whom do the ends justify the means? Social class and utilitarian moral judgment. Journal of Personality and Social Psychology, 104(3), 490-503. doi: 10.1037/a0030931 
Cotner, S., Thompson, S., \& Wright, R. (2017). Do biology majors really differ from non-STEM majors? CBE-Life Sciences Education, 16(3). doi:10.1187/cbe.16-110329

Cribbs, A. P., \& Perera, S. M. W. (2017). Science and bioethics of CRISPR-Cas9 gene editing: An analysis towards separating facts and fiction. Yale Journal of Biology and Medicine, 90, 625-634.

Crowe, A., Dirks, C., \& Wenderoth, M. P. (2008). Biology in Bloom: Implementing Bloom's Taxonomy to Enhance Student Learning in Biology. CBE_Life Sciences Education, 7(4), 368-381. https://doi.org/10.1187/cbe.08-05-0024

Curtis, M. B., Conover, T. L., \& Chui, L. C. (2012). A cross-cultural study of the influence of country of origin, justice, power Distance, and gender on ethical decision making. Journal of International Accounting Research, 11(1), 5-34. doi: $10.2308 /$ jiar-10213

Cyranoski, D. (2019). What's next for CRISPR babies? Nature, 566, 440-443.

Dar-Nimrod, I. (2012). Postgenomics and genetic essentialism. Behavioral and Brain Sciences, 35(5), 362-363. doi:10.1017/s0140525x12000982

Dar-Nimrod, I., \& Heine, S. J. (2006). Exposure to scientific theories affects women's math performance. Science, 314(5798), 435-435. doi:10.1126/science.1131100

Dar-Nimrod, I. \& Heine, S. J. (2011). Genetic essentialism: On the deceptive determinism of DNA. Psychological Bulletin, 137(5), 800-818.

Daston, L. (2014). The naturalistic fallacy is modern. Isis, 105(3), 579-587. doi: $10.1086 / 678173$ 
Destin, M., Rheinschmidt-Same, M., \& Richeson, J. A. (2017). Status-based identity: A conceptual approach integrating the social psychological study of socioeconomic status and identity. Perspectives on Psychological Science, 12(2), 270-289. doi: $10.1177 / 1745691616664424$

Deutch, C. E. (2018). Mendel or molecules first: What is the best approach for teaching general genetics? The American Biology Teacher, 80(4), 264-269. https://doi.org/10.1525/abt.2018.80.4.264

Dewsbury, B., \& Brame, C. J. (2019). Inclusive teaching. CBE-Life Sciences Education, 18(2). doi: 10.1187/cbe.19-01-0021

Dhull, I., \& Kumar, N. (2012). Development of moral reasoning in the context of intelligence and socio-economic status following value clarification. Journal of Education and Practice, 3(14), 33-38.

Donovan, B. M. (2014). Playing with fire? The impact of the hidden curriculum in school genetics on essentialist conceptions of race. Journal of Research in Science Teaching, 51(4), 462-496. doi:10.1002/tea.21138

Donovan, B. M. (2016). Framing the genetics curriculum for social justice: An experimental exploration of how the biology curriculum influences beliefs about racial difference. Science Education, 100(3), 586-616. doi:10.1002/sce.21221

Donovan, B. M. (2017). Learned inequality: Racial labels in the biology curriculum can affect the development of racial prejudice. Journal of Research in Science Teaching, 54(3), 379-411. https://doi.org/10.1002/tea.21370

Donovan, B. M., Semmens, R., Keck, P., Brimhall, E., Busch, K. C., Weindling, M., Duncan, A., Stuhlsatz, M., Bracey, Z. B., Bloom, M., Kowalski, S., Salazar, B. 
(2019a). Toward a more humane genetics education: Learning about the social and quantitative complexities of human genetic variation research could reduce racial bias in adolescent and adult populations. Science Education, 103(3), 529-560. https://doi.org/10.1002/sce.21506

Donovan, B. M., Stuhlsatz, M. A. M., Edelson, D. C., \& Bracey, Z. E. B. (2019b). Gendered genetics: How reading about the genetic basis of sex differences in biology textbooks could affect beliefs associated with science gender disparities. Science Education, 103(4), 719-749. https://doi.org/10.1002/sce.21502

Donovan, B. M., Weindling, M., Salazar, B., Duncan, A., Stuhlsatz, M., \& Keck, P. (2020). Genomics literacy matters: Supporting the development of genomics literacy through genetics education could reduce the prevalence of genetic essentialism. Journal of Research in Science Teaching, 1-31. https://doi.org/10.1002/tea.21670

Doudna, J. A. (2018). Prologue: The wave [Preface]. In 967767390751804567 J. A. Doudna \& 967767391751804567 S. H. Sternberg (Authors), A crack in creation: Gene editing and the unthinkable power to control evolution (pp. Xi-Xx). Boston: Marine Books.

Dougherty, M. J. (2009). Closing the gap: Inverting the genetics curriculum to ensure an informed public. The American Journal of Human Genetics, 85(1), 6-12. doi:10.1016/j.ajhg.2009.05.010 Dougherty, M. J. (2010). It's time to overhaul our outdated genetics curriculum. The American Biology Teacher, 72(4), 218-218. doi:10.1525/abt.2010.72.4.2 
Dougherty, M., Pleasants, C., Solow, L., Wong, A., \& Zhang, H. (2011). A comprehensive analysis of high school genetics standards: Are states keeping pace with modern genetics? CBE_Life Sciences Education, 10(3), 318-327. https://doi.org/10.1187/cbe.10-09-0122

Downie, R., \& Clarkeburn, H. (2005). Approaches to the teaching of bioethics and professional ethics in undergraduate courses. Bioscience Education, 5(1), 1-9. https://doi.org/10.3108/beej.2005.05000003

Doyle, A. E., Willcutt, E. G., Seidman, L. J., Biederman, J., Chouinard, V.-A., Silva, J., \& Faraone, S. V. (2005). Attention-deficit/hyperactivity disorder endophenotypes. Biological Psychiatry, 57(11), 1324-1335.

https://doi.org/10.1016/j.biopsych.2005.03.015

Ebert-May, D., Brewer, C., \& Allred, S. (1997). Innovation in large lectures: Teaching for active learning. BioScience, 47(9), 601-607. https://doi.org/10.2307/1313166

Eidson, R. C., \& Coley, J. D. (2014). Not so fast: Reassessing gender essentialism in young adults. Journal of Cognition and Development, 15(2), 382-392. doi:10.1080/15248372.2013.763810

Evans, M., \& Rosenthal, J. S. (2010). Probability and statistics: The science of uncertainty (2nd ed.). New York: W.H. Freeman and Co.

Falk, R. (2014). The allusion of the gene: Misunderstandings of the concepts heredity and gene. Science \& Education, 23(2), 273-284. doi:10.1007/s11191-012-9510-4

Fitzgerald, B., Morgan, J., Keene, N., Rollinson, R., Hodgson, A., \& Dalrymple-Smith, J. (2000). An investigation into diet treatment for adults with previously untreated 
phenylketonuria and severe intellectual disability. Journal of Intellectual Disability

Research, 44(1), 53-59. doi:10.1046/j.1365-2788.2000.00260.x

Fleming, R. (1986). Adolescent reasoning in socio-scientific issues, part I: Social cognition. Journal of Research in Science Teaching, 23(8), 677-687. doi: 10.1002/tea.3660230803

Freeman, S., Eddy, S. L., McDonough, M., Smith, M. K., Okoroafor, N., Jordt, H., \& Wenderoth, M. P. (2014). Active learning increases student performance in science, engineering, and mathematics. Proceedings of the National Academy of Sciences of the United States of America, 111(23), 8410-8415. https://doi.org/10.1073/pnas.1319030111

Freeman, S., O'connor, E., Parks, J. W., Cunningham, M., Hurley, D., Haak, D., Dirks, C., \& Wenderoth, M. P. (2007). Prescribed Active Learning Increases Performance in Introductory Biology. CBE—Life Sciences Education, 6(2), 132139. https://doi.org/10.1187/cbe.06-09-0194

Freidus, A., \& Noguera, P. A. (2017). Making difference matter: Teaching and learning in desegregated classrooms. The Teacher Educator, 52(2), 99-113. doi: $10.1080 / 08878730.2017 .1294925$

Friedmann, T. (2019). Genetic therapies, human genetic enhancement, and ... eugenics? Gene Therapy, 26(9), 351-353. doi: 10.1038/s41434-019-0088-1

Frisell, T., Pawitan, Y., Långström, N., \& Lichtenstein, P. (2012). Heritability, assortative mating and gender differences in violent crime: Results from a total population sample using twin, adoption, and sibling models. Behavior Genetics, 42(1), 3-18. https://doi.org/10.1007/s10519-011-9483-0 
Gandhi, R., Frank, M. B., Crane, E., Tannenbaum, J., \& Elliott, K. (2009). Module 3. In Exploring bioethics. essay, Education Development Center.

Garver, K. L., \& Garver, B. (1991). Eugenics: Past, present, and the future. Human Genetics Education, 49, 1109-1118.

Gelman, S. A. (2003). The essential child: Origins of essentialism in everyday thought. New York: Oxford University Press.

Gelman, S. A., \& Rhodes, M. (2012). "Two-thousand years of stasis": How psychological essentialism impedes evolutionary understanding. In K. S. Rosengren, S. K. Brem, M. E. Evans, \& G. M. Sinatra (Eds.), Evolution challenges (pp. 3-21). Oxford: Oxford University Press. doi:10.1093/acprof:oso/9780199730421.003.0001

Gericke, N. M., \& Hagberg, M. (2007). Definition of historical models of gene function and their relation to students' understanding of genetics. Science \& Education, 16(7-8), 849-881. doi:10.1007/s11191-006-9064-4

Gericke, N. M., \& Hagberg, M. (2010a). Conceptual incoherence as a result of the use of multiple historical models in school textbooks. Research in Science Education, 40(4), 605-623. doi:10.1007/s11165-009-9136-y

Gericke, N. M., \& Hagberg, M. (2010b). Conceptual variation in the depiction of gene function in upper secondary school textbooks. Science \& Education, 19(10), 963994. doi:10.1007/s11191-010-9262-y

Gericke, N. M., Hagberg, M., Santos, V. C., Joaquim, L. M., \& El-Hani, C. N. (2014). Conceptual variation or incoherence? Textbook discourse on genes in six countries. Science \& Education, 23(2), 381-416. doi:10.1007/s11191-012-9499-8 
Gericke, N., Carver, R., Castéra, J., Evangelista, N. A., Marre, C. C., \& El-Hani, C. N. (2017). Exploring relationships among belief in genetic determinism, genetics knowledge, and social factors. Science \& Education, 26(10), 1223-1259. doi:10.1007/s11191-017-9950-y

Gericke, N., Hagberg, M., \& Jorde, D. (2013). Upper secondary students’ understanding of the use of multiple models in biology textbooks - The importance of conceptual variation and incommensurability. Research in Science Education, 43(2), 755-780. doi:10.1007/s11165-012-9288-z

Gerson, M. W., \& Neilson, L. (2014). The importance of identity development, principled moral reasoning, and empathy as predictors of openness to diversity in emerging adults. SAGE Open, 4(4), 215824401455358. doi:

$10.1177 / 2158244014553584$

Gilligan, C. (1982). In a different voice: Psychological theory and womens development. Cambridge, MA: Harvard University Press.

Gleason, B. L., Peeters, M. J., Resman-Targoff, B. H., Karr, S., Mcbane, S., Kelley, K., Thomas, T., \& Denetclaw, T. H. (2011). An Active-Learning Strategies Primer for Achieving Ability-Based Educational Outcomes. American Journal of Pharmaceutical Education, 75(9), 186. https://doi.org/10.5688/ajpe759186

Glossary and key to acronyms. (2019, March 8). Retrieved May 10, 2020, from https://ncses.nsf.gov/pubs/nsf19304/digest/glossary-and-key-to-acronyms

Gould, W. A., \& Heine, S. J. (2012). Implicit essentialism: Genetic concepts are implicitly associated with fate concepts. PLoS ONE, 7(6). doi:10.1371/journal.pone.0038176 
Gunderson, M. (2007). Seeking perfection: A Kantian look at human genetic engineering. Theoretical Medicine and Bioethics, 28(2), 87-102. doi: $10.1007 / \mathrm{s} 11017-007-9030-4$

Haidt, J., Koller, S. H., \& Dias, M. G. (1993). Affect, culture, and morality, or is it wrong to eat your dog? Journal of Personality and Social Psychology, 65(4), 613-628.

Hammond, J. (2010). Genetic engineering to avoid genetic neglect: From chance to responsibility. Bioethics, 24(4), 160-169. doi: 10.1111/j.1467-8519.2008.00685.x

Haslam, N., Bastian, B., Bain, P., \& Kashima, Y. (2006). Psychological essentialism, implicit theories, and intergroup relations. Group Processes \& Intergroup Relations, 9(1), 63-76. doi:10.1177/1368430206059861

Haslam, N., Rothschild, L., \& Ernst, D. (2000). Essentialist beliefs about social categories. British Journal of Social Psychology, 39(1), 113-127. doi:10.1348/014466600164363

Haslam, N., Rothschild, L., \& Ernst, D. (2002). Are essentialist beliefs associated with prejudice? British Journal of Social Psychology, 41(1), 87-100. doi:10.1348/014466602165072

Henderson, C., Beach, A., \& Finkelstein, N. (2011). Facilitating change in undergraduate STEM instructional practices: An analytic review of the literature. Journal of Research in Science Teaching, 48(8), 952-984. https://doi.org/10.1002/tea.20439

Holvino, E. (2008). Intersections: The simultaneity of race, gender and class in organization studies. Gender, Work \& Organization, 17(3), 248-277. https://doi.org/10.1111/j.1468-0432.2008.00400.x 
Holvino, E. (2008). Intersections: The simultaneity of race, gender and class in organization studies. Gender, Work \& Organization, 17(3), 248-277. https://doi.org/10.1111/j.1468-0432.2008.00400.x

Human Genome Editing Initiative. (n.d.). Retrieved from https://www.nationalacademies.org/our-work/human-gene-editing-initiative

Jaffee, S., \& Hyde, J. S. (2000). Gender differences in moral orientation: A metaanalysis. Psychological Bulletin, 126(5), 703-726. doi: 10.1037/00332909.126.5.703

Jamie, S. (2011, May 15). The man who was cured of HIV. Retrieved from http://sitn.hms.harvard.edu/flash/2011/issue93/

Jamieson, A., \& Radick, G. (2017). Genetic determinism in the genetics curriculum: An exploratory study of the effects of Mendelian and Weldonian emphases. Science \& Education, 26(10), 1261-1290. doi:10.1007/s11191-017-9900-8

Jayaratne, T. E., Ybarra, O., Sheldon, J. P., Brown, T. N., Feldbaum, M., Pfeffer, C. A., \& Petty, E. M. (2006). White Americans' genetic lay theories of race differences and sexual orientation: Their relationship with prejudice toward Blacks, and gay men and lesbians. Group Processes \& Intergroup Relations, 9(1), 77-94. doi:10.1177/1368430206059863

Jinek, M., Chylinski, K., Fonfara, I., Hauer, M., Doudna, J. A., \& Charpentier, E. (2012). A Programmable Dual-RNA-Guided DNA Endonuclease in Adaptive Bacterial Immunity. Science, 337(6096), 816-821. doi:10.1126/science.1225829Jinek, M., East, A., Cheng, A., Lin, S., Ma, E., \& Doudna, J. (2013). RNA-programmed genome editing in human cells. Elife, 2, e00471. doi:10.7554/eLife.00471 
Johansen, C. K., \& Harris, D. E. (2000). Teaching the ethics of biology. The American Biology Teacher, 62(5), 352-358. https://doi.org/10.2307/4450918

Johnson, D. W., Johnson, R. T., \& Smith, K. A. (1991). Active learning: cooperation in the college classroom. Interaction Book Co.

Josephine, J. (2018, November 29). Gene editing will force us to deal with a moral quandary. Retrieved from https://www.statnews.com/2018/11/29/what-makesgood-parenting-age-gene-editing/ Kaufman, D., Sutow, E., \& Dunn, K. (1997). Three approaches to cooperative learning in higher education. The Canadian Journal of Higher Education, 27(2), 37-66.

Kampourakis, K. (2017). Making sense of genes. Cambridge: Cambridge University Press.

Keller, E. F. (2005). The century beyond the gene. Journal of Biosciences, 30(1), 3-10. doi:10.1007/bf02705144

Keller, J. (2005). In genes we trust: The biological component of psychological essentialism and its relationship to mechanisms of motivated social cognition. Journal of Personality and Social Psychology, 88(4), 686-702. doi:10.1037/00223514.88 .4 .686

Kemaladewi, D. U., Bassi, P. S., Erwood, S., Al-Basha, D., Gawlik, K. I., Lindsay, K., Hyatt, E., Kember, R., Place, K. M., Marks, R. M., Durbeej, M., Prescott, S. A., Ivakine, E. A., \& Cohn, R. D. (2019). A mutation-independent approach via transcriptional upregulation of a disease modifier gene rescues muscular dystrophy in vivo. Nature, 572, 125-130. doi:10.1101/286500

Kendler, K. S., Maes, H. H., Lönn, S. L., Morris, N. A., Lichtenstein, P., Sundquist, J., \& Sundquist, K. (2015). A Swedish national twin study of criminal behavior and its 
violent, white-collar and property subtypes. Psychological Medicine, 45(11), 2253-2262. https://doi.org/10.1017/s0033291714002098

Keyser, M. W. (2000). Active learning and cooperative learning: understanding the difference and using both styles effectively. Research Strategies, 17(1), 35-44. https://doi.org/10.1016/s0734-3310(00)00022-7

Kim, R. Y. (2011). Religion and ethnicity: Theoretical connections. Religions, 2(3), 312329. doi:10.3390/rel2030312

Kim, S. Y., \& Irving, K. E. (2009). History of science as an instructional context: Student learning in genetics and nature of science. Science \& Education, 19(2), 187-215. doi: 10.1007/s11191-009-9191-9

King, P. M., \& Mayhew, M. J. (2002). Moral judgement development in higher education: Insights from the defining issues test. Journal of Moral Education, 31(3), 247-270. doi: 10.1080/0305724022000008106

Kitcher, P. (2004). Responsible biology. BioScience, 54(4), 331. https://doi.org/10.1641/0006-3568(2004)054[0331:rb]2.0.co;2

Kleinstiver, B. P., Pattanayak, V., Prew, M. S., Tsai, S. Q., Nguyen, N. T., Zheng, Z., \& Joung, J. K. (2016). High-fidelity CRISPR-Cas9 nucleases with no detectable genome-wide off-target effects. Nature, 529(7587), 490-495. doi:10.1038/nature16526

Klemmensen, R., Hatemi, P. K., Hobolt, S. B., Skytthe, A., \& Nørgaard, A. S. (2012). Heritability in Political Interest and Efficacy across Cultures: Denmark and the United States. Twin Research and Human Genetics, 15(1), 15-20. https://doi.org/10.1375/twin.15.1.15 
Klionsky, D. J. (2004). Points of view: Lectures: Can't learn with them, can't learn without them: Talking biology: Learning outside the book — and the lecture. Cell Biology Education, 3(4), 204-211. https://doi.org/10.1187/cbe.04-07-0055

Knight, J. K., \& Smith, M. K. (2010). Different but equal? How nonmajors and majors approach and learn genetics. CBE_Life Sciences Education, 9(1), 34-44. doi:10.1187/cbe.09-07-0047

Kohlberg, L. (1981). The philosophy of moral development: Moral stages and the idea of justice. Cambridge: Harper \& Row.

Kolata, G., \& Belluck, P. (2018, December 05). Why Are Scientists So Upset About the First Crispr Babies? Retrieved from https://www.nytimes.com/2018/12/05/health/crispr-gene-editing-embryos.html

Krimsky, S. (2019). The moral choices on CRISPR babies. The American Journal of Bioethics, 19(10), 15-16. doi: 10.1080/15265161.2019.1644824

Ksiazkiewicz, A., \& Krueger, R. F. (2017). The Role of Genes and Environments in Linking the Need to Evaluate with Political Ideology and Political Extremity. Social Justice Research, 30(4), 381-407. https://doi.org/10.1007/s11211-0170292-3

Lander, E. (2016). The heroes of CRISPR. Cell, 164(1-2), 18-28. doi:10.1016/j.cell.2015.12.041Lee, H., Chang, H., Choi, K., Kim, S.-W., \& Zeidler, D. L. (2012). Developing character and values for global citizens: Analysis of pre-service science teachers' moral reasoning on socioscientific issues. International Journal of Science Education, 34(6), 925-953. doi: $10.1080 / 09500693.2011 .625505$ 
Ledford, H. (2019). CRISPR babies: When will the world be ready? Nature, 570(7761), 293-296. https://doi.org/10.1038/d41586-019-01906-z

Lemke, J. L. (2001). Articulating communities: Sociocultural perspectives on science education. Journal of Research in Science Teaching, 38(3), 296-316. doi: 10.1002/1098-2736(200103)38:3<296::aid-tea1007>3.0.co;2-r

Leonard, M. J., Kalinowski, S. T., \& Andrews, T. C. (2014). Misconceptions yesterday, today, and tomorrow. CBE-Life Sciences Education, 13(2), 179-186. https://doi.org/10.1187/cbe.13-12-0244

Lewis, C., \& Moje, E. B. (2003). Sociocultural perspectives meet critical theories. International Journal of Learning, 10, 1979-1995.

Li, J.-R., Walker, S., Nie, J.-B., \& Zhang, X.-Q. (2019). Experiments that led to the first gene-edited babies: the ethical failings and the urgent need for better governance. Journal of Zhejiang University-SCIENCE B, 20(1), 32-38. https://doi.org/10.1631/jzus.b1800624

Lichtenstein, P., Yip, B. H., Björk, C., Pawitan, Y., Cannon, T. D., Sullivan, P. F., \& Hultman, C. M. (2009). Common genetic determinants of schizophrenia and bipolar disorder in Swedish families: a population-based study. The Lancet, 373(9659), 234-239. https://doi.org/10.1016/s0140-6736(09)60072-6

Lobo, D. S. S., \& Kennedy, J. L. (2009). Genetic aspects of pathological gambling: a complex disorder with shared genetic vulnerabilities. Addiction, 104(9), 14541465. https://doi.org/10.1111/j.1360-0443.2009.02671.x

Lockdown Browser (Version 4.0) [Computer software]. (n.d.). Retrieved from https://web.respondus.com/k12/respondus/ 
Loike, J. D., Rush, B. S., Schweber, A., \& Fischbach, R. L. (2013). Lessons learned from undergraduate students in designing a science-based course in bioethics. $C B E-$ Life Sciences Education, 12(4), 701-710. https://doi.org/10.1187/cbe.13-01-0012

Lynch, K. E., Morandini, J. S., Dar-Nimrod, I., \& Griffiths, P. E. (2018). Causal Reasoning About Human Behavior Genetics: Synthesis and Future Directions. Behavior Genetics, 49(2), 221-234. doi:10.1007/s10519-018-9909-z

Martin, A., Wolcott, N. S., \& O'connell, L. A. (2020). Bringing immersive science to undergraduate laboratory courses using CRISPR gene knockouts in frogs and butterflies. The Journal of Experimental Biology, 223(Suppl 1). https://doi.org/10.1242/jeb.208793

Martin, C. L., \& Parker, S. (1995). Folk theories about sex and race differences. Personality and Social Psychology Bulletin, 21(1), 45-57. doi:10.1177/0146167295211006

Martuzzi, M., \& Tickner, J. (2004). The precautionary principle: Protecting public health, the environment and the future of our children. Copenhagen: WHO Regional Office for Europe.

Mayhew, M. J. (2012). A multilevel examination of the influence of institutional type on the moral reasoning development of first-year Students. The Journal of Higher Education, 83(3), 367-388. doi: 10.1353/jhe.2012.0020

Mayhew, M. J., \& Engberg, M. E. (2010). Diversity and moral reasoning: How negative diverse peer interactions affect the development of moral reasoning in undergraduate students. The Journal of Higher Education, 81(4), 459-488. doi: 10.1353/jhe.0.0104 
Mcconnell, D. A., Steer, D. N., \& Owens, K. D. (2003). Assessment and active learning strategies for introductory geology courses. Journal of Geoscience Education, 51(2), 205-216. https://doi.org/10.5408/1089-9995-51.2.205

Mehta, S. S., Newbold, J. J., \& O'Rourke, M. A. (2011). Why do first-generation students fail? College Student Journal, 45(1), 20-35.

Mehta, S. S., Newbold, J. J., \& O'Rourke, M. A. (2011). Why do first-generation students fail? College Student Journal, 45(1), 20-35.

Meyer, L. M. N., Bomfim, G. C., \& El-Hani, C. N. (2013). How to understand the gene in the twenty-first century? Science \& Education, 22(2), 345-374. https://doi.org/10.1007/s11191-011-9390-z

Miller, C. J., Mcnear, J., \& Metz, M. J. (2013). A comparison of traditional and engaging lecture methods in a large, professional-level course. Advances in Physiology Education, 37(4), 347-355. https://doi.org/10.1152/advan.00050.2013

Moll, L. C., Amanti, C., Neff, D., \& Gonzalez, N. (1992). Funds of knowledge for teaching: Using a qualitative approach to connect homes and classrooms. Theory into Practice, 31(2), 132-141.

Moreland, C., \& Leach, M. M. (2001). The relationship between Black racial identity and moral development. Journal of Black Psychology, 27(3), 255-271. doi: $10.1177 / 0095798401027003001$

Morton, T. R., \& Parsons, E. C. (2018). \#BlackGirlMagic: The identity conceptualization of Black women in undergraduate STEM education. Science Education, 102(6), 1363-1393. https://doi.org/10.1002/sce.21477 
Moss, L. (2008). The meanings of the gene and the future of the phenotype. Genomics, Society and Policy, 4(1). doi:10.1186/1746-5354-4-1-38

National Research Council. (1996). National science education standards. Washington, DC: The National Academies Press. https://doi.org/10.17226/4962

Newman, G. E., \& Knobe, J. (2019). The essence of essentialism. Mind \& Language, 34(5), 585-605. doi:10.1111/mila.12226

Nucci, L. (2016). Recovering the role of reasoning in moral education to address inequity and social justice. Journal of Moral Education, 45(3), 291-307. doi: $10.1080 / 03057240.2016 .1167027$

Nunnally, J. C. (1978). Psychometric theory. McGraw-Hill.

NVivo Version 11, NVivo Qualitative Data Analysis Software. 2015, QSR International Pty Limited. Retrieved from: https://www.qsrinternational.com/nvivo-qualitativedata-analysis-software/home

Öhman, J., \& Östman, L. (2007). Continuity and change in moral meaning-making-a transactional approach. Journal of Moral Education, 36(2), 151-168. doi: $10.1080 / 03057240701325258$

Parsons, E. C. (2001). Using power and caring to mediate White male privilege, equality, and equity in an urban elementary classroom: Implications for teacher preparation. The Urban Review, 33(4), 321-338.

Piaget, J. (1972). Intellectual Evolution from Adolescence to Adulthood. Human Development, 15(1), 1-12. doi: 10.1159/000271225 
Pollack, A. (2014, March 3). A powerful new way to edit DNA. Retrieved from https://www.nytimes.com/2014/03/04/health/a-powerful-new-way-to-edit$\underline{\text { dna.html }}$

Posner, G. J., Strike, K. A., Hewson, P. W., \& Gertzog, W. A. (1982). Accommodation of a scientific conception: Toward a theory of conceptual change. Science Education, 66(2), 211-227. https://doi.org/10.1002/sce.3730660207

Powell, M., \& Ansic, D. (1997). Gender differences in risk behaviour in financial decision-making: An experimental analysis. Journal of Economic Psychology, 18(6), 605-628. doi: 10.1016/s0167-4870(97)00026-3

Prentice, D. A., \& Miller, D. T. (2007). Psychological essentialism of human categories. Current Directions in Psychological Science, 16(4), 202-206. doi:10.1111/j.14678721.2007.00504.x

Prince, M. (2004). Does active learning work? A review of the research. Journal of Engineering Education, 93(3), 223-231. https://doi.org/10.1002/j.21689830.2004.tb00809.x

Ran, F. A., Hsu, P. D., Wright, J., Agarwala, V., Scott, D. A., \& Zhang, F. (2013). Genome engineering using the CRISPR-Cas9 system. Nat Protoc, 8(11), 22812308. doi:10.1038/nprot.2013.143

Raposo, V. L. (2019). The first chinese edited babies: A leap of faith in science. JBRA Assisted Reproduction. https://doi.org/10.5935/1518-0557.20190042

Reardon, S. (2016). The CRISPR zoo. Nature, 531, 160-163. 
Resnik, D. B., \& Vorhaus, D. B. (2006). Genetic modification and genetic determinism. Philosophy, Ethics, and Humanities in Medicine, 1(1), 1-11. https://doi.org/10.1186/1747-5341-1-9

Rest, J. (1974). Judging the important issues in moral dilemmas: An objective measure of development. Developmental Psychology, 10(4), 491-501. doi: $10.1037 / \mathrm{h} 0036598$

Rest, J. R., Narvaez, D., Thoma, S. J., \& Bebeau, M. J. (1999). DIT2: Devising and testing a revised instrument of moral judgment. Journal of Educational Psychology, 91(4), 644-659. doi: 10.1037/0022-0663.91.4.644

Rogers, L. O., \& Meltzoff, A. N. (2017). Is gender more important and meaningful than race? An analysis of racial and gender identity among Black, White, and mixedrace children. Cultural Diversity and Ethnic Minority Psychology, 23(3), 323334. https://doi.org/10.1037/cdp0000125

Roth, W. D., Yaylac1, Ş, Jaffe, K., \& Richardson, L. (2020). Do genetic ancestry tests increase racial essentialism? Findings from a randomized controlled trial. Plos One, 15(1). doi:10.1371/journal.pone.0227399

Rubin, M., \& Wright, C. L. (2014). Age differences explain social class differences in students' friendship at university: Implications for transition and retention. Higher Education, 70(3), 427-439. doi: 10.1007/s10734-014-9844-8

Russa, M. F., \& Qi, L. S. (2015). The new state of the art: Cas9 for gene activation and repression. Molecular and Cellular Biology, 35(22), 3800-3809.

doi:10.1128/mcb.00512-15 
Sadler, T. D. (2004a). Informal reasoning regarding socioscientific issues: A critical review of research. Journal of Research in Science Teaching, 41(5), 513-536. doi: 10.1002/tea.20009

Sadler, T. D. (2004b). Moral and ethical dimensions of socioscientific decision-making as integral components of scientific literacy. Science Educator, 13(1), 39-48.

Sadler, T. D., Amirshokoohi, A., Kazempour, M., \& Allspaw, K. M. (2006). Socioscience and ethics in science classrooms: Teacher perspectives and strategies. Journal of Research in Science Teaching, 43(4), 353-376. https://doi.org/10.1002/tea.20142

Sadler, T. D., \& Donnelly, L. A. (2006). Socioscientific argumentation: The effects of content knowledge and morality. International Journal of Science Education, 28(12), 1463-1488. doi: 10.1080/09500690600708717

Sadler, T. D., \& Zeidler, D. L. (2003). The morality of socioscientific issues: Construal and resolution of genetic engineering dilemmas. Science Education, 88(1), 4-27. doi: $10.1002 /$ sce. 10101

Sadler, T. D., \& Zeidler, D. L. (2004). The significance of content knowledge for informal reasoning regarding socioscientific issues: Applying genetics knowledge to genetic engineering issues. Science Education, 89(1), 71-93. doi: $10.1002 /$ sce. 20023

Sagoff, M. (2001). Genetic engineering and the concept of the natural. Retrieved October 9, 2020, from https://ecommons.cornell.edu/handle/1813/49935

Saldaña, J. (2016). The coding manual for qualitative researchers. Los Angeles, CA: SAGE. 
Salk, R. H. \& Hyde, J. S. (2012). Contemporary genetics for gender researchers: Not your grandma's genetics anymore. Psychology of Women Quarterly, 36(4), 395410.

Santos, V. C., Joaquim, L. M., \& El-Hani, C. N. (2012). Hybrid deterministic views about genes in biology textbooks: A key problem in genetics teaching. Science \& Education, 21(4), 543-578. doi:10.1007/s11191-011-9348-1

Schechter, M. S. (2011). Nongenetic influences on cystic fibrosis outcomes. Current Opinion in Pulmonary Medicine, 1. doi:10.1097/mcp.0b013e32834ba899

Schwartz, S. H. (1992). Universals in the content and structure of values: Theoretical advances and empirical tests in 20 Countries. Advances in Experimental Social Psychology, 25(1), 1-65. doi: 10.1016/s0065-2601(08)60281-6

Shaw, D. (2020). The consent form in the Chinese CRISPR study: In search of ethical gene editing. Journal of Bioethical Inquiry, 17(1), 5-10. https://doi.org/10.1007/s11673-019-09953-X

Shostak, S., Freese, J., Link, B. G., \& Phelan, J. C. (2009). The politics of the gene: Social status and beliefs about genetics for individual outcomes. Social Psychology Quarterly, 72(1), 77-93. doi:10.1177/019027250907200107

Shtulman, A., \& Schulz, L. (2008). The relation between essentialist beliefs and evolutionary reasoning. Cognitive Science: A Multidisciplinary Journal, 32(6), 1049-1062. doi:10.1080/03640210801897864

Siani, M., \& Assaraf, O. B.-Z. (2015). The moral reasoning of genetic dilemmas amongst Jewish Israeli undergraduate students with different religious affiliations and 
scientific backgrounds. Journal of Genetic Counseling, 25(3), 596-609. doi: $10.1007 / \mathrm{s} 10897-015-9918-5$

Skadhauge, L., Christensen, K., Kyvik, K., \& Sigsgaard, T. (1999). Genetic and environmental influence on asthma: a population-based study of 11,688 Danish twin pairs. European Respiratory Journal, 13(1), 8-14. https://doi.org/10.1183/09031936.99.13100899

Slutske, W. S., Zhu, G., Meier, M. H., \& Martin, N. G. (2010). Genetic and environmental influences on disordered gambling in men and women. Archives of General Psychiatry, 67(6), 624. https://doi.org/10.1001/archgenpsychiatry.2010.51

Smiler, A. P., \& Gelman, S. A. (2008). Determinants of gender essentialism in college students. Sex Roles, 58(11-12), 864-874. doi:10.1007/s11199-008-9402-х

Smith, M. K., \& Knight, J. K. (2012). Using the genetics concept assessment to document persistent conceptual difficulties in undergraduate genetics courses. Genetics, 191(1), 21-32. https://doi.org/10.1534/genetics.111.137810

Smith, M. K., Wood, W. B., \& Knight, J. K. (2008). The genetics concept assessment: A new concept inventory for gauging student understanding of genetics. CBE-Life Sciences Education, 7(4), 422-430. doi:10.1187/cbe.08-08-0045

Smith, M. U., \& Adkison, L. R. (2010). Updating the model definition of the gene in the modern genomic era with implications for instruction. Science \& Education, 19(1), 1-20. doi:10.1007/s11191-008-9161-7

Smith, M. U., \& Gericke, N. M. (2015). Mendel in the modern classroom. Science \& Education, 24(1-2), 151-172. doi:10.1007/s11191-013-9629-y 
Steele, C. M. (1997). A threat in the air: How stereotypes shape intellectual identity and performance. American Psychologist, 52(6), 613-629. https://doi.org/10.1037/0003-066x.52.6.613

Steneck, N. H. (2004). Ori introduction to the responsible conduct of research. Rockville, MD: U.S. Dept. of Health and Human Services, Office of Research Integrity.

Stern, F., Kampourakis, K., Delaval, M., \& Müller, A. (2020). Development and validation of a questionnaire measuring secondary students' genetic essentialism and teleology (GET) conceptions. International Journal of Science Education, 42(2), 218-252. doi:10.1080/09500693.2019.1707905

Strand, S., \& Boes, K. E. (2019). Drawing a link between genetic inheritance and meiosis: A set of exercises for the undergraduate biology classroom $\uparrow$. Journal of Microbiology \& Biology Education, 20(2). https://doi.org/10.1128/jmbe.v20i2.1733

Subramaniam, B. (2014). Ghost stories for Darwin: The science of variation and the politics of diversity. Urbana, IL: University of Illinois Press.

Summa, S. D., Graziano, F., Pilato, B., Pinto, R., Danza, K., Lacalamita, R., Serratì, S., Sambiasi, D., Grassi, M., Tommasi, S. (2017). Six low-penetrance SNPs for the estimation of breast cancer heritability: A family-based study in Caucasian Italian patients. Oncology Letters, 14(4), 4384-4390. https://doi.org/10.3892/ol.2017.6725

Tagliabue, G. (2016). The precautionary principle: Its misunderstandings and misuses in relation to "GMOs." New Biotechnology, 33(4), 437-439. doi:

10.1016/j.nbt.2016.02.007 
Tate, K. A., Caperton, W., Kaiser, D., Pruitt, N. T., White, H., \& Hall, E. (2015). An exploration of first-generation college students' career development beliefs and experiences. Journal of Career Development, 42(4), 294-310. doi: $10.1177 / 0894845314565025$

Tavakol, M., \& Dennick, R. (2011). Making sense of Cronbach's alpha. International Journal of Medical Education, 2, 53-55. doi:10.5116/ijme.4dfb.8dfd

Taylor, S. (2011). A population-based survey in Australia of men's and women's perceptions of genetic risk and predictive genetic testing and implications for primary care. Public Health Genomics, 14(6), 325-336.

Terenzini, P. T., Springer, L., Yaeger, P. M., Pascarella, E. T., \& Nora, A. (1996). Firstgeneration college students: Characteristics, experiences, and cognitive development. Research in Higher Education, 37(1), 1-22. doi:

10.1007/bf01680039

Thomsen, S. F., Sluis, S. V. D., Kyvik, K. O., Skytthe, A., \& Backer, V. (2010). Estimates of asthma heritability in a large twin sample. Clinical \& Experimental Allergy, 40(7), 1054-1061. https://doi.org/10.1111/j.1365-2222.2010.03525.x

Titus, M. A. (2006). Understanding college degree completion of students with low socioeconomic status: The influence of the institutional financial context. Research in Higher Education, 47(4), 371-398. doi: 10.1007/s11162-005-9000-5

Tygart, C. E. (2000). Genetic causation attribution and public support of gay rights. International Journal of Public Opinion Research, 12(3), 259-275.

doi:10.1093/ijpor/12.3.259 
Uher, R. (2014). Gene environment interactions in severe mental illness. Frontiers in Psychiatry, 5. https://doi.org/10.3389/fpsyt.2014.00048

Ullemar, V., Magnusson, P. K. E., Lundholm, C., Zettergren, A., Melén, E., Lichtenstein, P., \& Almqvist, C. (2016). Heritability and confirmation of genetic association studies for childhood asthma in twins. Allergy, 71(2), 230-238.

$\underline{\text { https://doi.org/10.1111/all.12783 }}$

Vera-Estay, E., Seni, A. G., Champagne, C., \& Beauchamp, M. H. (2016). All for one:

Contributions of age, socioeconomic factors, executive functioning, and social cognition to moral reasoning in childhood. Frontiers in Psychology, 7. doi:10.3389/fpsyg.2016.00227

Villarroel, J. D., Nuño, T., Eulate, L. P. D., Etxabe, J. M., Díez, J. R., \& Ruipérez, T. (2012). A Study of the Relationship between the Understanding of the Basic Genetic Concepts and Perspectives Regarding Genetically Modified Products and Local Production among Undergraduate and High School Students. Procedia Social and Behavioral Sciences, 46, 204-208. https://doi.org/10.1016/j.sbspro.2012.05.094

Vizcarrondo, F. E. (2014). Human enhancement: The new eugenics. The Linacre Quarterly, 81(3), 239-243. https://doi.org/10.1179/2050854914y.0000000021

Vygotsky, L. S. (1978). Mind in society: the development of higher psychological processes. (M. Cole, V. John-Steiner, S. Scribner, \& E. Souberman, Eds.). Cambridge, Mass: Harvard University Press.

Weber, R. P. (1990). Basic Content Analysis (2nd ed.). Newbury Park, CA: Sage Publications. 
Wenz, P. (2005). Engineering genetic injustice. Bioethics, 19(1), 1-11. doi:

10.1111/j.1467-8519.2005.00421.x

Widiyawati, Y. (2020). Global warming \& climate change: Integration of socio-scientific issues to enhance scientific literacy. Journal of Physics: Conference Series, 1511, 1-11. https://doi.org/doi:10.1088/1742-6596/1511/1/012071

Wilkins, J. (2013). Essentialism in biology. In K. Kampourakis (Ed.), The philosophy of biology: A companion for educators (pp. 395-420). Dordrecht: Springer.

Willemsen, G., Ward, K. J., Bell, C. G., Christensen, K., Bowden, J., Dalgård, C., Harris, J. R., Kaprio, J., Lyle, R., Magnusson, P.K.e., Mather, K. A., Ordoňana, J. R., Perez-Riquelme, F., Pedersen, N.L., Pietiläinen, K. H., Sachdev, P. S., Boomsma, D. I., \& Spector, T. (2015). The Concordance and Heritability of Type 2 Diabetes in 34,166 Twin Pairs From International Twin Registers: The Discordant Twin (DISCOTWIN) Consortium. Twin Research and Human Genetics, 18(6), 762-771. https://doi.org/10.1017/thg.2015.83

Wollert, D. (2020). The fascinating \& controversial new science of CRISPR. The American Biology Teacher, 82(5), 279-288.

https://doi.org/10.1525/abt.2020.82.5.279

Xu, C. L., Ruan, M. Z., Mahajan, V. B., \& Tsang, S. H. (2019). Viral delivery systems for CRISPR. Viruses, 11(1), 28. doi:10.3390/v11010028

Yaylacı, Ş, Roth, W. D., \& Jaffe, K. (2019). Measuring racial essentialism in the genomic era: The genetic essentialism scale for race (GESR). Current Psychology. doi:10.1007/s12144-019-00311-z 
Yzerbyt, V., Rocher, S., \& Schadron, G. (1997). Stereotypes as explanations: A subjective essentialistic view of group perception. In R. Spears, P. J. Oakes, N. Ellemers, \& S. A. Haslam (Eds.), The social psychology of stereotyping and group life (p. 20-50). Oxford: Blackwell Publishing.

Zaikowski, L. A., \& Garrett, J. M. (2004). A three-tiered approach to enhance undergraduate education in bioethics. BioScience, 54(10), 942. https://doi.org/10.1641/0006-3568(2004)054[0942:atateu]2.0.co;2

Zaytoun, K. D. (2005). Identity and learning: The inextricable link. About Campus, 9(6), 8-15. https://doi.org/10.1002/abc.112

Zeidler, D. L., Herman, B. C., \& Sadler, T. D. (2019). New directions in socioscientific issues research. Disciplinary and Interdisciplinary Science Education Research, 1(1). doi: 10.1186/s43031-019-0008-7

Zeidler, D. L., \& Keefer, M. (2003). The role of moral reasoning and the status of socioscientific issues in science education: Philosophical, psychological and pedagogical considerations. In D. L. Zeidler (Ed.), The role of moral reasoning on socioscientific issues and discourse in science education. Dordrecht: Kluwer Academic Publishers.

Zeidler, D. L., \& Sadler, T. D. (2007). Social and ethical issues in science education: A prelude to action. Science \& Education, 17(8-9), 799-803. doi: 10.1007/s11191007-9130-6

Zeidler, D. L., Sadler, T. D., Simmons, M. L., \& Howes, E. V. (2005). Beyond STS: A research-based framework for socioscientific issues education. Science Education, 89(3), 357-377. doi: 10.1002/sce.20048 
Zeidler, D. L., Schafer, L. E. (1984). Identifying mediating factors of moral reasoning in science-education. Journal of Research in Science Teaching, 21(1), 1-15. doi: 10.1002/tea.3660210102

Zeidler, D. L., Walker, K. A., Ackett, W. A., \& Simmons, M. L. (2002). Tangled up in views: Beliefs in the nature of science and responses to socioscientific dilemmas. Science Education, 86(3), 343-367. https://doi.org/10.1002/sce.10025 


\section{APPENDICES}

\section{APPENDIX A}

\section{Gene Editing Assignment Prompt}

Instructions: Read the short article on gene editing and then write an essay that responses to the prompts provided below. There is no word maximum for the essay, but you should write at least 500 words when addressing all of the material required for full credit.

Points $=\ldots$ points

Due date $=$

Article:

(1) Read the New York Times article entitled "A Powerful New Way to Edit DNA".

Essay Prompt

Do you think CRISPR/Cas9 gene editing technology should be used for non-medical enhancement in humans? Non-medical enhancement is the modification of genes not for the purpose of curing or preventing diseases. Pretend that you are talking to your close friend who is not a science major. Write a persuasive essay that reflects what you would say to your friend to convince them of your stance on the question posed above. You may reference the article to defend your argument, but you may not use direct quotes. 
To receive full credit, you must:

a) Discuss what CRISPR/Cas9 is and describe how scientists are able to use it to edit genetic material

b) Clearly argue for or against its' use for non-medical enhancement

\section{a. Explain your reasoning}

c) To strengthen your argument, describe at least one dilemma over CRISPR/Cas9 use that a member of society may experience

a. Explain whether you, personally, identify with this dilemma or not and why Demographic Questions:

1. What is your age?

2. What is your gender?
a. Male
b. Female
c. Other
d. Prefer not to answer

3. What is your main field of study at the university?

4. Are you a:
a. High school student
b. Freshman (have completed less than 30 hours at the college level)
c. Sophomore (have completed 30-59 hours at the college level)
d. Junior (have completed 60-89 hours at the college level)
e. Senior (have completed 90 or more hours at the college level)
f. Post-baccalaureate student 
g. Graduate student

5. What is your ethnicity or race?

6. When was your last biology course?

7. How many science courses at the college level have you completed?

8. Are you Pell grant eligible?
a. Yes
b. No
c. Don't know
d. Prefer not to answer

9. Are you a first-generation college student?
a. Yes
b. No
c. Don't know
d. Prefer not to answer

\section{Criteria used to determine which CC9 essays were discarded and which were used}

\section{for moral reasoning coding}

\section{Essays were assigned to "discard" if:}

1) The student stated that CC9 is a gene editing technology but made no attempt to explain how it can be used to edit genomes or its' origin in bacteria cells. If they explained one of these topics in more depth and not the other, the essay was $\underline{\text { not discarded }}$

- Assigned letter D1 
2) The student incorrectly stated that CC9 functions as an adaptive immune system in humans

- Assigned letter D2

- If assigned D2 in combination with $\mathrm{K} 1$ or K2 (described below), the essay was discarded

3) The response was difficult to understand or gauge the students' understanding from due to lack of structure

- Assigned letter D3

\section{Essays were assigned to "keep" for further coding if:}

1) The student attempted to explain the origin of CRISPR in bacteria (must include a statement about its' function to protect against viruses that the bacteria have been previously exposed to)

- Assigned letter K1

\section{AND/OR}

2) The student attempted to explain that CC9 can be used with Cas9/gRNA (did not have to use these specific terms, or use them with complete accuracy) to edit genomes by cutting the DNA. Student may or may not have mentioned the role of DNA repair in the genome editing process

- Assigned letter K2 


\section{APPENDIX B}

Why Are Scientists So Upset About the First Crispr Babies?

Only because a rogue researcher defied myriad scientific and ethical norms and guidelines. We break it down.

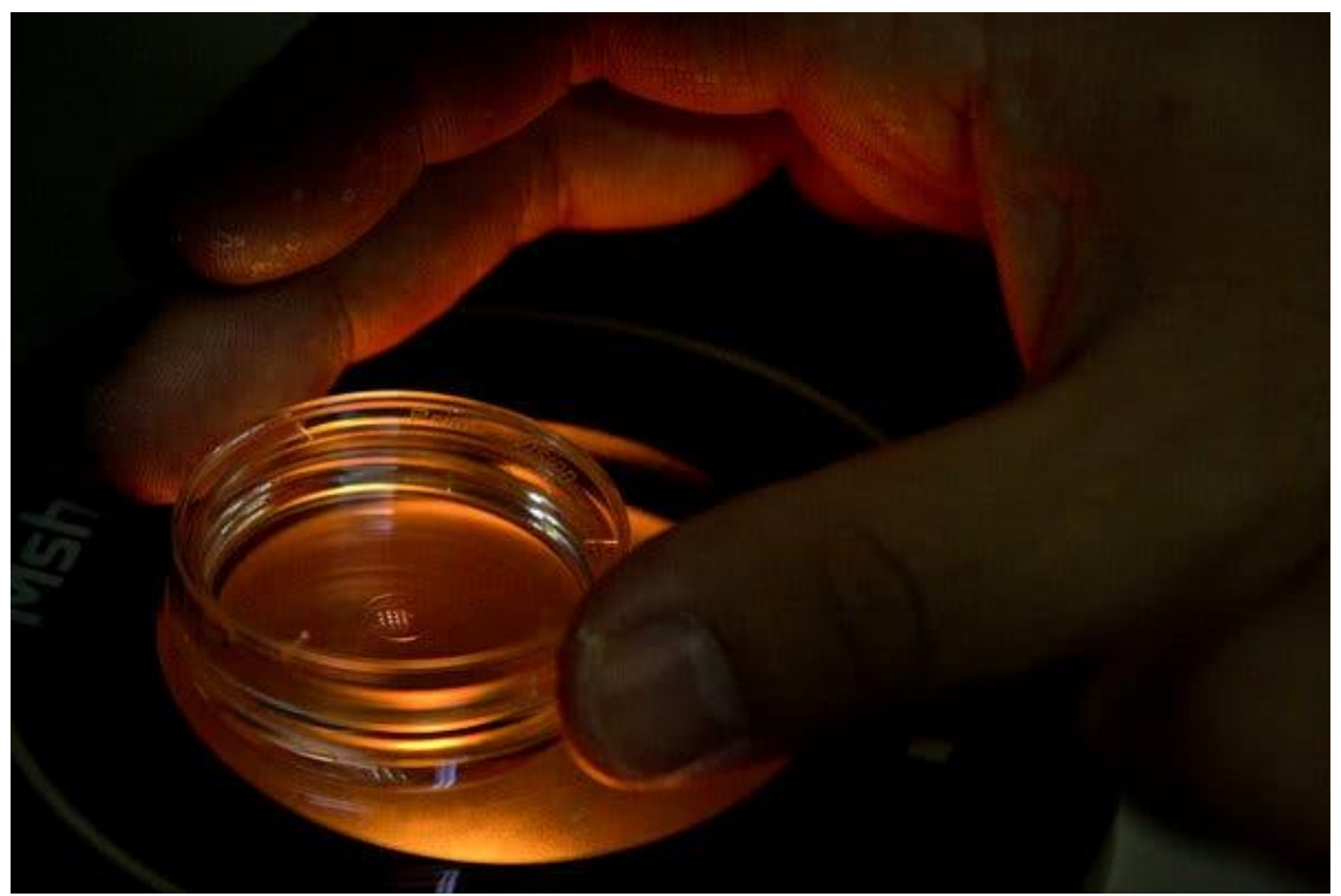

A microplate containing embryos in the lab of He Jiankui, in Shenzhen, China. Dr. He says he edited genes in the embryos, resulting in the world's first gene-edited babies. CreditCreditMark Schiefelbein/Associated Press

A Chinese scientist recently claimed he had produced the world's first gene-edited babies, setting off a global firestorm. If true - the scientist has not yet published data that would confirm it - his actions would be a sensational breach of international scientific conventions. Although gene editing holds promise to potentially correct dangerous disease-causing mutations and treat some medical conditions, there are many safety and ethical concerns about editing human embryos.

Here are answers to some of the numerous questions swirling around this development.

\section{What happened?}

The scientist, He Jiankui, said he used Crispr, a gene-editing technique, to alter a gene in human embryos - and then implanted the embryos in the womb of a woman, who gave birth to twin girls in November. 
That is illegal in many countries, including the United States. China has halted Dr. He's research and is investigating whether he broke any laws there. Among the concerns are whether the couples involved in Dr. He's research were adequately informed about the embryo editing and the potential risks involved.

Dr. He says he has submitted his research to a scientific journal. But nothing has been published yet, and he announced the births of the twins before his research could be peerreviewed by fellow scientists. He also appears to have taken other secretive steps that defy scientific standards.

\section{Which gene did he edit and why?}

The gene is called CCRs. It creates a protein that makes it possible for H.I.V., the virus that causes AIDS, to infect people's cells. Dr. He said that with the help of an H.I.V./AIDS advocacy organization in China, he recruited couples in which the man had H.I.V. and the woman did not. He used the Crispr-Cas9 editing technique to try to disable the $\mathrm{CCR}_{5}$ gene in their embryos, with a goal, he said, of creating babies who would be resistant to H.I.V. infection.

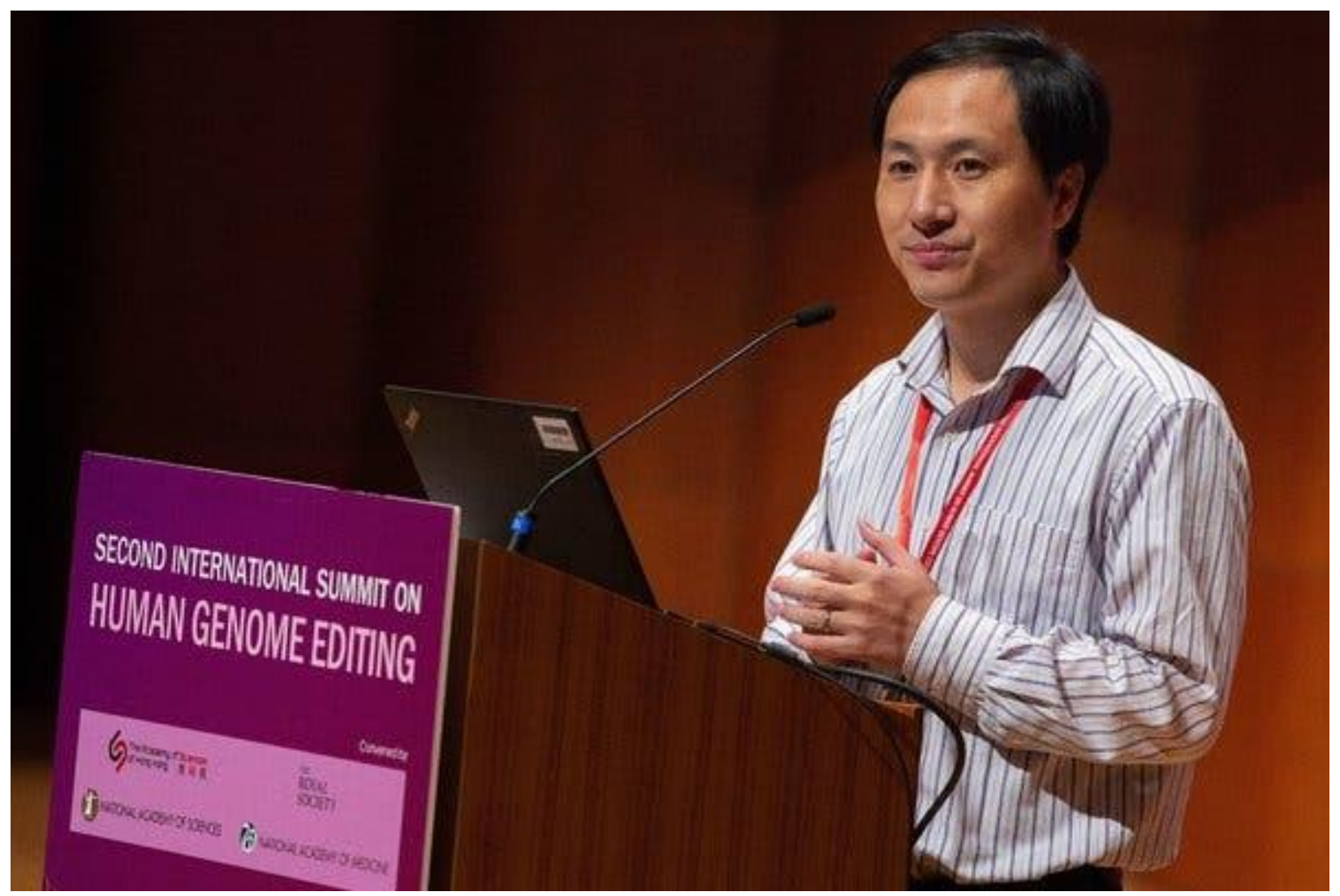

Dr. He presented his findings last month at the Second International Summit on Human Genome Editing at the University of Hong Kong. CreditAlex Hofford/EPA, via Shutterstock 


\section{What is Dr. He's background?}

Dr. He, 34, first worked with the Crispr gene-editing technology while obtaining a doctorate in biophysics from Rice University in Houston. He did postdoctoral research at Stanford and returned to his native China in 2012 under a program designed to draw Western-trained Chinese researchers back home. There, he founded two genetic-testing companies, and became affiliated with the Southern University of Science and Technology in Shenzhen.

He presented early phases of his Crispr research to American scientists at conferences in the United States, but disclosed to very few people that he was planning to actually create pregnancies by implanting edited embryos in women.

Gina Kolata writes about science and medicine. She has twice been a Pulitzer Prize finalist and is the author of six books, including "Mercies in Disguise: A Story of Hope, a Family's Genetic Destiny, and The Science That Saved Them.”@ ginakolata F Facebook

Pam Belluck is a health and science writer. She was one of seven Times staffers awarded the 2015 Pulitzer Prize for International Reporting for coverage of the Ebola epidemic. She is the author of "Island Practice," about a colorful and contrarian doctor on Nantucket.@PamBelluck

Citation:

Kolata, G., \& Belluck, P. (2018, December 05). Why Are Scientists So Upset About the First Crispr Babies? Retrieved from https://www.nytimes.com/2018/12/05/health/crispr-gene-editing-embryos.html 


\section{Clicker questions for the beginning of class:}

1. What is the function of CRISPR?

a. To act as an adaptive immune system in humans

b. To cut up the genome of viruses infecting bacteria

c. To cut up the genome of bacteria in humans

d. To remove or modify pieces of the human genome

e. A and C

2. What is the function of CRISPR/Cas9 genome editing?

a. To act as an adaptive immune system in humans

b. To cut up the genome of infecting viruses in bacteria

c. To cut up the genome of bacteria in humans

d. To remove or modify pieces of the human genome

e. A and $\mathrm{C}$

3. What gene did Dr. He disable with CRISPR/Cas9 technology and why?

a. CXCR4; to produce HIV resistant babies

b. CCR5; to produce HIV resistant babies

c. CXCR4; to produce HIV sensitive babies

d. CCR5; to produce babies with green eyes

e. None of the above

4. What is the concern about Dr. He's research?

a. The editing of human embryos

b. Improper informed consent of the participants

c. Dr. He was personally involved with participants

d. A \& B

e. $\mathrm{A} \& \mathrm{C}$ 


\section{APPENDIX C}

\section{READING A}

\section{THE MAN WHO WAS CURED OF HIV}

You may have recently heard of the first person to be cured of human immunodeficiency virus (HIV), the virus that causes acquired immunodeficiency syndrome (AIDS) [1]. Timothy Ray Brown was HIV-positive and also had acute myeloid leukemia, a cancer that affects white blood cells. To treat the leukemia, doctors first used radiation to kill virtually all of his white blood cells - a dangerous procedure since it is these cell that make up the immune system and protect us from disease-causing viruses and bacteria. A bone marrow transplant was then performed to give Brown the stem cells necessary to develop new white blood cells and eventually regain a healthy immune system. Doctors used this bone marrow transplant not only to treat Brown's leukemia but to also tackle his HIV infection. HIV can infect some of the white blood cells that grow out of bone barrow. When choosing a bone marrow donor for Brown, doctors selected an individual who had a rare genetic mutation that prevents most strains of HIV from infecting their white blood cells. After receiving a successful transplant from this donor, Brown now has a new immune system full of HIV-resistance cells. Since his transplant he has not needed any anti-retrovirals, the medications used to treat HIV/AIDS, and still no HIV can be detected in his blood. Because Brown has been stably HIV-free for three years, doctors think that he is cured! But what does that mean for the 30 million other people [2] infected with HIV around the world? Is the fight against AIDS over? Definitely not - but this first cure may bring us closer to the end of an

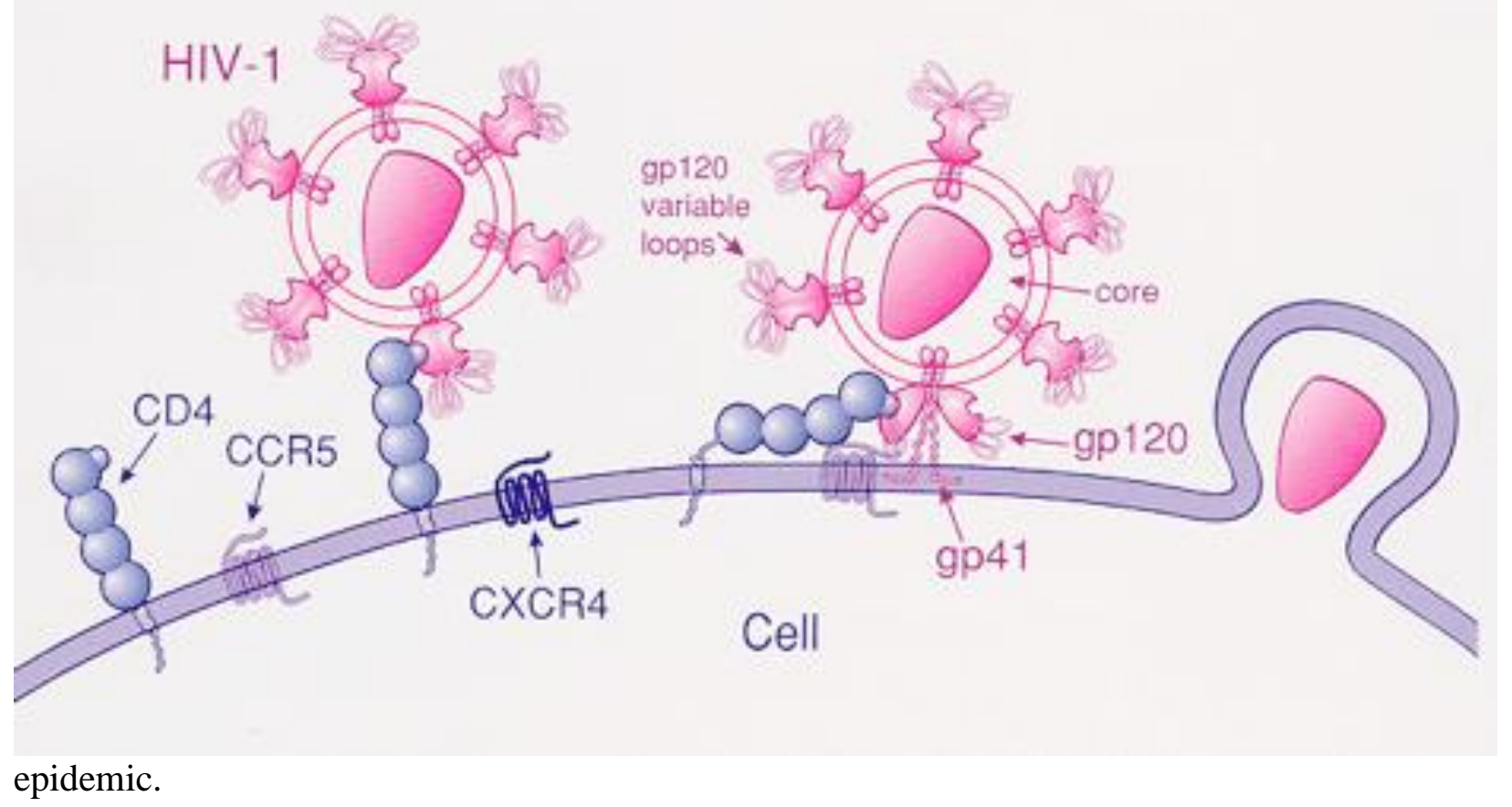


Figure 1. HIV Entry: HIV binds to its receptor, CD4, on the cell surface through the virus' gp120 protein (left). The virus then binds to its co-receptor, either CCR5 or CXCR4 (center). Binding to the co-receptor allows the virus to fuse with the cell surface, and enter the interior of the cell to cause infection (right). (Image credit: National Institute of Allergy and Infectious Diseases)

\section{How can cells be HIV-resistant?}

HIV mainly infects a special type of white blood cell, called a $\mathbf{T}$ cell, by interacting with two proteins that stick out from the T cell's surface: a receptor and co-receptor. HIV first binds to its receptor protein, called CD4, to start the entry process whereby the virus gets into the cell [3]. After binding to CD4, HIV then binds to one of two co-receptors, either CCR5 or CXCR4, to enter the cell. Just like people are different from each other, one HIV virus can be different from another. Most HIVs use CCR5 as the co-receptor that allows them to enter the T cell and cause infection. But interestingly, some people have a genetic mutation that prevents them from producing the CCR5 protein. These individuals don't have any CCR5 on the surface of their R cells, meaning that most types of HIV cannot infect these cells. Since the bone marrow used for Brown's transplant came from a person with such a mutation, HIV resistant T cells grew from the transplanted stem cells.

People with the CCR5 mutations for HIV-resistance still produce CXCR4, the alternative co-receptor for HIV entry that can be used by some varieties of HIV. Therefore cells with a CCR5 deficiency can still be infected by rare forms of HIV. Luckily for Brown, having immune cells without the CCR5 receptor has been enough to stop the virus in its tracks. HIV has not been detected in his blood for three years, leading doctors to clinically classify hi as cured of HIV.

References:

1. "Man appears free of HIV after stem cell transplant" http://articles.cnn.com/2009-0211/health/health.hiv.stemcell_1_cell-transplant-ccr5-cd4?_s=PM:HEALTH

2. “Joint United Nation Program on HIV/AIDS" http://www.unaids.org/en/

3. "HIV Structure and Life Cycle" http://www.avert.org/hiv-virus.htm

Citation:

Jamie, S. (2011, May 15). The man who was cured of HIV. Retrieved from http://sitn.hms.harvard.edu/flash/2011/issue93/ 


\section{Reading A reading guide}

Name

Date

Question 1

A) Who was the first person to be cured of HIV?

Timothy Ray Brown

B) How was he cured? What did this procedure do? And, what did it cure?

A bone marrow transplant - put new WBCs in; cured acute myeloid leukemia \& $H I V$

C) What was important about the donor bone marrow?

The donor had a rare genetic mutation that prevents most of HIV from infecting

Question 2

A) Explain how HIV infects cells. Include: the type of cell and receptor(s) and coreceptor(s) involved.

Binds to receptor CD4 and then a co-receptor (CXCR4 or CCR5)

B) Which co-receptor is used most often by HIV?

CCR5

C) Which co-receptor do some people have a natural mutation in? Is this the same or different mutation that Dr. He used in his study?

CCR5. The same

D) Does that mutation lead to complete resistance to HIV? Why or why not?

No, some HIV strains use the other receptor (CXCR4) 


\section{$\underline{\text { READING B }}$}

\section{Chapter 3. The Protection of Human Subjects - selected sections}

The use of human subjects in research benefits society in many ways, from contributing to the development of new drugs and medical procedures to understanding how we think and act. It also can and has imposed unacceptable risks on research subjects. To help ensure that the risks do not outweigh the benefits, human subjects research is carefully regulated by society.

\section{Excerpts, Nuremberg Code (1947)}

1. The voluntary consent of the human subject is absolutely essential.

2. The experiment should be such as to yield fruitful results for the good of society.

3. The experiment should be so designed and based on the results of animal experimentation and a knowledge of the natural history of the disease.

4. The experiment should be so conducted as to avoid all unnecessary physical and mental suffering and injury.

5. No experiment should be conducted where there is an a priori reason to believe that death or disabling injury will occur.

6. The degree of risk to be taken should never exceed that determined by the humanitarian importance of the problem to be solved by the experiment.

7. Proper preparations should be made and adequate facilities provided to protect the experimental subject against even remote possibilities of injury, disability, or death.

8. The experiment should be conducted only by scientifically qualified persons.

9. During the course of the experiment the human subject should be at liberty to bring the experiment to an end.

10. During the course of the experiment the scientist in charge must be prepared to terminate the experiment at any stage, if he has probable cause to believe, in the exercise of the good faith, superior skill and careful judgment required of him that a continuation of the experiment is likely to result in injury, disability, or death to the experimental subject.

http://www.hhs.gov/ohrp/references/nurcode.htm

Investigators who conduct research involving humans that is subject to regulation must comply with all relevant Federal regulations as well as any applicable state and local laws, regulations, and policies related to the protection of human subjects. They are also expected to follow other relevant codes that have been formulated by professional groups. To meet these responsibilities requires, among other things:

- Knowing what research is subject to regulation

- Understanding and following the rules for project approval

- Getting appropriate training

- Accepting continuing responsibility for compliance through all stages of a project $\underline{\text { 3a. Federal regulations }}$

Society protects the welfare of individuals in many ways, but it did not specifically address the issues of welfare of research subjects until after World War II. 
Following the War, widespread concerns about atrocities committed during the War in the name of research led to the formation of a code for human subjects research known as the Nuremberg Code (1947). Although not binding on researchers, the Nuremberg Code and the later Declaration of Helsinki (1964; latest revision and clarification, 2002) provided the first explicit international guidelines for the ethical treatment of human subjects in research.

The Nuremberg Code and Declaration of Helsinki did not put an end to unethical human subjects research. During the Cold War, U.S. researchers tested the effects of radiation on hospital patients, children, and soldiers without obtaining informed consent or permission to do so. Through the 1950's and 1960's, well after antibiotics effective for the treatment of syphilis were discovered, scores of Africa-American males in a longterm syphilis study (conducted by the U.S. Public Health Service in Tuskegee, Alabama) were not offered treatment with the new drugs so that researchers could continue to track the course of the disease. These and other questionable practices raised serious public concern and led eventually to government regulation.

To prevent these and similar abuses from continuing, in 1974 Congress required the Department of Health, Education and Welfare (HEW, currently Health and Human Services - HHS) to clarify its rules for the use of human subjects in research. With this mandate in hand, HEW codified its procedures under Title 45 of the Code of Federal Regulations, Part 46 (45 CFR 46). (At roughly the same time, the FDA codified its rules for human subjects research under 21 CFR 50 and 56.)

Congress also called in 1974 for the creation of a National Commission for the Protection of Human Subjects of Biomedical and Behavioral Research. During the 4 years it met, the Commission issues a number of reports on the protection of research subjects and recommended principles for judging the ethics of human subjects research (discussed below).

In 1991 most Federal departments and agencies that conduct or support human subjects research adopted a common set of regulations for the protection of human subjects referred to as the "Common Rule" (45 CFR, 46, Subpart A). Additional requirements on three sensitive research areas are also included in 45 CFR 46:

- Subpart B - Additional Protections for Pregnant Women, Human Fetuses and Neonates Involved in Research.

- Subpart C - Additional Protections Pertaining to Biomedical and Behavioral Research Involving Prisoners as Subjects.

- Subpart D - Additional Protections for Children Involved as Subjects in Research. Together, 45 CFR 46, Subparts A-D, provide a comprehensive articulation of society's expectations for the responsible use of human subjects in research.

Authority for enforcing the HHS regulations for the protection of human subjects who participate in research conducted or supported by HHS now rests with the Office for Human Research Protections (OHRP) in the Office of Public Health and Science (OPHS). If you have specific questions about the Federal requirements for the protection of human subjects, contact your local institutional officials, OHRP (for research conducted or supported by HHS), or appropriate officials at the department or agency conducting or supporting the research. Chapter 3c. IRB membership and deliberations 
Federally funded research that uses human subjects must be reviewed and approved by an independent committee called an Institutional Review Board or IRB. The IRB provides an opportunity and place for individuals with different backgrounds to discuss and make judgments about the acceptability of projects, based on criteria set out in the Common Rule. Under the Common Rule, IRBs must have at least five members and include at least one scientist, one non-scientist, and "one member who is not otherwise affiliated with the institution and who is not part of the immediate family of a person who is affiliated with the institution" ( $§ 46.107(d))$. IRBs have authority to approve, require modification of (in order to secure approval), and disapprove all research activities covered by the Common Rule. They also are responsible for conducting continuing review of research at least once per year and for ensuring that proposed changes in approved research are not initiated without IRB review and approval, except when necessary to eliminate apparent immediate hazards to the subject. IRB weigh many factors before approving proposals. Their main concern is to determine whether $(\S 46.111(\mathrm{a}))$ :

- Risks to subjects are minimized;

- Risks to subjects are reasonable in relation to anticipated benefits, if any, to subjects, and the importance of the knowledge that may reasonably be expected to result;

- Selection of subjects is equitable;

- Informed consent will be sought from each prospective subject or the subject's legally authorized representative;

- Informed consent will be appropriately documented;

- When appropriate, the research plan makes adequate provision for monitoring the data collected to ensure the safety of subjects; and

- When appropriate, there are adequate provisions to protect the privacy of subjects and to maintain the confidentiality of data.

Researchers should consider each of these issues before completing their research plan and submitting it to an IRB for approval.

Making decisions about whether human subjects will be treated fairly and appropriately or given adequate information requires judgments about right and wrong (moral judgments). In the 1797 Belmont Report, the National Commission recommended three principles for making these judgments:

- Respect for persons and their right to make decisions for and about themselves without undue influence or coercion from someone else (the researcher in most cases);

- Beneficence or the obligation to maximize benefits and reduce risks to the subject; and

- Justice or the obligation to distribute benefits and risks equally without prejudice to particular individuals or groups, such as the mentally disadvantaged or members of a particular race or gender.

While this list does not exhaust the principles that can be used for judging the ethics of human subjects research, it has nonetheless been accepted as a common standard for most IRB deliberations. Knowing this, researchers should spend time considering whether their work does provide adequate respect for persons, appropriately balances risks and benefits, and is just. 
Chapter 3f. Ethical issues

Despite the many rules governing research with humans, tough choices continually arise that have no easy answers.

Informed consent. It is widely agreed that research subjects should be fully informed about experiments in which they may participate and give their consent before they enroll. However, some subjects, such as children, some adults with impaired decision-making capacity, and some critically ill patients, cannot give informed consent, either because they are not old enough to understand the information being conveyed or because they have lost their ability to understand.

These and other problems could be eliminated by forbidding researchers to do studies that raise difficult questions about respect for persons, beneficence, and justice, but this would make it difficult or even impossible to get some crucial information needed to make informed decisions about medicine and public health. Since children do not respond to medicines in the same way as adults, it is important to include children in some clinical trials. However, it is not easy to decide when they should be included and how consent can/should be obtained.

Right to withdraw. It is widely agreed that research subjects should have the right to withdraw from experiments at any time, but in some cases they cannot. In the final stages of development, mechanical hearts are tested on patients whose own heart is about to fail. But if it has not failed, and once the mechanical heart replaces the weakened heart, there is no turning back. The patient can technically withdraw from the experiment and undergo further testing, but he or she cannot withdraw from the conditions imposed by the experiment, no matter how distressing living with the mechanical heart might be. Knowing this, under what conditions should these experiments be allowed?

Risk without benefit. In one recent experiment, researchers wanted to tested whether a common surgical procedure used to relieve arthritis pain had any benefits. To gather information about benefits they designed a clinical trial in which subjects in the control group received sham surgery. An operation was performed, but the common surgical procedure was not performed.

The researchers in this case complied with all regulations, which included thorough IRB review. None of the patients experienced any adverse effects, and the study concluded that the common surgical procedure did not provide significant benefits. However, since surgery always involves some risk, the subjects in the control group were placed at risk without any expectation that they would benefit. Should this be allowed, and if so, under what circumstances?

These and other questions must ultimately be answered by IRBs during the review process. Researchers who serve on IRBs need additional training to help them deal with the growing complexities of biomedical, social, and behavioral research. Researchers who use human subjects in research should seriously consider having some formal training in bioethics so that they can participate in the critical reasoning process needed to respond to the complex moral issues raised by the use of human subjects in research.

Citation:

Steneck, N. H. (2004). Ori introduction to the responsible conduct of research. Rockville, MD: U.S. Dept. of Health and Human Services, Office of Research Integrity. 


\section{Reading B reading guide}

Name

Date

Question 1

Does Dr. He's research involve additional requirements for protection of the subjects involved? If so, what specific protection does his research involve and why?

Yes-protection of pregnant women and human fetuses

Working on pregnant moms

Question 2

A) Which one of the three ethical issues discussed applies to the research Dr. He performed and why?

Informed consent - embryos edited

Embryos cannot consent, so parents consent for them

USE ARTICLE 3 OF THE INFORMED CONSENT TO ANSWER THE FOLLOWING QUESTIONS:

B) Is there a place in the informed consent that discusses the risks of genetic modification? What does it say the primary risk is?

Yes, off-target effects

C) Does it discuss any risks that are specific to genetic modification of human embryos, such as genetic mosaicism (where some cells are edited and others are not)?

NO.

D) Is there a place in the informed consent that discusses the risks of genetic modification for the children that are modified and/or future generations? If so, what does it say?

NO.

Question 3

A) In the first paragraph, what type of project does Dr. He's informed consent say the research is a part of?

Producing a vaccine for HIV

B) What is a vaccine? You may use outside resources to answer this question.

C) Does the research described in the article before class and in the class discussion before the activity appear in line with Dr. He's description of the project you found in part A? Explain. 


\section{READING C}

\section{Why Are Scientists So Upset About the First Crispr Babies?}

Only because a rogue researcher defied myriad scientific and ethical norms and guidelines. We break it down.

\section{Why are scientists up in arms?}

Changing the genes in an embryo means changing genes in every cell. If the method succeeds, the baby will have alterations that will be inherited by all of the child's progeny. And that, scientists agree, is a serious undertaking that must be done with great deliberation and only to treat a serious disease for which there are no other options - if it is to be done at all.

Instead, Dr. He went ahead and disabled a perfectly normal gene, CCR . While people who are born with both copies of $\mathrm{CCR}_{5}$ disabled are resistant to H.I.V., they are more susceptible to West Nile virus and Japanese encephalitis. And there are simpler and safer ways to prevent H.I.V. infection.

More worryingly, Crispr often inadvertently alters genes other than the one being targeted, and there are also circumstances, called mosaicism, where some cells contain the edited gene and others do not. Dr. He claimed in a video that Crispr did not affect other genes in the twins and that the babies were "born normally and healthy," but there is no way to know if that is true.

In fact, some of the data Dr. He presented at a conference in Hong Kong, after he announced the birth of the twins, is concerning, several scientists said. For one thing, it indicates that he was able to disable both copies of the $\mathrm{CCR}_{5}$ gene in only one of the twins, whom Dr. He identified as "Nana." In the other twin, "Lulu," only one copy of $\mathrm{CCR}_{5}$ was disabled, providing limited, if any, protection against H.I.V., but Dr. He implanted the embryo anyway. He said he informed the parents and they wanted both embryos implanted.

Some scientists said the data Dr. He presented also suggested several potential issues resulting from the editing process.

Most importantly, said Dr. Kiran Musunuru, a geneticist at the University of Pennsylvania who reviewed the data, "there's clear evidence of mosaicism" in the edited embryos of both twins. "I was so furious," Dr. Musunuru said. "This would have been disturbing anyway — gene-edited babies. It made it a hundred times worse knowing that he had totally mosaic embryos. It's as if you took the embryos and dipped them in acid and said 'You know what, I'm just going to go ahead with the implantation anyway.' It's not that much different." 
While it is unclear if the babies themselves ended up with a mosaic patchwork of cells, Dr. Musunuru said the data shows that Lulu's placenta was mosaic, which is not a good sign.

Finally, it is not known if his study subjects knew what they were agreeing to. The consent they signed was for an AIDS vaccine development project, and it did not mention all the risks of disabling $\mathrm{CCR}_{5}$. It said that if Crispr altered other genes, "the project team is not responsible for the risk."

\section{What are the potential implications?}

Many scientists are concerned that Dr. He's experiment could have a chilling effect on support for legitimate and valuable gene-editing research.

"Should such epic scientific misadventures proceed, a technology with enormous promise for prevention and treatment of disease will be overshadowed by justifiable public outrage, fear, and disgust," said Dr. Francis Collins, director of the National Institutes of Health.

\section{What are the safeguards against this?}

In the United States, Congress has barred the Food and Drug Administration from even considering clinical trials involving human embryo editing. The National Institutes of Health is prohibited from funding such research. The National Academies of Science, Engineering, and Medicine issued a report in 2017 concluding that editing the genes of human embryos should only be acceptable in the narrowest of circumstances. It would have to be used to correct a serious genetic disorder that causes disease or disability; there would have to be no other alternatives; there would have to be good evidence that the benefits would outweigh the risks; and there would have to be a plan in place to follow the gene-edited children. 


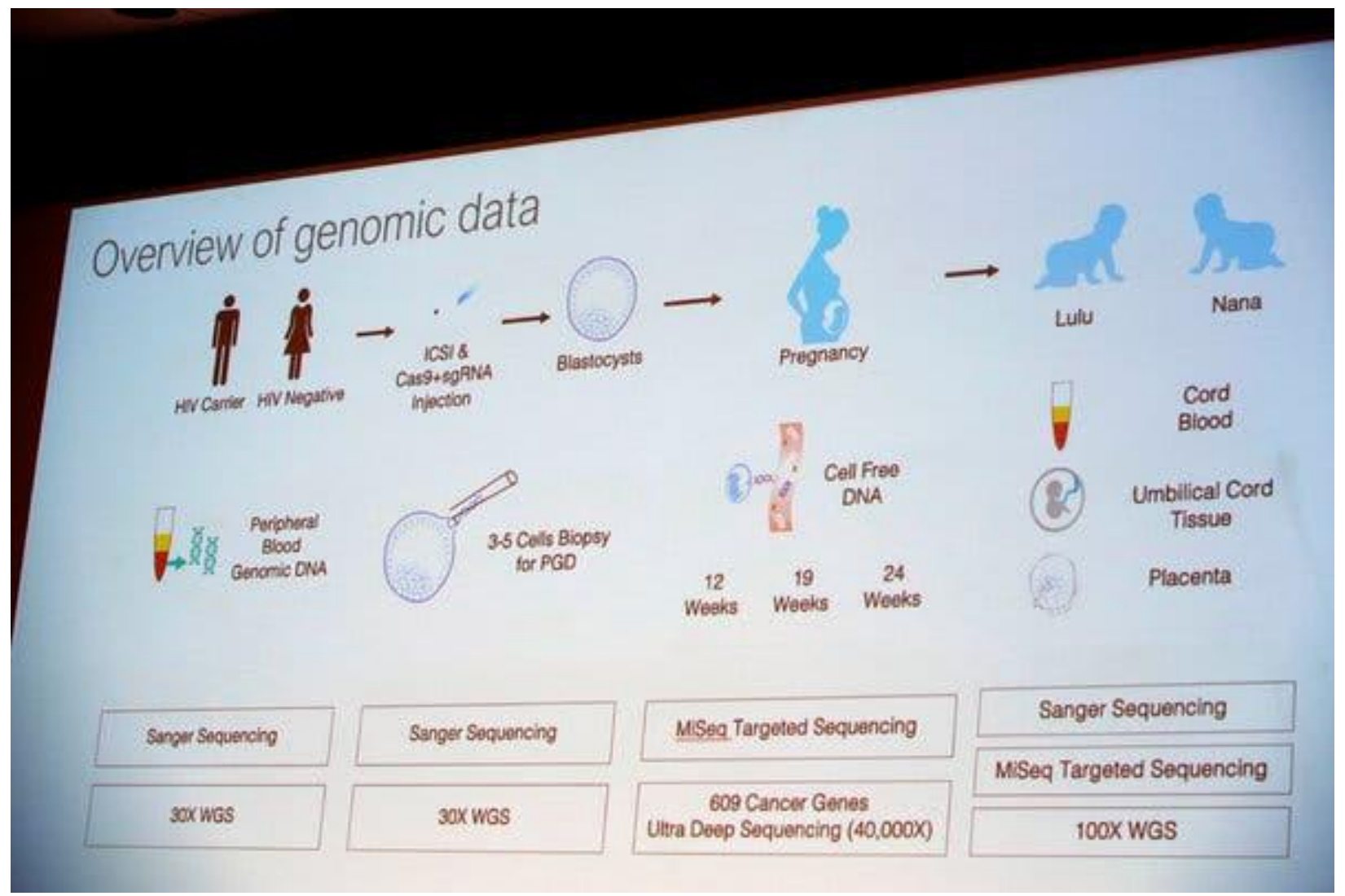

A slide from Dr. He's presentation in Hong Kong.CreditKin Cheung/Associated Press

\section{What are the ethical concerns?}

Some worry that this is the first step toward using gene editing to create people with extreme intelligence, beauty or athletic ability. But that, for now, is not possible. Such traits are thought to be affected by possibly hundreds of genes acting in concert, and affected in turn by the environment.

The biggest ethical concerns for now are with rogue scientists enticing couples who do not realize the risks to babies that might result from the experiments. And when those children grow up, the altered genes will be passed on to their children, and to their children's children, for generations to come.

\section{What do we still not know?}

Until Dr. He publishes the results of his work in a peer-reviewed medical journal, we will not know the detailed results of the embryo editing, or even whether the twins were actually born.

Dr. He has not submitted his data, nor has he identified the children or parents, other than to provide first names for the twin girls, Lulu and Nana; these may be pseudonyms. We won't know for many years if Crispr affected genes other than $\mathrm{CCR}_{5}$. Nor can we gauge the health of the babies now or in the future. 
And, of course, we do not know if other scientists will be emboldened to try their own experiments editing the genes of human embryos.

Gina Kolata writes about science and medicine. She has twice been a Pulitzer Prize finalist and is the author of six books, including "Mercies in Disguise: A Story of Hope, a Family's Genetic Destiny, and The Science That Saved Them.” @ ginakolata • Facebook

Pam Belluck is a health and science writer. She was one of seven Times staffers awarded the 2015 Pulitzer Prize for International Reporting for coverage of the Ebola epidemic. She is the author of "Island Practice," about a colorful and contrarian doctor on Nantucket. @ PamBelluck

Citation:

Kolata, G., \& Belluck, P. (2018, December 05). Why Are Scientists So Upset About the First Crispr Babies? Retrieved from https://www.nytimes.com/2018/12/05/health/crispr-gene-editing-embryos.html 


\section{Reading $\mathbf{C}$ reading guide}

Name

Date

Question 1

A) What gene did Dr. He claim to disable in the embryos?

CCR5 receptor gene

B) What are three issues about the genetic editing that Dr. He performed that are discussed in the article?

1. Increased risk of getting West Nile virus \& Japanese encephalitis

2. Genetic mosaicism - some cells get the edit and some do not

3. Must disable both copies; disabling only ONE provides limited, if any, protection

Question 2-

A) What four circumstances make it acceptable to edit human embryos, according to the National Academies of Science, Engineering, and Medicine report from 2017?

1. correct a serious genetic disorder

2. no other alternatives

3. evidence of benefit outweighing risks

4. plan in place to follow edited children

B) Did Dr. He meet the four circumstances above, according to the knowledge you have about the study? For each, answer yes or no and explain why or why not.

1. No-HIV is not a serious genetic disorder

2. No-there are alternative treatments available

3. Hard to come to conclusion here; I'd say risks outweigh benefits

4. No-none in place that we know of

Question 3:

What is one ethical concern going forward? Why is that a concern?

Scientists performing genetic modification procedures with embryos and parents not knowing/understanding the full risks involved. 


\section{READING D}

\section{Beyond safety questions, gene editing will force us to deal with a moral quandary By JOSEPHINE JOHNSTON \\ NOVEMBER 29, 2018}

After a Chinese scientist announced this week the birth of twin girls whose DNA he had altered many months earlier when they were microscopic, single-cell embryos, condemnation of this previously secret experiment was swift and absolute. Scientists and ethicists from around the world called it "premature" and "irresponsible."

The majority of this criticism is motivated by major concerns about safety - we simply do not yet know enough about the impact of CRISPR-Cas9, the powerful new geneediting tool, to use it create children. But there's a second, equally pressing concern mixed into many of these condemnations: that gene-editing human eggs, sperm, or embryos is morally wrong.

That moral claim may prove more difficult to resolve than the safety questions, because altering the genomes of future persons - especially in ways that can be passed on generation after generation - goes against international declarations and conventions, national laws, and the ethics codes of many scientific organizations. It also just feels wrong to many people, akin to playing God.

As a bioethicist and a lawyer, I am in no position to say whether CRISPR will at some point prove safe and effective enough to justify its use in human reproductive cells or embryos. But I am willing to predict that blanket prohibitions on permanent changes to the human genome will not stand. When those prohibitions fall — as today's announcement from the Second International Summit on Human Genome Editing suggests they will — what ethical guideposts or moral norms should replace them?

Few would argue that we should not try to prevent the transmission of genes associated with life-shortening or otherwise extremely serious genetic diseases like Huntington's disease, Tay-Sachs disease, or even some breast and ovarian cancers. Indeed, doing so is already an accepted practice in medicine.

As genome-sequencing pioneer Eric Lander and others have said, instead of using gene editing, parents with or at high risk of genetic diseases can use in vitro fertilization combined with preimplantation genetic testing to identify embryos unaffected by one or more particular conditions. Or they can undergo prenatal testing to determine if a particular fetus carries a potentially devastating gene. 
For some people, though, discarding embryos and terminating pregnancies are morally unacceptable acts. If an embryo's DNA could be edited instead, families with moral or religious misgivings could transfer all their embryos, as could prospective parents who, like many IVF patients, have few embryos to begin with. More importantly, prospective parents worried about more than one genetic marker, and who therefore might not have any "unaffected" embryos, could use gene editing to make changes at multiple places in their embryos' genomes.

If that scenario sounds like something out of the science fiction movie GATTACA, that's because it is. Yet that's the very prospect that the emergence and refinement of CRISPR and other gene-editing tools, and this week's news, seem to place just within reach. In GATTACA, the parents of a young boy they conceived naturally visit a genetics clinic to select the genetic make-up of their second child. When their doctor lists the many changes he has made to their embryos - from eliminating genes associated with myopia and alcoholism to those for premature baldness, as well as selecting eye, hair, and skin color - the couple balks, asking "if it's good to leave a few things to chance?" Their doctor reassures them that they are just giving their child "the best possible start" by relieving him of "additional burdens."

The difficult moral question that this ever-less-remote technology raises, then, is not whether it is ever morally acceptable to eliminate, edit, or repair the genes of future persons. It will be very difficult to cogently argue that such an action is wrong in principle.

Instead, the question must become how far to take the very laudable impulse to offer children the best possible chances in life. This is a question for international bodies, like the United Nations, as well as the leaders at this week's Second International Summit on Human Genome Editing in Hong Kong, and for national governments, many of which have laws prohibiting any and all germline modification in humans.

But it is also a question for ordinary people, both because we elect those who will be asked to change such laws and because we - especially anyone who is today a teenager or a child - will be the prospective users of this technology. In a country such as the U.S., which has up until now been very hands-off when it comes to most uses of assistedreproduction technologies, there's a very real chance that decisions about whether to use gene-editing in embryos, and in what ways, will eventually be left up to individuals. That means that my daughter, who is now 9 years old, may well be offered gene editing services for her embryos 20 or 30 years from now (most likely for a considerable fee). How will she decide what to do-and if she does use the technology, how far to go with it? 
Some ethicists and the CEOs of some genetics companies are enthusiastic about parents using genetic technologies not simply to prevent serious disease but to have "the best children." They look forward to a future in which gene editing of eggs, sperm, or embryos for a variety of diseases and traits is on offer. When the technology comes to market, I expect them to argue that using it to alter all sorts of genes is a responsibility of parenting - that gene editing is what good parents do.

My hope is that by the time such services arrive, people around the world will have developed a more sober attitude towards genetic technology than the almost blind optimism that today drives people to give their DNA to companies who promise to tell them who they really are, and will agree that the impulse to control their descendants' genes, like the impulse to choose their descendants' professions or passions or spouses, should generally be held in check.

Cultivating an attitude of acceptance and wonder when it comes to their child's or grandchild's DNA does not oblige future parents to do nothing about lethal or lifelimiting genetic diseases. Indeed, I think that blanket prohibitions on germline modification must be scrapped. But this cautious attitude towards gene editing does counsel restraint and deliberation, suggesting we use germline gene editing sparingly.

We must remain skeptical of the notion that it makes sense to speak of having the best child or of maximizing a future person's genes, and be on guard against the notion that doing so is a necessary element of good parenting. Humans have known for centuries, if not millennia, that children are a gift, and the civil rights and disability rights movements have shown us the diverse ways in which people with highly varied genomes can flourish. As we enter an age of gene editing, these are the norms and values that must guide us.

Josephine Johnston is director of research and a research scholar at The Hastings Center, a bioethics research institute in Garrison, N.Y., where she works on ethical, legal, and policy issues in genetics and reproductive medicine.

\section{Citation:}

Josephine, J. (2018, November 29). Gene editing will force us to deal with a moral quandary. Retrieved from https://www.statnews.com/2018/11/29/what-makesgood-parenting-age-gene-editing/ 


\section{Reading D reading guide}

Name

Date

Question 1

A) What is the concern with safety?

We do not know the impact on future generations

B) Does the twin study bring up this concern? Why or why not?

It brings up both since he edited embryos without knowing the full effect (safetywise)

Question 2

A) What is Huntington's disease? You may use outside resources to answer this question, but you must include the citation (website or book name is enough) to get full credit.

Fatal genetic disorder that involves regression of mental and physical capabilities. Extremely painful.

B) What is in vitro fertilization combined with preimplantation genetic testing used for? What happens to the embryos that are not implanted?

Screening of embryos to find an unaffected one prior to implantation; discard others embryos that aren't used

C) What is prenatal testing used to determine?

Testing fetus to determine if it carries a disease - could choose to terminate

D) How is B \& C similar or different to using CRISPR to genetically modify embryos? 1. Termination of pregnancy \&/or discarding embryos is seen as being wrong by some; CRISPR would be a way to modify embryos without being seen as wrong in this way.

2. CRISPR would solve the issue of not having enough embryos to begin with.

3.CRISPR would give individuals whose embryos have more than one genetic marker a chance to make multiple changes to their embryos.

E) In the article, it mentions that it is conceivable to use CRISPR to edit fatal genetic disorders. What, then, is the main question regarding the use of CRISPR in embryos? should not

How far to go - where to draw the line of what we should change and what we

Question 3

What is cystic fibrosis? You may use outside resources to answer this question, but you must include the citation (website or book name is enough) to get full credit.

Genetic disease that effects lungs; usually results in shorter lifespans.

\section{APPENDIX D}


Name

Date

Your assigned article letter

$\underline{\text { Reading summaries from jigsaw activity }}$

Directions: For each article letter, provide 1-2 sentences summarizing your group members description of the article. Do not provide a summary for the article you were assigned - turn in your reading guide for your assigned article.

A

B

$\mathrm{C}$

$\mathrm{D}$ 


\section{CURRICULUM VITAE}

Katie M. Seiter*

University of Louisville, Department of Biology, Louisville KY 40292

Email: kmhumr01@louisville.edu | Phone: (502) 852-3157

*Note that I changed my last name from "Humrick" to "Seiter" during summer 2020

\section{EDUCATION}

2016-2020 Ph. D. in Biology, University of Louisville, Louisville, KY

Dissertation title: Student understanding of genetics, genome editing

technology, and reasoning about genetic socioscientific issues.

Advisor: Dr. Linda Fuselier Ph. D., Department of Biology

Cumulative GPA: 4.0

2016 B. A. Biology, University of Louisville, Louisville, KY

Cumulative GPA: 3.92, magna cum laude

2012 High School Degree, Boone County Public High School, Florence, KY

Cumulative GPA: 3.9

\section{PROFESSIONAL POSITIONS}

2018-2020 Doctoral Candidate and Researcher, Department of Biology, University of Louisville, Louisville, KY

Duties: Conduct biology education research related to an academic project, analyze results using quantitative and qualitative research methods, and perform academic writing for the publication of novel, biology education research.

2016-18 Graduate Teaching Assistant, Department of Biology, University of Louisville, Louisville, KY

Duties: Plan and implement lectures which describe the activities and content for each meeting, assist students in performing activities, assess students on quality of work.

2015-16 Undergraduate Research Assistant, Department of Biology, University of Louisville, Louisville, KY 
Duties: Assisted graduate researcher by constructing a series of 36 strains of Salmonella that are individually deleted for the known effectors using specialized transduction.

2014-15 REACH Tutor, University of Louisville, Louisville, KY

Subjects: General and organic chemistry, biology, and anatomy.

2013-14 Customer Service Representative, Fifth Third Bank, Louisville, Louisville, KY

Duties: Assisted customers in making deposits and withdraws, resolved problems associated with customer accounts, and advised customers about bank resources.

ACADEMIC AWARDS AND SCHOLARSHIPS

2020

2020

2020

2019

2019

2018-Present University Fellowship, School of Interdisciplinary and Graduate Studies, University of Louisville, Louisville, KY

2016-18 Graduate Teaching Assistant, Department of Biology, University of Louisville, Louisville, KY

2012-16 Trustees Academic Scholarship, University of Louisville, Louisville, KY

2012-16 KEES Scholarship, State of KY

2013 Nursing Scholarship Award, University of Louisville, Louisville, KY

HONORS

2016

2012-16
Magna cum laude, University of Louisville, Louisville, KY

Deans List, University of Louisville, Louisville, KY 
FUNDING

2019

2017

Graduate Student Council Travel Scholarship, Travel funds to present at the National Association for Research in Science Teaching in Portland, Oregon in March 2020. Requested: \$350. Funded: \$200.

NIH Ruth L. Kirschstein NRSA Fellowship, Identification and characterization of host factors involved in reverse transmigration of Salmonella-infected dendritic cells. Co-PI with Dr. Micah Worley. $\underline{\text { Requested: Tuition and stipend. Unfunded. }}$

\section{PROFESSIONAL EXPERIENCE}

\section{Invited Academic Presentations}

2020

Seiter, K. M. Moral Reasoning About Human Genetic Enhancement Using CRISPR, Oral presentation to be given at the National Association for Research in Science Teaching annual international conference, Portland, Oregon. Conference cancelled due to COVID-19 concerns.

2020

Seiter, K. M. Genetics Knowledge and Belief in Genetic Determinism of Biology and Nursing Students, Poster presentation to be given at the National Association for Research in Science Teaching annual international conference, Portland, Oregon. Conference cancelled due to COVID-19 concerns.

2019

2019

2019

2017

Humrick, K. M. College Students Consider Diversity and Designer Babies when Reasoning about uses of CRISPR/Cas9, Poster presentation at the Society for the Advancement of Biology Education Research annual national meeting, Minneapolis, MN.

Humrick, K. M. Understanding of Genetics Among Biology Major and Nursing Track Students, Poster presentation at the Graduate Student Regional Research Conference, Louisville, KY.

Humrick, K. M. Analysis of Students Reasoning about Genetic Engineering as a Socioscientific Issue, Oral presentation at the Discourse and Semiotics Workshop, University of Louisville, Louisville, KY.

Humrick, K. M. Reverse Transmigration of Salmonella-Infected Dendritic Cells. Oral presentation of grant proposal in Seminar II, Department of Biology, University of Louisville, Louisville, KY.

\section{Professional Development}

2019

Sandra K. Abell Institute. Prestigious event hosted by the National Association for Research in Science Teaching to mentor doctoral students. Middle Tennessee State University, Murfreesboro, TN. 
Service

2018 Volunteer Judge. Louisville Regional Science and Engineering Fair. Category: Microbiology. Division: Junior and Senior.

TEACHING EXPERIENCE

Courses Taught

2017-18

Teaching Assistant, Human Anatomy and Physiology Laboratory, University of Louisville, Louisville, KY

2016-17 Teaching Assistant, Laboratory for Introduction to Biological Systems (biology laboratory for non-majors), University of Louisville, Louisville, KY

Spring 2016 Undergraduate Teaching Assistant, Principles in Quantitative Biology Laboratory (biology laboratory for majors), University of Louisville, Louisville, KY

Spring 2013 Student Instructor, Smoking Cessation, Study Abroad, Croatia Description: Created and planned all lessons for a total of three days' instruction at a high school in Croatia, educated students about smoking cessation, instructed students in activities, and assessed student outcomes

\section{Guest Lectures}

2019

CRISPR Twin Study Activity, two sections of Biology: Current Issues and Applications (biology for non-majors) and one section of Unity of Life (biology for majors), University of Louisville, Louisville, KY. 75-minute activity.

2018-19 CRISPR/Cas9, two sections of General Microbiology and one section of Gene Structure and Function, University of Louisville, Louisville, KY. 2030 minute lecture.

2018 Genome Editing Technology, six sections of Biology: Current Issues and Applications (biology for non-majors), University of Louisville, Louisville, KY. Two online sections. 40-75 minute lecture.

2018 CRISPR, two sections of Unity of Life (biology for majors), University of Louisville, Louisville, KY. One online section. 20-minute lecture.

Fall 2017 Introduction to Heritability, Introduction to Biological Systems (biology for non-majors), University of Louisville, Louisville, KY

Description: Educated 350 students in a non-majors biology course on the core concepts of heritability, designed and implemented the lesson and group assignment, assessed outcomes. 


\section{Undergraduate Mentoring}

I have mentored multiple undergraduate students involved in research at the University of Louisville. Student names are underlined.

2019-20 Miranda Massmann. Project title: Characterizing Belief in Genetic Determinism in Study Essay Responses about Genetic Engineering. Recipient of the Undergraduate Mentor Research Award, received course credit, and presented research at the Undergraduate Research Showcase in Spring 2020.

2019-20 Jenna Wilkerson. Project title: Identifying Genetics Knowledge and Misconceptions Related to Belief in Genetic Determinism. Received course credit.

2019-20 Margaret Adams. Project title: Identifying and Characterizing Misconceptions about CRISPR and CRISPR/Cas9 Genome Editing. Received course credit.

2017-18 Taylor Allen, participated in preparation of reverse transmigration experiments using aseptic technique. Supported by N15 grant and received course credit.

2017-18 Abby Durbin, involved in performing aseptic techniques to isolate monocytes from murine bone marrow. Supported by N15 grant and received course credit.

2016-17 Julie Beck, participated in transfection of Salmonella with pPCP20. Supported by N15 grant, received course credit and participated in REU program.

2016-17 Kayla Feagins, involved in inserting GFP into a series of Salmonella mutant strains by transfection. Received course credit.

\section{AFFILIATIONS}

2015-16 Alpha Epsilon Delta, Good standing member, USA

\section{REFERENCES}

Available upon request 